\title{
Um método para modificar vias de sinalização molecular por meio de análise de banco de dados de interatomas
}

\author{
Lulu $\mathrm{Wu}$ \\ DissERTAÇÃo APRESENTADA \\ AO \\ Instituto De Matemática e Estatística \\ DA \\ Universidade DE SÃo PAUlo \\ PARA \\ OBTENÇÃO DO TÍTULO \\ $\mathrm{DE}$ \\ Mestre em Ciências da ComputaÇão \\ Programa: Ciência da Computação \\ Orientador: Prof. Dr. Junior Barrera
}

Durante o desenvolvimento deste trabalho o autor recebeu auxílio financeiro da CAPES

São Paulo, 19 de agosto de 2015 


\title{
Um método para modificar vias de sinalização molecular por meio de análise de banco de dados de interatomas
}

\author{
Esta versão da dissertação contém as correções e alterações sugeridas \\ pela Comissão Julgadora durante a defesa da versão original do trabalho, \\ realizada em 14/08/2015. Uma cópia da versão original está disponível no \\ Instituto de Matemática e Estatística da Universidade de São Paulo.
}

Comissão Julgadora:

- Prof. Dr. Junior Barrera (orientador) - IME, USP

- Dr. Marcelo da Silva Reis - LETA-CeTICS, Instituto Butantan

- Prof. Dr. Saulo José de Souza - UFRN 


\section{Agradecimentos}

Ao Instituto de Matemática e Estatística (IME) da Universidade de São Paulo (USP), Laboratório Especial de Toxinologia Aplicada (LETA) do Instituto Butantan. seu corpo docente, direção e administração de ter me dado a oportunidade de fazer este projeto de mestrado.

Ao meu orientador Prof. Dr. Junior Barrera pela oportunidade, dedicação e ideias valiosas na elaboração deste trabalho.

Ao pesquisador Dr. Marcelo S. Reis pela dedicação, incentivo, paciência, discussões e correções no decorrer deste trabalho.

A todos os professores por me proporcionar o conhecimento, por tanto que se dedicaram a mim, para que este trabalho seja concluído.

Ao meu companheiro e parceiro Cristiano R. F. Granzotti pelo apoio, amor, incentivo, e pelos tantos momentos inesquecíveis que me proporcionou nesta nova etapa da minha vida.

A toda minha família, principalmente aos meus pais Wu Shaofu e Chen Jianyan, a minha querida vovó, Zhu Meifang e ao meu irmão "chato"Wenye Wu, por me dado todo esse amor e educação para eu ser quem eu sou hoje.

As minhas duas grandes amigas, Amanda S. Guimarães e Ana Lívia R. Queiroz, por todos esses anos de companheirismo e amizade.

A família do meu namorado Cristiano, a dona Sueli, seu Zé e ao Zé Mayquinho.

A todos os colegas de laboratório, Vincent Nöel, Oberlan, Milson, John, Lucy, Érica, Marisol, e todos os outros.

A todos que direta ou indiretamente fizeram parte da minha formação, o meu muito obrigada!!! 


\section{Resumo}

WU, L. Um método para modificar vias de sinalização molecular por meio de análise de banco de dados de interatomas. $84 \mathrm{f}$. Dissertação (Mestrado) - Instituto de Matemática e Estatística, Universidade de São Paulo, São Paulo, 2015.

A capacidade das células para responder corretamente a sinais externos e perceber mudanças no seu microambiente é a base do desenvolvimento, reparação de tecidos e de imunidade, bem como a homeostase do tecido normal. Transdução de sinal é o principal meio pelo qual as células respondem a sinais externos de seu ambiente e coordenam alterações celulares complexas. O estudo das vias de sinalização molecular permite-nos tentar compreender o funcionamento dessas transduções de sinais e, consequentemente, as respostas celulares a estímulos externos. Uma abordagem adequada para tais estudos é o uso de modelos matemáticos para simular a cinética das reações químicas que descrevem uma dada via de sinalização, o que nos permite gerar predições testáveis de processos celulares. Construir modelos cinéticos preditivos de vias de sinalização molecular através de dados de alto rendimento produzidos utilizando técnicas ômicas (i.e., genômica, transcriptômica, (fosfo-)proteômica) constitui um dos atuais desafios enfrentados pelos pesquisadores na área de Biologia Molecular. Recentemente, para lidar com este desafio, o arcabouço de e-Science SigNetSim foi introduzido pelo Grupo de Biologia Computacional e de Bioinformática do Instituto Butantan. Esse arcabouço permite fazer a descrição de vias de sinalização molecular através da descrição da estrutura de um modelo através de um conjunto de reações químicas, que por sua vez é mapeado para um sistema de Equações Diferencias Ordinárias (EDOs), numericamente simuladas e avaliadas. Todavia, modificações na estrutura das vias precisam ser feitas manualmente, o qual restringe severamente o número de estruturas da via que precisam ser testadas, especialmente no caso de modelos grandes. Portanto, diante desse panorama, este trabalho propõe o desenvolvimento de um método para modificar vias de sinalização molecular. Esse método se baseia no uso de bancos de dados de interatomas para fornecer um conjunto de espécies químicas candidatas para serem incluídas na via de sinalização. Um componente integrado ao arcabouço SigNetSim capaz de testar diferentes hipóteses de modificação de vias foi desenvolvido neste projeto utilizando a metodologia de heurística incremental. Para avaliar a eficiência do componente implementado, utilizamos como estudo de caso um modelo de vias sinalização de MAPKs e PI3K/Akt para realizar testes experimentais e analisar os resultados obtidos.

Palavras-chave: Otimização Combinatória, Teoria dos Grafos, Vias de Sinalização Molecular, Cinética Química. 


\section{Abstract}

WU, L. A method to modify molecular signaling networks through examination of interactome databases. 84 f. Dissertação(Mestrado) - Instituto de Matemática e Estatística, Universidade de São Paulo, São Paulo, 2015.

The ability of cells to respond correctly external signals and to perceive changes in their microenvironment is the basis for development, tissue repair and immunity as well as normal tissue homeostasis. Signal transduction is the primary means by which cells respond to external signals from their environment and coordinate complex cellular changes. The study of molecular signaling pathways allows us to understand the operation of each process of cellular signal transduction. The use of mathematical models to simulate the kinetics of chemical reactions that describe a given signaling pathway, allow us to generate testable predictions of the cell processos. To Build Kinetic predictive models to molecular signaling pathways through massive data omics produced using modern techniques, Genomics, transcriptomics, (Phospho) proteomics, is one of the current challenges faced by researchers in the field of molecular biology. Recently, the framework SigNetSim e-Science was introduced by the Biological Computacional and Bioinformatical Group from the Butantan Institute to face this challenge. This framework makes the description of molecular signaling pathways through a set of chemical reactions, which are mapped into a system of ordinary differential equations, this system will be numerically simulated and evaluated . However, changes in the structure of the pathways need to be updated manually presented in this work, which severely restricts the number of track structures that need to be tested, especially for the large models. Therefore, given this background, we present the method to modify the molecular signaling pathways. This method relies on the use of interactome database to provide a set of chemical species candidates to be included in the signaling pathway. An component integrated to SigNetSim framework able to test different hypotheses of pathways modification was developed in this project using the incremental heuristic methodology. To evaluate the implemented component, we used the MAPKs and PI3K/Akt pathways model as case study, in order to perform experimental tests and to analyze the obtained results.

Keywords: Combinatorial Optimization, Graph Theory, Molecular Signaling Networks, Chemical Kinetics. 


\section{Sumário}

$\begin{array}{ll}\text { Lista de Abreviaturas } & \text { ix }\end{array}$

Lista de Figuras

Lista de Tabelas $\quad$ xvii

1 Introdução $\quad 1$

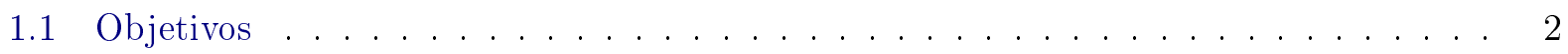

1.2 Organização do Trabalho . . . . . . . . . . . . . . . . . . 3

2 Fundamentos Teóricos 5

2.1 Via de Sinalização Molecular . . . . . . . . . . . . . . . . 5

2.2 Cinética Química . . . . . . . . . . . . . . . . . . 6

2.2 .1 Cinética Enzimática . . . . . . . . . . . . . . . . . 6

2.3 Bancos de dados de interatomas . . . . . . . . . . . . . . . . 7

2.3.1 Kyoto Encyclopedia of Genes and Genomes (KEGG) . . . . . . . . . . . 7

3 Modelagem matemática da cinética de vias de sinalização molecular 9

3.1 Definição do modelo cinético . . . . . . . . . . . . . . . . . . . . 9

3.2 Determinação das constantes de velocidade do modelo cinético . . . . . . . . . . . . 10

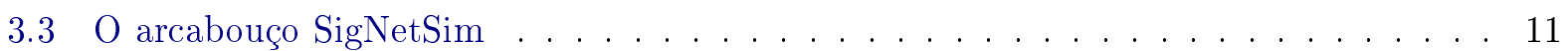

3.4 Exemplo de aplicação: determinação de módulo funcional de uma via de sinalização molecular . . . . . . . . . . . . . . . . . . . . 12

4 Métodos de modificação de Grafos de Interação Molecular (GIMs) 17

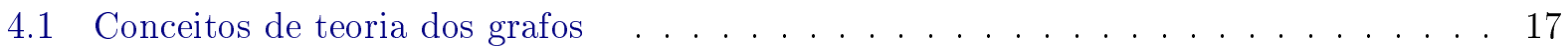

4.2 Geração de GIMs de recortes de via . . . . . . . . . . . . . . . . . . . . . . 19

4.3 Geração de GIMs de banco de dados de interatomas

(GIM geral) . . . . . . . . . . . . . . . . . . . 19

4.3.1 Produzindo GIMs a partir de mapas do KEGG . . . . . . . . . . . . . . 20

4.4 Algoritmos de modificação de GIMs de recorte de via . . . . . . . . . . . . . . . . . 21

4.4 .1 Heurísticas gulosas . . . . . . . . . . . . . . . . . . . . 22

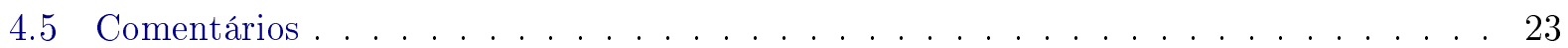


5 Mapeamento de recorte de vias de sinalização molecular em conjunto de reações químicas

5.1 Formalização de regras de mapeamentos . . . . . . . . . . . . . . . 26

$5.1 .1 \quad$ Interações do tipo PPrel . . . . . . . . . . . . . . . . . . 26

5.1 .2 Interações do tipo PCrel . . . . . . . . . . . . . . . . . . . 30

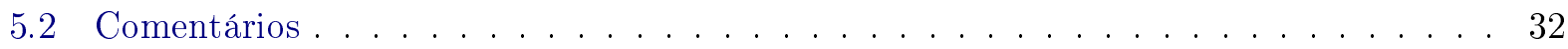

6 Experimentos $\quad \mathbf{3 3}$

6.1 O componente Hyp Test do arcabouço SigNetSim . . . . . . . . . . . . . . . 33

6.2 Recuperação de estrutura de modelo a partir da escolha de recortes aleatórios . . . . 33

6.2.1 Estudo de caso: um modelo de EGFR e IGF1R em câncer de pulmão . . . . . 34

6.2 .2 Aplicação da estratégia de incremento de vértices . . . . . . . . . . . . . . . 34

6.3 Análise dos resultados . . . . . . . . . . . . . . . . . . . 36

6.3.1 Recuperação de estrutura do modelo original . . . . . . . . . . . . . 36

6.3.2 Desempenho do processo de otimização . . . . . . . . . . . . . . . . . . 37

7 Conclusões $\quad 43$

7.1 Recapitulação do conteúdo deste trabalho . . . . . . . . . . . . . . . . . 43

7.2 Contribuições deste trabalho . . . . . . . . . . . . . . . . . . . . . 43

7.3 Sugestões para Pesquisas Futuras . . . . . . . . . . . . . . . . . . . 44

A Systems Biology Markup Language (SBML) 45

$\begin{array}{ll}\text { B KEGG Markup Language (KGML) } & 57\end{array}$

C Um componente para teste de hipóteses utilizando o arcabouço SigNetSim $\quad 59$

$\begin{array}{ll}\text { Referências Bibliográficas } & 63\end{array}$ 


\section{Lista de Abreviaturas}

EDO Equação Diferencial Ordinária

EGFR Receptor de fator de crescimento epidermal (Epidermal Growth Factor Receptor)

GAP Proteína de ativação GTPase (GTPase Activating Protein)

GDP Difosfato de Guanosina (Guanosine Diphosphate)

GEF Fatores de troca nucleotídeos de guanina (Guanine nucleotide Exchange Factors)

GF Angiopoietin 1

GIM Grafo de Interação Molecular

GTP Trifosfato de Guanosina (Guanosine Triphosphate)

IGF1R Fator de crescimento insulina tipo 1 (type 1 Insulin-like Growth Factor)

KEGG Enciclopédia Kyoto para Genes e Genomas (Kyoto Encyclopedia for Genes and genomes )

KGML Linguagem de marcação do KEGG (KEGG Markup Language )

MAPK Proteína quinase ativada por mitógeno (Mitogen-Activated Protein Kinase)

Ras Proteína Rat Sarcoma (Rat Sarcoma Protein)

RTK Receptor do fator estimulante 1 (colony stimulating factor 1 receptor)

SBML Linguagem de marcação para sistemas biológicas (Systems Biology Markup Language)

SBS busca sequencial para trás (Sequential Backward Selection)

SFS Busca sequencial para frente (Sequential Forward Selection)

SMVSM Sistema de Modificação de Vias de Sinalização Molecular

SOS Filho da proteína Sevenless (protein Sevenless Son )

UML Linguagem de modelagem unificada (Unified Modeling Language)

VSM Via de Sinalização Molecular 


\section{Lista de Figuras}

1.1 exemplo do resultado de um experimento de Western blot; este experimento descreve as cinéticas de expressão das proteínas ciclina A e HPRT da célula Y1 DIG; figura extraída do tese de doutorado de M.H.S. Dias [Dia12] . . . . . . . . . . . . . . . . .

1.2 fluxograma da metodologia proposta para modificação de uma via de sinalização molecular. Os retângulos em azul denotam atividades, enquanto que os de cor alaranjada representam o fluxo de dados. Os números entre parênteses nas atividades correspondem a suas respectivas descrições apresentadas na seção 1.1 (atividades 1-6).

2.1 exemplo de via de sinalização molecular (via de sinalização Ras). O ligante GF se acopla ao receptor RTK, disparando assim um sinal que ativa a GTPase Ras (molécula Ras-GTP). Figura extraída do banco de dados de interatomas KEGG ${ }^{1}$. . . . . . . . 5

2.2 exemplo mostrando a cinética das espécies químicas ao longo de um tempo arbitrário da equação 2.3 sob condições fisiológicas comuns; observe que a concentração inicial do substrato $S_{0}$ é muito maior que a da enzima; durante a fase de transição, a concentração de $E S$ mantenha-se constante até que o substrato $S$ é esgotado; exemplo extraído do livro Biochemistry de D. Voet e J.G. Voet [VV10]. . . . . . . . . . . .

3.1 exemplo de análise de ajuste de curva para determinação dos valores das constantes de velocidade de um modelo cinético. A curva azul é uma cinética medida de experimentos biológicos, enquanto que as curvas vermelha e verde foram simuladas utilizando diferentes conjuntos de valores de constantes de velocidade. . . . . . . . . 11

3.2 Fluxo de atividades do arcabouço SigNetSim. Os retângulos em azul denotam atividades, enquanto que os de cor alaranjada representam o fluxo de dados. . . . . . . . 12

3.3 espécies químicas e reações escolhidas que fazem parte de nossa hipótese inicial para um módulo funcional da via de sinalização Ras. . . . . . . . . . . . . . . . . . . . . 13

3.4 teste da hipótese de módulo funcional de Ras não reproduz o fenômeno observado: após otimização das constantes de velocidade, 5 minutos de simulação com alta concentração de SOS produz resultados satisfatórios (Figura 3.4(a)); porém, o mesmo não ocorre na simulação de 5 minutos com baixa concentração de SOS (Figura 3.4(b)). 14

3.5 expansão do módulo funcional de Ras, de forma a incluir a enzima "RasGAP"(destacada em azul) e a reação química da qual essa enzima participa. . . . . . . . . . . . . . . . . 14

3.6 teste da nova hipótese de módulo funcional de Ras reproduz o fenômeno observado: após otimização das constantes de velocidade, 5 minutos de simulação com alta concentração de SOS produz resultados satisfatórios (Figura 3.6(a)); o mesmo ocorre na simulação de 5 minutos com baixa concentração de SOS (Figura 3.6(b)) . . . . . . . . 15 
4.1 Sequência de atividades do processo de modificação de uma via de sinalização. Os retângulos em azul denotam atividades, os quais são unidades de trabalhos realizados no processo; os de cor alaranjado são arquivos de entrada ou de saída das atividades; o retângulo de cor cinza encapsula as atividades 4,5 e $6 \ldots \ldots \ldots \ldots$. . . . . 18

4.2 Grafo de Interação Molecular (GIM) de um recorte de via molecular de sinalização mostrado na figura $3.3 \ldots \ldots \ldots \ldots \ldots$

4.3 exemplo do processo de união de mapas funcionais do banco KEGG. Neste exemplo, quatro mapas funcionais foram convertidos em seus respectivos GIMs, que por sua vez foram unidos em um único GIM geral.

4.4 topologia do GIM geral produzido a partir da união de todos GIMs dos mapas funcionais de transdução de sinal presentes no KEGG para camundongo (Mus musculus). 21

4.5 instâncias para a simulação do algoritmo de incremento de vértices. A figura 4.5(a) representa um GIM de recorte de via, enquanto que o grafo da figura 4.5(a) é um GIM geral. . . . . . . . . . . . . . . . . . . . . . . 23

4.6 etapas de simulação do processo de incremento de vértices. . . . . . . . . . . . . . . 24

5.1 diagrama mostrando o fluxo de trabalho do mapeamento de recorte de vias de sinalização molecular em conjunto de reações químicas (atividade 4 na figura 1.2), incluindo suas entrada e saída. . . . . . . . . . . . . . 26

5.2 PPrel Ativação. . . . . . . . . . . . . . . . . . . . . . . . 28

5.3 PPrel Inibição. . . . . . . . . . . . . . . . . . . . . . . . . . . 28

5.4 PPrel Associação. . . . . . . . . . . . . . . . . . . . . . . . 28

5.5 PPrel Fosforilação. . . . . . . . . . . . . . . . . . . . . . . . . . . . . . . 29

5.6 PPrel Desfosforilação. . . . . . . . . . . . . . . . . . . . . . . . . . . . 29

5.7 PPrel Ubiquitinação. . . . . . . . . . . . . . . . . . . . . . . . . . . . . . . . 29

5.8 PPrel Metilação. . . . . . . . . . . . . . . . . . . . . . . . 30

5.9 PCrel Ativação. . . . . . . . . . . . . . . . . . . . . . . . . . 30

5.10 PCrel Inibição. . . . . . . . . . . . . . . . . . . . . . . . . . 31

5.11 PCrel Fosforilação. . . . . . . . . . . . . . . . . . . . . . . . . 31

5.12 PCrel Desfosforilação . . . . . . . . . . . . . . . . . . . . . . . 31

6.1 representação gráfica do modelo de vias de MAPKs e PI3K/Akt apresentado por Bioconi e colegas $\left[\mathrm{BBL}^{+} 12\right]$. Os retângulos representam proteínas e as setas representam interações entre elas; as setas tracejadas e não tracejadas descrevem interações de inibição e ativação, respectivamente. O retângulo maior representa o conjunto de fatores de transcrição à jusante dessas vias, os quais ativam os eventos de transcrição, diferenciação e proliferação celular. Retângulos e setas em azul representam, respectivamente, proteínas e interações presentes no GIM geral. . . . . . . . . . . . 36

6.2 recortes sorteados do modelo de vias de MAPKs e PI3K/Akt apresentado por Bioconi e colegas $\left[\mathrm{BBL}^{+} 12\right]$. Os retângulos representam proteínas e as setas representam interações entre elas; as setas tracejadas e não tracejadas descrevem interações de inibição e ativação, respectivamente. . . . . . . . . . . . . . . . . 
6.3 representações gráficas da recuperação da estrutura do modelo após 25 iterações do componente Hyp Test; os retângulos representam proteínas e compostos, e as setas, as interações entre eles. Os retângulos de borda azul representam as proteínas originais do recorte e os de borda verde representam os compostos químicos; já os retângulos de preenchimento azul assinalam as proteínas do modelo original que foram recuperadas. Os números dentro dos retângulos representam a sequência em que cada elemento é acrescentado. As setas tracejadas e não tracejadas representam as interações de inibição e de ativação, respectivamente; + p ou -p representam as interações de fosforilação e desfosforilação, respectivamente; enquanto que $+\mathrm{u}$ e + m representam as interações de ubiquitinação e metilação, respectivamente. . . . . . . . . . . . . . 40

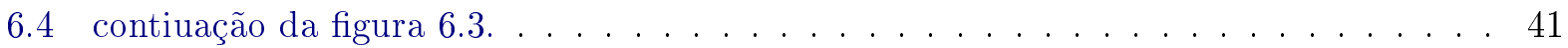

6.5 gráficos de evolução do custo computado em função do incremento de proteínas. Os gráficos das figuras 6.5(a)-6.5(j) correspondem, respectivamente, ao incremento dos recortes mostrados nas figuras 6.2(a)-6.2(j). Em cada gráfico, o eixo das abscissas corresponde ao i-ésimo incremento de proteína no recorte, enquanto que o eixo das ordenadas representa o valor obtido na otimização de ajuste de curva. . . . . . . . . 42

B.1 Visão geral do KGML [KEG14]. O elemento pathway é o elemento raiz, um elemento pathway é especificada para um mapa pathway em KGML. Os elementos entry, relation e reaction especificam as informações do grafo, e os demais elementos especificam informações mais detalhadas sobre os vértices e arestas do grafo. $\quad \ldots . \ldots . .58$

C.1 diagrama de classes em UML do componente HypTest. . . . . . . . . . . . . . . 60

C.2 diagrama de relação entre as classes em UML do componente Hyp Test. . . . . . . . . 61 


\section{List of Algorithms}

1 AUGMENT-VERTICES-GRAPH $(\mathrm{G}, \mathrm{H}) \ldots \ldots \ldots \ldots \ldots \ldots \ldots$ 


\section{Lista de Tabelas}

5.1 PPrel: nomes dos subtipos e explicação sobre cada subtipo. . . . . . . . . . . . 27

5.2 ECrel: nomes dos subtipos e explicação sobre cada subtipo. . . . . . . . . . . . . 27

5.3 GErel: nomes dos subtipos e explicação sobre cada subtipo. . . . . . . . . . . . . . 27

5.4 PCrel: nomes dos subtipos e explicação sobre cada subtipo. . . . . . . . . . . . . 27

6.1 Lista das espécies químicas presentes no modelo de MAPKs e PI3K/Akt em câncer de pulmão descrito por Bioconi e colegas $\left[\mathrm{BBL}^{+} 12\right] . \ldots \ldots \ldots \ldots \ldots$

6.2 Tempo mínimo necessário para executar os experimentos descritos nesta seção, considerando um total de 15.335 chamadas da função custo, na qual cada chamada leva 30 minutos. . . . . . . . . . . . . . . . . . 36

6.3 Estatísticas dos testes para 25 iterações do componente. Os recortes 1 e 2 têm 5 proteínas, enquanto que os demais têm 4 proteínas cada. Para cada tamanho, os recortes que mais se aproximaram do modelo original estão indicados em negrito e sublinhado. A distância entre o modelo original e um recorte recuperado foi computada utilizando

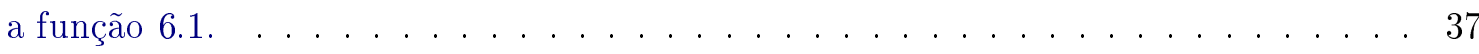


xviii LISTA DE TABELAS 


\section{Capítulo 1}

\section{Introdução}

Na área de Biologia Celular, o sistema de comunicação que coordena os diversos processos celulares é constituído por entidades denominadas vias de sinalização molecular. Uma via de sinalização molecular serve como rota para um sinal que é iniciado a partir da ocorrência de um determinado evento celular (e.g., um ligante que se acopla a um receptor na superfície da célula), levando a célula a uma resposta; por exemplo, a adição de fatores de crescimento ao meio de cultura pode induzir a proliferação celular, num processo que envolve a ligação do fator de crescimento ao receptor e o consequente disparo de um sinal através de uma via de sinalização molecular. Uma via de sinalização molecular é composta por espécies químicas; a concentração de cada espécie química pode se alterar ao longo de um determinado período de tempo, em particular quando um sinal é transmitido pela via em questão. O estudo da cinética de uma via de sinalização molecular é coberto pela disciplina conhecida como Cinética Química, e requer uma combinação de abordagens experimentais biológicas e computacionais.

Entre as abordagens experimentais biológicas, destacam-se as técnicas ômicas modernas e de alto rendimento, tais como a genômica, a transcriptômica e a (fosfo-)proteômica. Estas técnicas nos permitem monitorar, em tempo quase real e de forma quantitativa, milhares de espécies químicas ao mesmo tempo. Por outro lado, dados ômicos de baixo rendimento, tal como a proteômica feita através da quantificação de experimentos de Western blot, também são relevantes para estudos de vias de sinalização molecular. A quantificação das cinéticas obtidas dos experimentos de Western blot é feita utilizando programas de processamento de imagem, e as quantificações relativas obtidas com esses programas, por sua vez, constituem a cinética do experimento biológico. A figura 1.1 mostra um exemplo do resultado de um experimento de Western blot [Dia12].

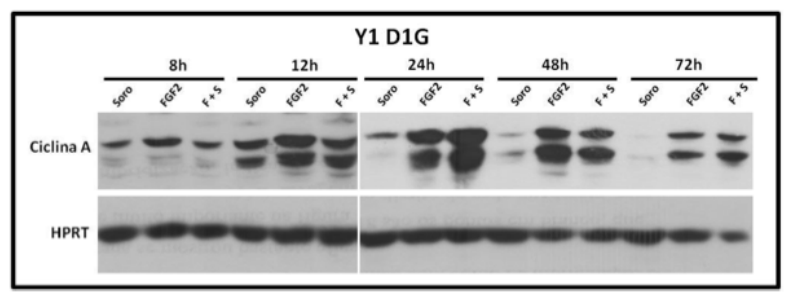

Figura 1.1: exemplo do resultado de um experimento de Western blot; este experimento descreve as cinéticas de expressão das proteínas ciclina A e HPRT da célula Y1 DIG; figura extraída do tese de doutorado de M.H.S. Dias [Dia12]

Já as abordagens computacionais incluem o desenvolvimento e a simulação de modelos matemáticos [EI04]. Embora tais modelos não representem exatamente o processo biológico em questão, não obstante os mesmos representam uma aproximação do fenômeno estudado [IF12]. Modelos cinéticos têm que descrever a estrutura do recorte de uma via de sinalização molecular (i.e., um conjunto de espécies químicas envolvidas na via e como elas interagem entre si) e ser capaz de fazer previsões sobre o seu comportamento [EI04]; modelos com tais características são denominados módulos funcionais. Dessa forma, para estudar a cinética de uma via de sinalização molecular, precisamos 
desenhar um módulo funcional que possa ser utilizado para potencialmente identificar lacunas em nosso conhecimento bioquímico e destrinchar mecanismos biológicos.

Recentemente, foi introduzido o arcabouço de e-Science SigNetSim pelo Grupo de Biologia Computacional e de Bioinformática do Instituto Butantan $\left[\mathrm{RND}^{+} 14\right]$, para enfrentar o desafio de construção de modelos cinéticos das vias de sinalização molecular a partir de dados ômicos. Esse arcabouço permite fazer a descrição das vias através de um conjunto de reações químicas, o qual é mapeado para um sistema de equações diferencias ordinárias (EDOs). O sistema de EDOs é simulado (integrado numericamente) e é feita uma avaliação da cinética obtida. Essa avaliação pode ser feita comparando a cinética simulada com resultados experimentais biológicos (e.g., experimentos cinéticos constituídos de quantificações de Western blot). Caso a avaliação indique que a simulação não tenha reproduzido, de forma satisfatória dentro de algum critério escolhido, a cinética observada, é necessário modificar a estrutura que descreve a via de sinalização molecular. Entretanto, modificações na estrutura da via precisam ser realizadas manualmente no arcabouço SigNetSim, o que restringe severamente o número hipóteses (i.e., diferentes módulos funcionais candidatos a explicar o comportamento da via) testáveis, especialmente no caso de modelos grandes. Por este motivo, é premente o desenvolvimento de um método para testar diferentes hipóteses de módulos funcionais de via de sinalização molecular.

O componente Hyp Test integrado ao arcabouço SigNetSim capaz de testar diferentes hipóteses de módulos funcionais, foi desenvolvido neste projeto utilizando a metodologia de heurística incremental. Para testar a eficiência do nosso componente, baixamos o modelo de vias de MAPKs e PI3K/Akt apresentado por Bioconi e colegas $\left[\mathrm{BBL}^{+} 12\right]$ para ser o nosso estudo de caso. Através da análise dos resultados obtidos com os experimentos, identificamos possíveis direcionamentos da nossa pesquisa em trabalhos futuros.

\section{$1.1 \quad$ Objetivos}

Nesse trabalho, propomos o desenvolvimento de um método para testar diferentes hipóteses de módulos funcionais de vias de sinalização molecular. Esse método se baseia no uso de bancos de dados de interatomas para fornecer um conjunto de espécies e de reações químicas candidatas para serem incluídas no módulo funcional. A metodologia de modificação deverá incluir as seguintes atividades:

1. Mapeamento de um recorte da via de sinalização molecular em um grafo chamado Grafo de Interação Molecular (GIM) da via, no qual os vértices descrevem as espécies químicas e as arestas descrevem o tipo de interação entre pares de espécies químicas.

2. Mapeamento de banco de dados de interatomas em um grafo, da mesma forma que a ilustrada na atividade 1 , construindo assim o GIM geral.

3. Modificação do GIM do recorte da via por meio da inclusão de vértices presentes do GIM geral e/ou exclusão de vértices presentes no GIM da via, obtendo assim um GIM do recorte da via atualizado.

4. Utilização de um GIM do recorte da via atualizado para gerar um conjunto de reações químicas que descreva o recorte da via de sinalização molecular.

5. Execução da simulação de cinética do recorte da via de sinalização, utilizando para este fim o arcabouço SigNetSim e tendo como entrada o conjunto de reações químicas que descreve o recorte da via.

6. Avaliação dos resultados tendo como critério a análise de ajuste de curva, o que pode conduzir a uma nova simulação com um GIM modificado (atividade 3). O ciclo das atividades 3-6 é repetido até que a simulação do modelo corrente produza resultados satisfatórios, isto é, que para um número arbitrário de espécies químicas do recorte da via, o ajuste entre a curva 
dos dados de experimentos biológicos e a curva da cinética simulada seja bom o suficiente de acordo com uma dada medida de erro.

Na figura 1.2 mostramos um diagrama que ilustra o fluxograma da metodologia proposta, o que engloba as atividades $1-6$.

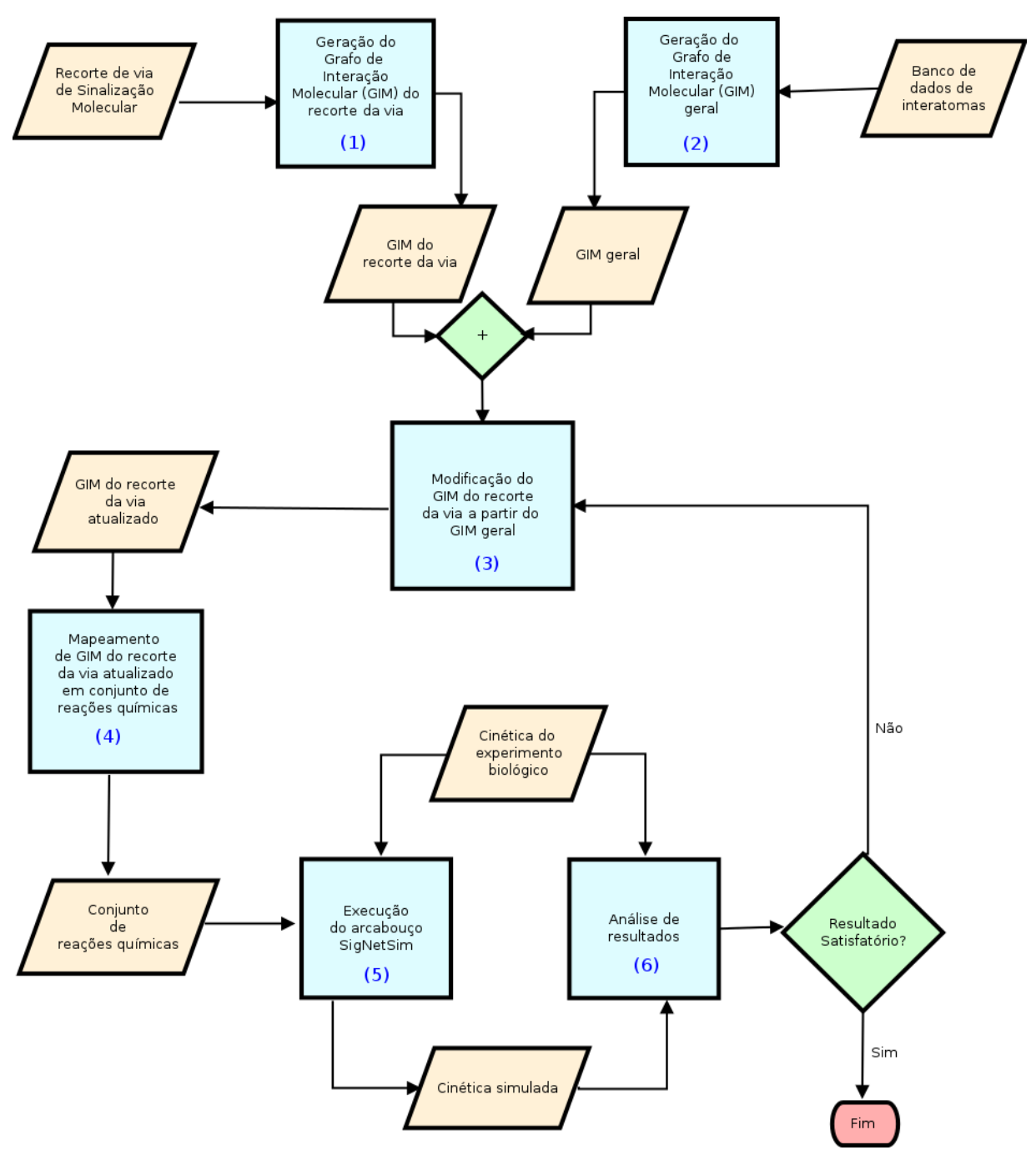

Figura 1.2: fluxograma da metodologia proposta para modificação de uma via de sinalização molecular. Os retângulos em azul denotam atividades, enquanto que os de cor alaranjada representam o fluxo de dados. Os números entre parênteses nas atividades correspondem a suas respectivas descrições apresentadas na seção 1.1 (atividades 1-6).

\subsection{Organização do Trabalho}

Após esta introdução, esta proposta de dissertação está organizada da seguinte maneira: no capítulo 2, abordaremos alguns fundamentos teóricos deste trabalho. No capítulo 3, recapitularemos o processo de desenho de um modelo cinético de um recorte de via de sinalização molecular e também mostraremos como o arcabouço SigNetSim pode auxiliar nesse processo. No capítulo 4, proporemos uma metodologia para testar hipóteses de módulos funcionais de vias de sinalização molecular. No capítulo 5, discutiremos uma maneira de mapear o GIM do recorte da via para um conjunto de reações químicas que descrevem um recorte de via de sinalização molecular. No capítulo 6 , mostraremos alguns resultados experimentais obtidos ao utilizar esta metodologia. Finalmente, 
no capítulo 7 faremos algumas considerações finais sobre este trabalho e apontaremos possíveis trabalhos futuros. 


\section{Capítulo 2}

\section{Fundamentos Teóricos}

Neste capítulo, abordaremos alguns fundamentos teóricos inerentes a este projeto. Iniciaremos explicando o que são vias de sinalização molecular. Em seguida, apresentaremos conceitos de Cinética Química. Por fim, discutiremos a utilização de banco de dados de interatomas; em particular, apresentaremos o banco de dados KEGG, que será empregado neste projeto.

\subsection{Via de Sinalização Molecular}

A capacidade das células para responder corretamente a sinais externos e perceber mudanças no seu microambiente é a base do desenvolvimento, regeneração de tecidos e de imunidade, bem como da homeostase do tecido normal. Erros no processamento de informação celular são responsáveis por doenças. Diante desse panorama, a sinalização molecular faz parte de um complexo sistema de comunicação que governa as atividades celulares básicas e coordena as ações celulares.

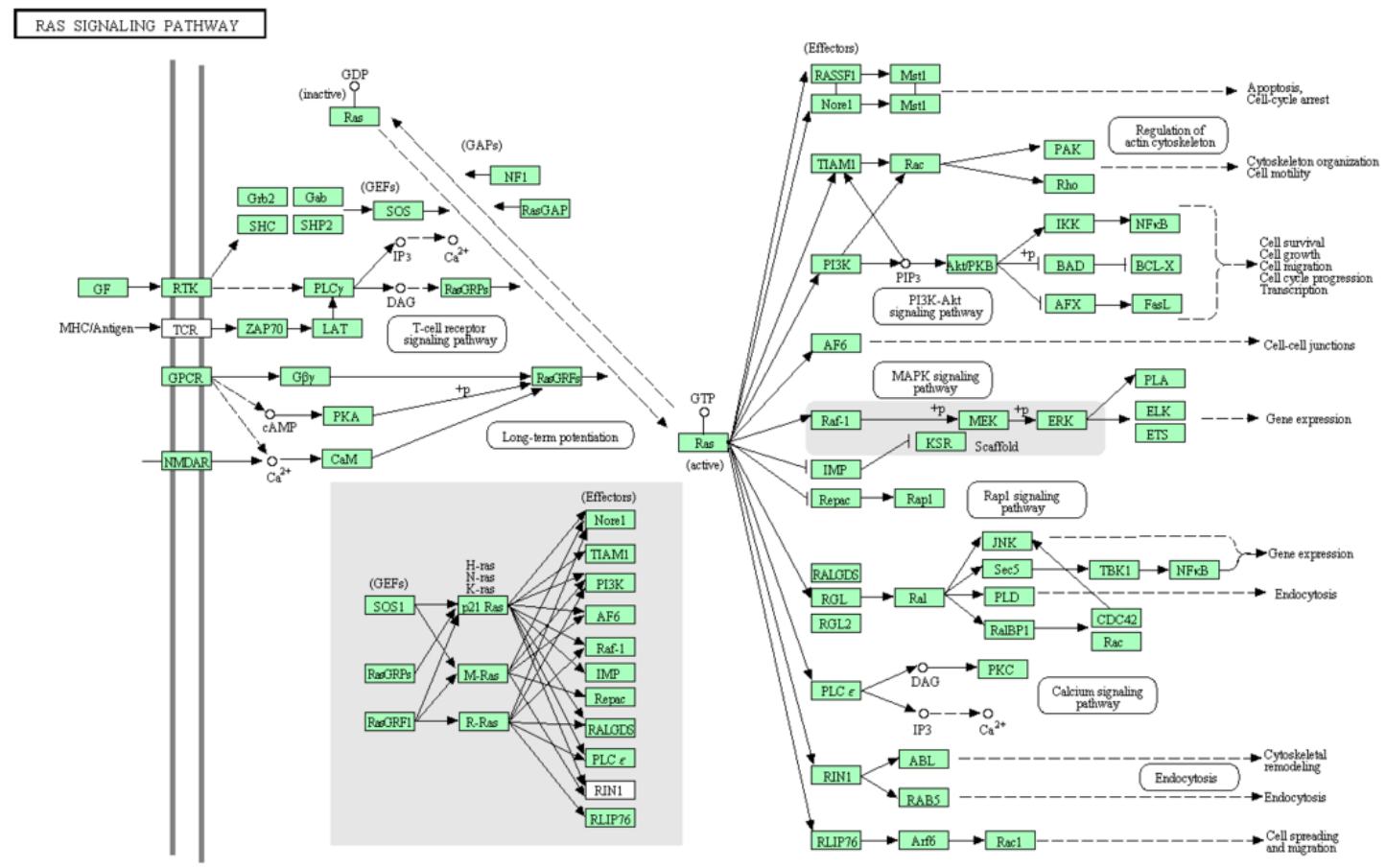

Figura 2.1: exemplo de via de sinalização molecular (via de sinalização Ras). O ligante GF se acopla ao receptor RTK, disparando assim um sinal que ativa a GTPase Ras (molécula Ras-GTP). Figura extraída do banco de dados de interatomas $K E G G^{1}$.

\footnotetext{
${ }^{1}$ http://www.genome.jp/kegg-bin/show_pathway/mmu04014.
} 
Vias de sinalização molecular (vias de transdução de sinais) são caracterizadas por módulos com entrada e saída bem definidas, por laços de retro-alimentação e por controles regulatórios multipasso [EI04]. Vias de sinalização molecular são muito estudadas em Biologia Sistêmica, uma vez que nos ajudam a compreender como mudanças na transmissão e no fluxo de informações afetam o fenótipo celular.

Normalmente, o fluxo de informação por uma via de sinalização molecular se inicia quando um sinal externo é reconhecido por receptores de membrana da célula (ligação ligante-receptor). Após o reconhecimento, segue-se a ativação de vias de sinalização intracelular que envolvem fosforilação e desfosforilação de proteínas, interação proteína-proteína, interação proteína-composto [LZ04]. Dessa forma, um dado receptor dispara uma cascata de sinalização até que este sinal seja levado até o núcleo, onde são ativados processos de proliferação celular, diferenciação, transcrição, morte celular, etc.

Na figura 2.1 mostramos um exemplo de via de sinalização molecular, a via de sinalização da GTPase Ras. Nesta figura, vemos que um receptor de tirosina quinase (Receptor tyrosine kinase $R T K$ ) é ativado por meio do reconhecimento de um fator de crescimento (Growth factor - GF). O receptor dispara uma cascata de sinalização, até que este sinal seja levado até o núcleo, ocasionando um evento celular, que pode ser proliferação, diferenciação, crescimento ou morte celular.

\subsection{Cinética Química}

Cinética Química é o estudo das velocidades das reações químicas de processos químicos e os fatores que as influenciam [VV10]. Por velocidade entendemos a mudança de concentração das espécies químicas ao longo do tempo.

Seja $R_{i}, 1 \leq i \leq m$, um reagente, enquanto que $P_{j}, 1 \leq j \leq n$, denota um produto, então uma reação química pode ser descrita, de forma geral, através da seguinte expressão:

$$
R_{1}+\ldots+R_{m} \rightarrow P_{1} \ldots P_{n}
$$

Seja $k_{i}, 1 \leq i \leq m$, uma constante de proporcionalidade conhecida como constante de velocidade e $r$ representa a mudança de concentração dos reagentes. $\mathrm{O}$ índice $m$ diz a ordem de uma reação: por exemplo, $R \rightarrow P$ é uma reação de primeira ordem, enquanto que $R_{1}+R_{2} \rightarrow P$ é de segunda ordem. Reações de terceira ordem ou maior normalmente não são consideradas em situações práticas, uma vez que colisões simultâneas de três ou mais moléculas são eventos raros [VV10]. Em temperatura constante, a velocidade de uma reação varia em relação às concentrações dos reagentes através da seguinte relação:

$$
r=k_{1}\left[R_{1}\right] \ldots k_{m}\left[R_{m}\right]
$$

onde

\subsubsection{Cinética Enzimática}

Enzimas são proteínas que operam como máquinas moleculares complexas, que catalisam diversas reações químicas. As milhares de enzimas conhecidas atualmente realizam reações de hidrólise, polimerização, transferência do grupo funcional, oxidação-redução, desidratação e isomerização.

O estudo da cinética enzimática elucida mecanismo catalíticos das enzimas. Em 1902, o cientista Andrian Brown [VV10] propôs que toda reação enzimática é composta de uma reação em que o substrato forma um complexo com a enzima, outra em que o complexo se dissocia novamente em substrato e enzima, e uma terceira na qual o substrato complexado com enzima é transformado em produto, liberando a enzima.

Sejam E, S, ES e P representando respectivamente a enzima, o substrato, o complexo substratoenzima e o produto; $k_{1}$ e $k_{-1}$ as constantes de velocidade de formação do complexo enzima-substrato 
e dissociação do complexo, respectivamente, e o $k_{\text {cat }}$, a constante da velocidade de transformação do substrato em produto. Então, a equação 2.3 nos mostra uma reação enzimática.

$$
\mathrm{E}+\mathrm{S} \underset{k_{-1}}{\stackrel{\mathrm{k}_{1}}{\rightleftharpoons}} \mathrm{ES} \stackrel{k_{c a t}}{\longrightarrow} \mathrm{E}+\mathrm{P}
$$

A figura 2.2 mostra a cinética das espécies químicas envolvidas na equação 2.3 sob condições fisiológicas comuns. Na figura 2.2, temos a concentração inicial do substrato $S_{0}$ é muito maior que a da enzima, ao longo do tempo, enquanto o substrato é consumido, aumenta-se a formação do produto.

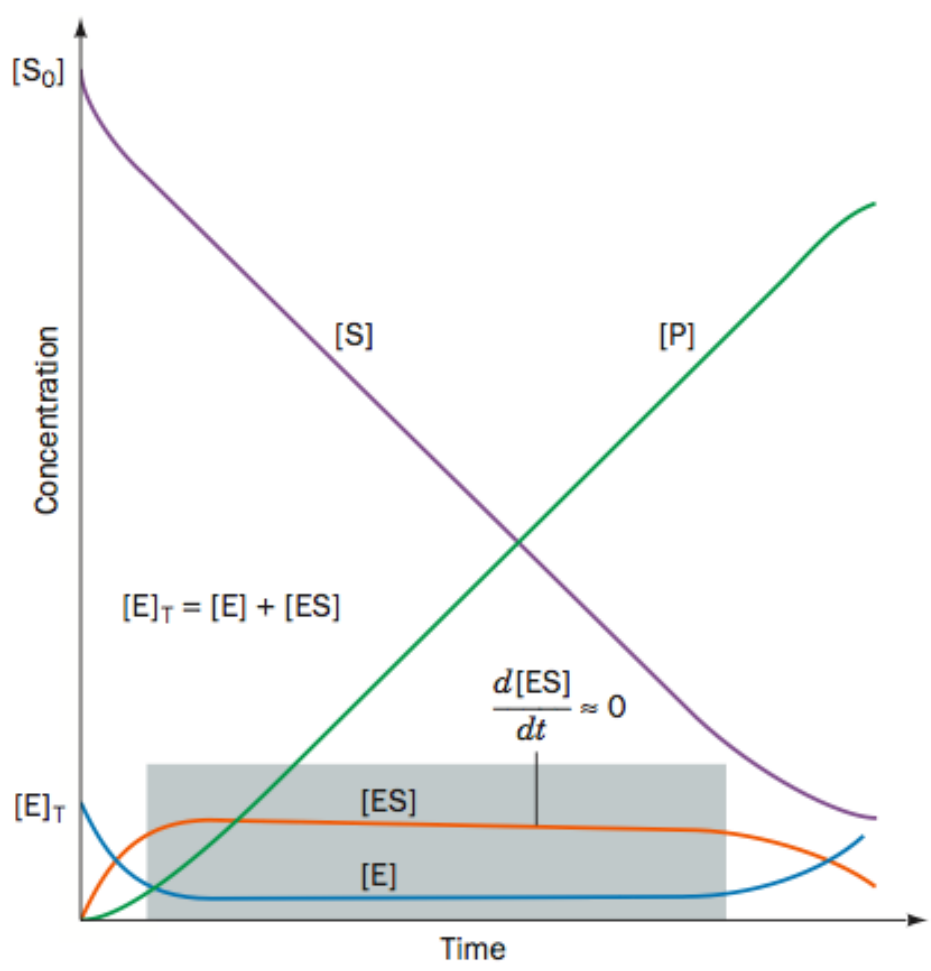

Figura 2.2: exemplo mostrando a cinética das espécies químicas ao longo de um tempo arbitrário da equação 2.3 sob condições fisiológicas comuns; observe que a concentração inicial do substrato $S_{0}$ é muito maior que a da enzima; durante a fase de transição, a concentração de ES mantenha-se constante até que o substrato $S$ é esgotado; exemplo extraído do livro Biochemistry de D. Voet e J.G. Voet [VV10].

\subsection{Bancos de dados de interatomas}

Mapas estáticos que descrevem um conjunto de espécies químicas que têm afinidade de reagirem entre si são conhecidos como interatomas. Bancos de dados de interatomas são repositórios que armazenam interatomas de diversos organismos, tecidos e condições biológicas. Esses bancos são abastecidos com dados experimentais de alto e de baixo rendimento, e alguns deles são curados manualmente.

\subsubsection{Kyoto Encyclopedia of Genes and Genomes (KEGG)}

Dentre os diversos bancos de dados de interatomas disponíveis publicamente, merece destaque o KEGG (Kyoto Encyclopedia of Genes and Genomes). KEGG é um banco de dados para análise sistêmica de funções gênicas e ligações genômicas com alta ordem de informação funcional [KG00]. Há muitos anos esse banco de dados tem sido uma das fontes mais importantes para a construção de modelos estruturais iniciais de várias vias de sinalização molecular [WBR ${ }^{+} 13$ ]. Este banco, que foi criado em 1995, contém mapas, curados manualmente, de várias vias de sinalização molecular. 
Estes mapas são visualizados na web e podem ser baixados gratuitamente (para acadêmicos) em uma linguagem de marcação própria denominada KGML (ver apêndice B).

As informações genômicas são armazenadas no banco de dados KEGG GENES ${ }^{2}$, o qual é uma coleção de catálogo de genes; as informações de alta ordem funcional são armazenadas no KEGG PATHWAY ${ }^{3}$; as informações de componentes químicas, moléculas enzimáticas e reações enzimáticas são armazenadas no KEGG LIGAND ${ }^{4}$.

O banco de dados KEGG PATHWAY contém representações gráficas de processos celulares, como metabolismo, transporte da membrana, transducção de sinal e ciclo celular. Esse banco contém uma coleção de mapas funcionais que representam vias de interação molecular responsáveis de funções celulares específicas. Esses mapas funcionais são desenhados e atualizados manualmente, contendo informações sobre genes, reações e relações nele contidas. Além disso, o KEGG PATHWAY oferece um serviço amplamente utilizado para vias metabólicas e não-metabólicas. Um exemplo de representação gráfica de um mapa funcional (via regulatória) é mostrado na figura 2.1: a via de sinalização Ras em camundongo (Mus musculus).

\footnotetext{
${ }^{2}$ http://www.genome.jp/kegg/genes.html

${ }^{3}$ http://www.genome.jp/kegg/pathway.html

${ }^{4}$ http://www.genome.jp/kegg/ligand.html
} 


\section{Capítulo 3}

\section{Modelagem matemática da cinética de vias de sinalização molecular}

Neste capítulo, faremos uma revisão da metodologia de modelagem matemática e simulação computacional da cinética de recortes de vias de sinalização molecular que é utilizada neste trabalho. Em particular, mostraremos como utilizar o arcabouço SigNetSim nesse processo e empregaremos um exemplo para ilustrar o teste de uma hipótese de módulo funcional de uma dada via de sinalização molecular, a utilização do arcabouço para corroborar ou descartar a hipótese, e por fim a necessidade de modificação do módulo funcional caso a hipótese não seja corroborada. A sistematização do teste de diferentes hipóteses para módulos funcionais de vias de sinalização molecular é o objetivo deste trabalho, e será abordada nos capítulos seguintes.

\subsection{Definição do modelo cinético}

No estudo de diversos mecanismos celulares, modelos cinéticos de uma via de sinalização molecular podem ser construídos a partir do mapeamento das reações químicas que a compõe em um sistema de equações diferenciais ordinárias (EDOs). Nas equações 2.1 e 2.2 mostramos como fazer esse mapeamento para uma reação de $m$-ésima ordem. Agora mostraremos como fazer o mapeamento para uma reação enzimática tal como a exibida na equação 2.3 ; iniciaremos decompondo essa reação em três reações elementares [RA14]:

$$
\begin{aligned}
E+S & \rightarrow^{k_{1}} E S \\
E S & \rightarrow^{k_{-1}} E+S \\
E S & \rightarrow{ }^{k_{c a t}} E+P,
\end{aligned}
$$

nas quais a equação 3.1a é uma reação de segunda ordem e as equações $3.1 b$ e 3.1c são de primeira ordem. Considere a concentração de uma espécie química A representada por $[\mathrm{A}]$, as respectivas taxas de mudança da concentração da enzima E para cada equação são:

$$
\begin{aligned}
& r 1=-k_{1}[E][S] \\
& r 2=k_{-1}[E S] \\
& r 3=k_{\text {cat }}[E S] .
\end{aligned}
$$

Para descrever a mudança de concentração de E no tempo $t$ na reação enzimática 2.3, levamos em conta o decréscimo de [E] e [S] devido à formação do complexo ES no tempo $t$, e o aumento de [E] devido à dissociação de ES em $t$ e a liberação da enzima após o processo de catálise em $t$. A 
taxa de mudança da concentração de E no instante $t$ é calculada da seguinte forma:

$$
\begin{aligned}
\frac{d[E]}{d t} & =r 1+r 2+r 3 \\
& =-k_{1}[E][S]+k_{-1}[E S]+k_{c a t}[E S] \\
& =-k_{1}[E][S]+\left(k_{-1}+k_{c a t}\right)[E S] .
\end{aligned}
$$

A equação 3.3 é uma EDO, onde $r 1$, r2, e r3 são calculadas nas equações 3.2a, 3.2b, e 3.2c, respectivamente. Aplicando a todas as espécies químicas o raciocínio que foi empregado para definir a equação 3.3, obtemos o seguinte sistema de EDOs:

$$
\begin{aligned}
\frac{d[E]}{d t} & =-k_{1}[E][S]+\left(k_{-1}+k_{c a t}\right)[E S] \\
\frac{d[S]}{d t} & =-k_{1}[E][S]+k_{-1}[E S] \\
\frac{d[E S]}{d t} & =k_{1}[E][S]-\left(k_{-1}+k_{c a t}\right)[E S] \\
\frac{d[P]}{d t} & =k_{c a t}[E S] .
\end{aligned}
$$

Considere $\mathcal{P} / \mathcal{R}$ o conjunto de reações nas quais $A$ é produzida/consumida, $k_{p} / k_{r}$ a constante de velocidade da reação $p / r, \theta_{p} / \theta_{r}$ a ordem da reação $p / r$, e $\left[R_{i}^{p}\right] /\left[R_{i}^{r}\right]$ a concentração do $i$-ésimo reagente da reação $p / r$. De forma generalizada, em conjuntos de reações químicas podemos descrever a mudança de concentração de uma espécie química $A$ através da seguinte equação:

$$
\frac{d[A]}{d t}=\sum_{p \in \mathcal{P}}\left(k_{p} \prod_{i=1}^{\theta_{p}}\left[R_{i}^{p}\right]\right)-\sum_{r \in \mathcal{R}}\left(k_{r} \prod_{i=1}^{\theta_{r}}\left[R_{i}^{r}\right]\right),
$$

Após obtermos um sistema de EDOs que descreve a cinética de cada espécie química das reações consideradas, precisamos definir valores para cada constante de velocidade desse sistema. Para este fim, existem duas possibilidades. A primeira delas é utilizar valores extraídos da literatura; tais valores podem ser tanto estimativas quanto medidas experimentais (in vitro ou in vivo). A segunda é utilizar um método de otimização que será descrito na seção a seguir.

\subsection{Determinação das constantes de velocidade do modelo cinético}

A seleção do melhor conjunto de constantes de velocidade para o sistema de EDOs é feita através do método de otimização conhecido como análise de ajuste de curva. Esse método de otimização consiste em simular o modelo cinético (aqui entendido como fazer a integração numérica do sistema de EDOs para um dado período de tempo) com diferentes conjuntos de valores para as constantes de velocidade. Para cada simulação com um dado conjunto de constantes de velocidade, obtemos uma cinética simulada; essa cinética é então comparada com a cinética obtida em experimentos biológicos, e a distância entre elas é calculada utilizando alguma medida de erro (e.g. distância Euclidiana). Quanto menor for o erro, melhor é o conjunto de valores das constantes de velocidade associado.

Para exemplificar a análise de ajuste de curva, uma instância do mesmo é apresentada na figura 3.1. Nesse gráfico, temos três curvas de evolução da concentração de uma dada espécie química ao longo de um tempo arbitrário. A curva azul mostra a cinética do experimento biológico (curva ideal); as demais curvas mostram os resultados de simulações com diferentes conjuntos de valores de constantes de velocidade. Utilizando distância Euclidiana como medida de erro, e comparando a proximidade entre as curvas azul e vermelho e entre azul e verde, percebemos que a curva vermelha está mais próxima da curva azul (bom ajuste) do que a curva verde (ajuste ruim). Isso nos mostra que o conjunto de valores de constantes de velocidade utilizados na simulação da curva vermelha 
é melhor que o conjunto utilizado para gerar a curva verde. Portanto, baseado nesta análise de ajuste de curva, o conjunto de valores de constante de velocidade empregados para produzir a curva vermelha seria selecionado para definir o modelo cinético.

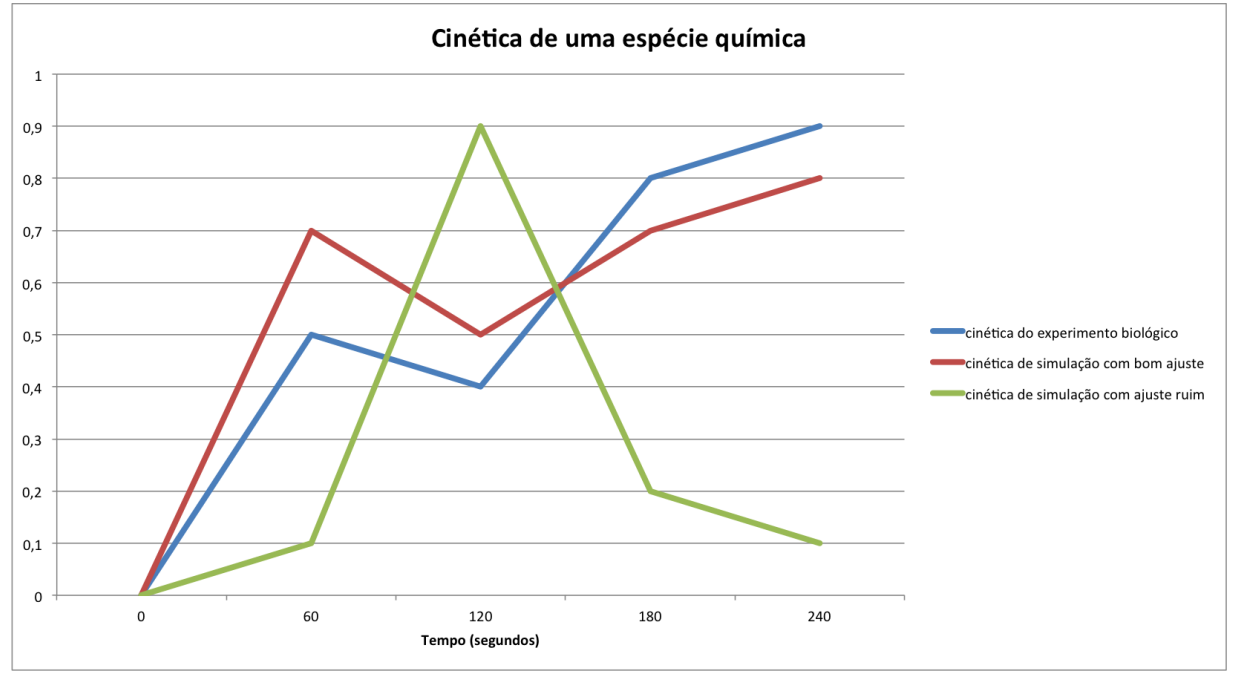

Figura 3.1: exemplo de análise de ajuste de curva para determinação dos valores das constantes de velocidade de um modelo cinético. A curva azul é uma cinética medida de experimentos biológicos, enquanto que as curvas vermelha e verde foram simuladas utilizando diferentes conjuntos de valores de constantes de velocidade.

A seguir, apresentaremos um arcabouço que pode ser utilizado para produzir um modelo cinético utilizando as metodologias apresentadas nas primeiras seções deste capítulo.

\subsection{O arcabouço SigNetSim}

SigNetSim é um arcabouço de e-Science desenvolvido para auxiliar na modelagem matemática e simulação computacional de vias de sinalização molecular. O desenho de um modelo cinético por meio do SigNetSim inclui as seguintes atividades:

1. mapeamento da descrição das reações químicas da via de sinalização molecular para um sistema de equações diferenciais ordinárias - EDOs (realizado conforme discutido na seção 3.1);

2. simulação numérica do sistema de EDOs;

3. avaliação dos resultados através da análise de ajuste de curva, a qual poderia conduzir a uma nova simulação (atividade 2) com os parâmetros ajustados.

Experimentos biológicos são usados para descrever a via de sinalização molecular e também como pontos de controle para a análise de ajuste de curva (atividade 3). O ciclo das atividades 2-3 é repetido até que a simulação numérica do modelo corrente produza resultados satisfatórios, isto é, que o ajuste entre os pontos de controle e as cinéticas simuladas seja bom o suficiente de acordo com uma dada medida de erro; este é um processo de otimização que visa ajustar os parâmetros do modelo cinético, conforme explicado na seção 3.2. Se o número de repetições das iterações for acima de um certo limiar e não houver produção de resultados satisfatórios, então há evidência de que precisamos considerar uma nova hipótese para o módulo funcional da via de sinalização molecular. A figura 3.2 mostra a sequência de atividades do arcabouço SigNetSim. 


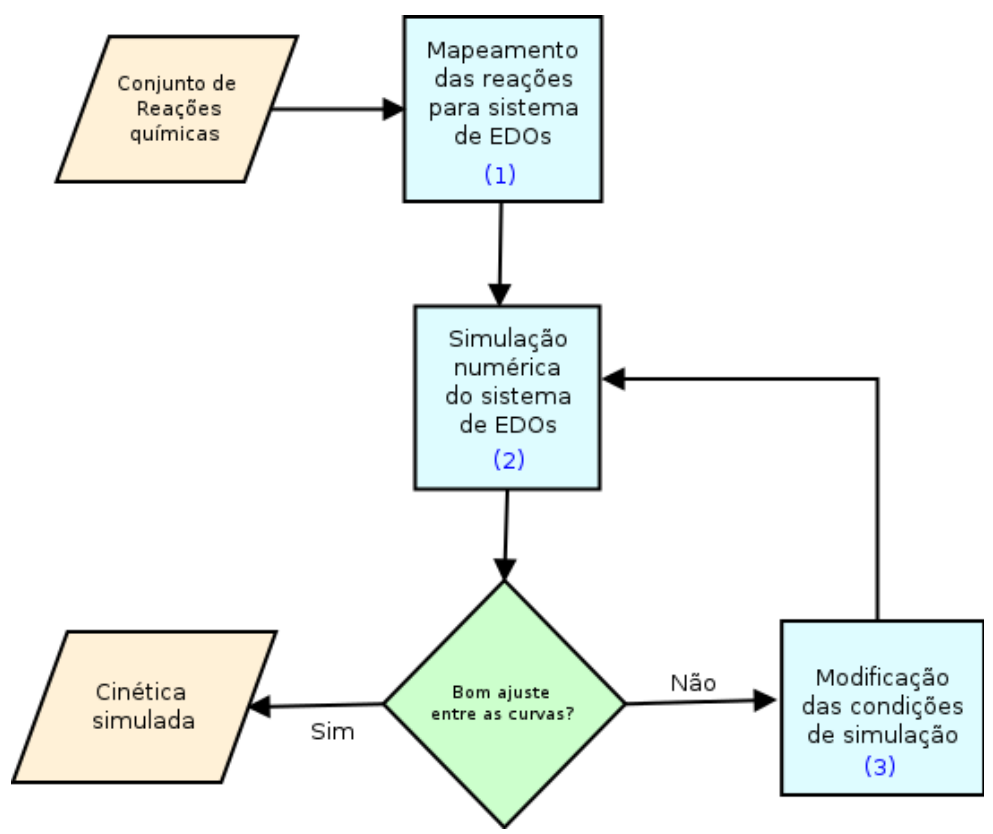

Figura 3.2: Fluxo de atividades do arcabouço SigNetSim. Os retângulos em azul denotam atividades, enquanto que os de cor alaranjada representam o fluxo de dados.

\subsection{Exemplo de aplicação: determinação de módulo funcional de uma via de sinalização molecular}

Por fim, mostraremos um exemplo de aplicação da metodologia de modelagem apresentada neste capítulo. Trata-se da determinação de um módulo funcional da via de sinalização Ras mostrada anteriormente na figura 2.1. Ras é uma GTPase, isto é, uma enzima hidrolase que tem como substrato guanosina trifosfato (GTP). A proteína Ras se torna ativa ${ }^{1}$ quando se associa a GTP e inativa quando está associada a guanosina difosfato (GDP). A natureza ligado/desligado da proteína Ras pode ser controlada pelas outras enzimas; por exemplo, a lenta troca de GDP por GTP é catalisada por fatores de troca nucleotídeos de guanina (GEFs). Um importante GEF é a proteína SOS [RA14].

Quando células de camundongo estão carenciadas (o que implica que não estão estimuladas por fatores de crescimento), observamos em experimentos biológicos os seguintes fatos:

- a concentração de SOS é relativamente baixa;

- a concentração de Ras ligado a GDP (Ras-GDP) é muito maior do que a de Ras ligado a GTP (Ras-GTP), o que denota que o Ras está "desligado".

Por outro lado, com o estímulo de fatores de crescimento, após cerca de cinco minutos observamos que:

- a concentração de SOS é alta;

- a concentração de Ras-GDP é muito menor do que a de Ras-GTP, o que denota que o Ras está "ligado".

Dessa forma, iniciemos definindo o módulo funcional do liga/desliga de Ras a partir do recorte no mapa estático da via de sinalização da GTPase Ras, exibido na figura 2.1; isto é, escolheremos algumas espécies químicas e também interações entre elas. Essa estrutura arbitrária é a hipótese que fazemos sobre quais seriam os componentes indispensáveis para reproduzir os valores observados em experimentos biológicos. Na figura 3.3, destacamos as espécies químicas escolhidas a partir do mapa exibido na figura 2.1: SOS, Ras-GDP e Ras-GTP.

\footnotetext{
${ }^{1}$ torna-se ativa no sentido de passar a interagir com outras proteínas, tal como a Raf.
} 


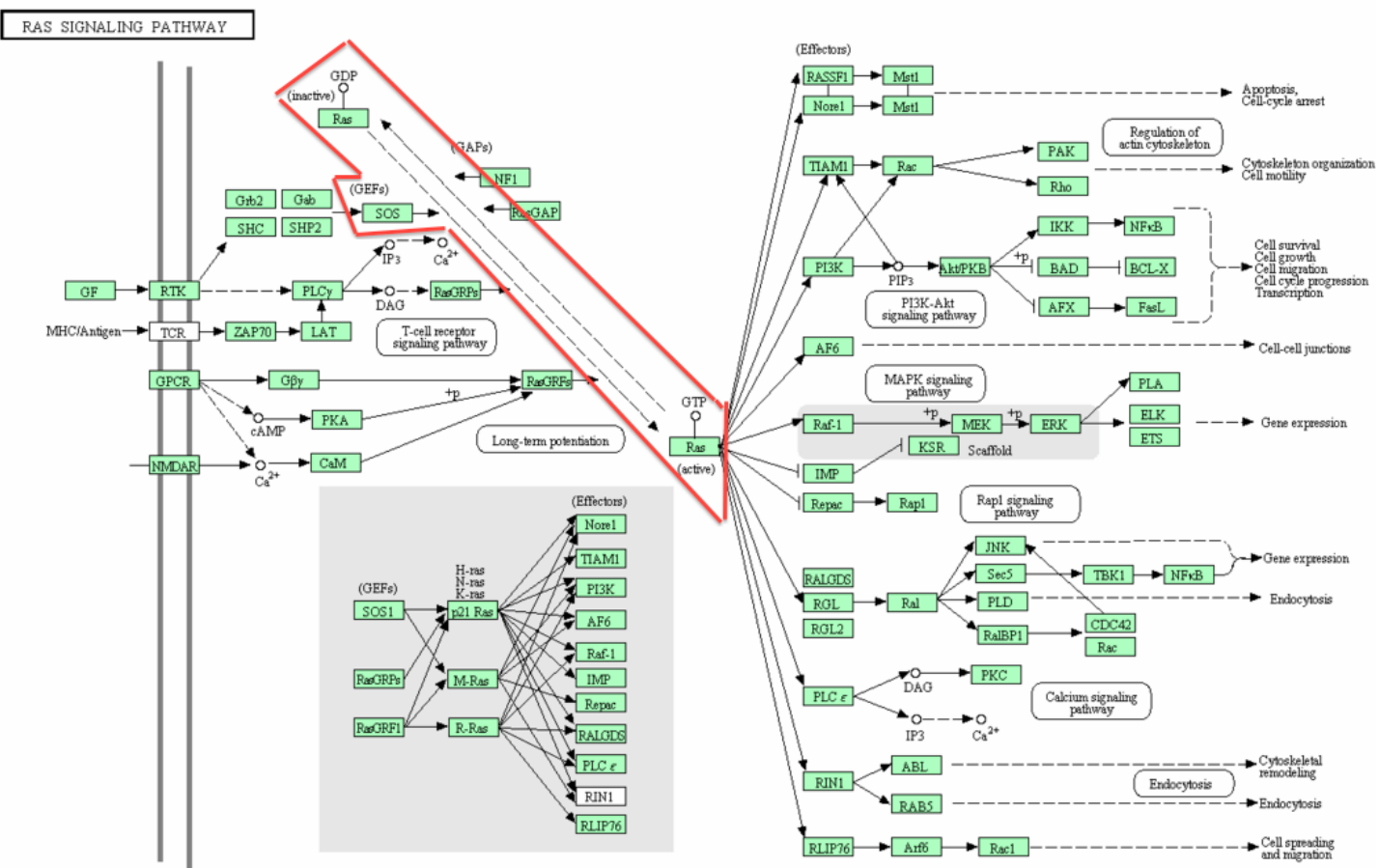

Figura 3.3: espécies químicas e reações escolhidas que fazem parte de nossa hipótese inicial para um módulo funcional da via de sinalização Ras.

A nossa hipótese inicial de módulo funcional é descrita pelas seguintes equações:

$$
\begin{aligned}
\operatorname{Ras}-G T P & \rightleftharpoons{ }_{k_{-1}}^{k_{1}} \text { Ras-GDP } \\
S O S+R a s-G D P & \rightleftharpoons{ }_{k_{-2}}^{k_{2}} \text { SOS-Ras-GDP } \rightarrow{ }^{k_{2}^{\text {cat }}} \text { SOS }+ \text { Ras-GTP }
\end{aligned}
$$

Para a construção do modelo cinético, essas equações, por sua vez, são mapeadas no seguinte sistema de EDOs:

$$
\begin{aligned}
& \frac{d[S O S]}{d t}=-k_{2}[S O S][R a s-G D P]+k_{-2}[S O S-R a s-G D P]+k_{2}^{\text {cat }}[S O S-R a s-G D P] \\
& \frac{d[S O S-R a s-G D P]}{d t}=+k_{2}[S O S][R a s-G D P]-k_{-2}[S O S-R a s-G D P]-k_{2}^{c a t}[S O S-R a s-G D P] \\
& \frac{d[\text { Ras }-G T P]}{d t}=-k_{1}[\text { Ras-GTP }]+k_{-1}[\text { Ras }-G D P]+k_{c a t}[S O S-R a s-G D P] \\
& \frac{d[\text { Ras }-G D P]}{d t}=+k_{1}[\text { Ras }-G T P]-k_{-1}[\text { Ras-GDP }]-k_{2}^{\text {cat }}[S O S-R a s-G D P]
\end{aligned}
$$

Utilizando medidas experimentais como concentrações iniciais do modelo cinético (figuras 3.4(a), 3.4(b), barras azuis), tentamos fazer o ajuste do modelo empregando a metodologia descrita na seção 3.2. O arcabouço SigNetSim é usado para auxiliar neste processo, no qual diferentes valores de constantes de velocidade são testados em simulações em que a cinética é simulada por 5 minutos. Fazemos a simulação em dois cenários: 5 minutos com baixa concentração de SOS (célula carenciada) e 5 minutos com alta concentração de SOS (estímulo por fatores de crescimento). Em ambos os cenários, ao final de cada simulação, comparamos as concentrações finais simuladas das espécies químicas com as que foram mensuradas experimentalmente. Consideramos que a hipótese de módulo funcional explica satisfatoriamente o fenômeno estudado se, utilizando um único conjunto de constantes de velocidade, conseguirmos um bom ajuste em ambos os cenários.

Suponhamos que, dentro da faixa de valores possíveis para as constantes de velocidade (i.e., 
valores que são termodinamicamente viáveis dentro do modelo estudado), não consigamos fazer um bom ajuste entre os valores dos experimentos biológicos e os obtidos de uma das simulações executadas: para o cenário de estímulo por fatores de crescimento bons ajustes são encontrados (figuras 3.4(a)), enquanto que para o experimento carenciado o processo de otimização não produz resultados satisfatórios (figura 3.4(b)). Isso nos leva à conclusão de que a hipótese adotada (i.e., a estrutura de via de sinalização molecular utilizada nas simulações) pode ser falsa, o que implicaria na necessidade de expansão do módulo funcional considerado, incluindo novas espécies e/ou reações químicas.

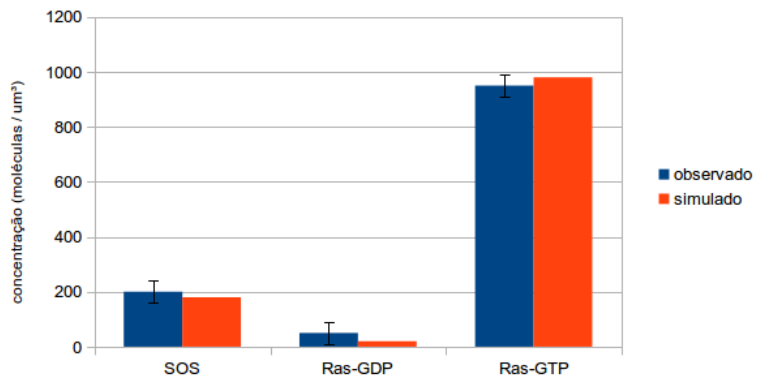

(a)

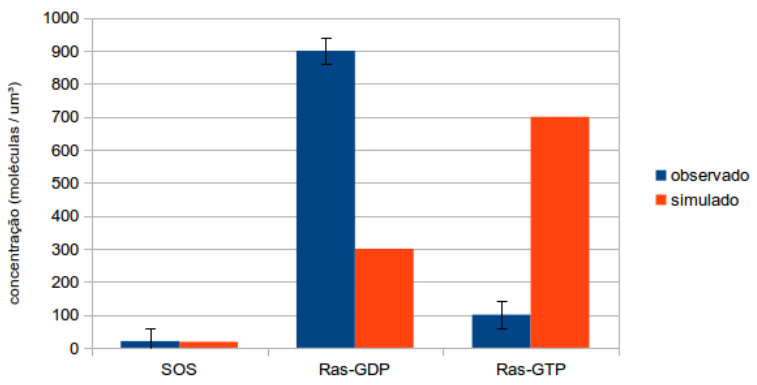

(b)

Figura 3.4: teste da hipótese de módulo funcional de Ras não reproduz o fenômeno observado: após otimização das constantes de velocidade, 5 minutos de simulação com alta concentração de SOS produz resultados satisfatórios (Figura 3.4(a)); porém, o mesmo não ocorre na simulação de 5 minutos com baixa concentração de SOS (Figura 3.4(b)).

Uma possibilidade de modificação do módulo funcional considerado é inclusão de uma reação que utilize Ras-GDP como substrato, produzindo no processo Ras-GTP: de fato, a hidrólise de GTP por Ras pode ser acelerada por proteínas de ativação de GTPase (GAPs). Voltando para o mapa estático da via de sinalização de Ras, observamos que existe uma GAP ("RasGAP", figura 3.5).

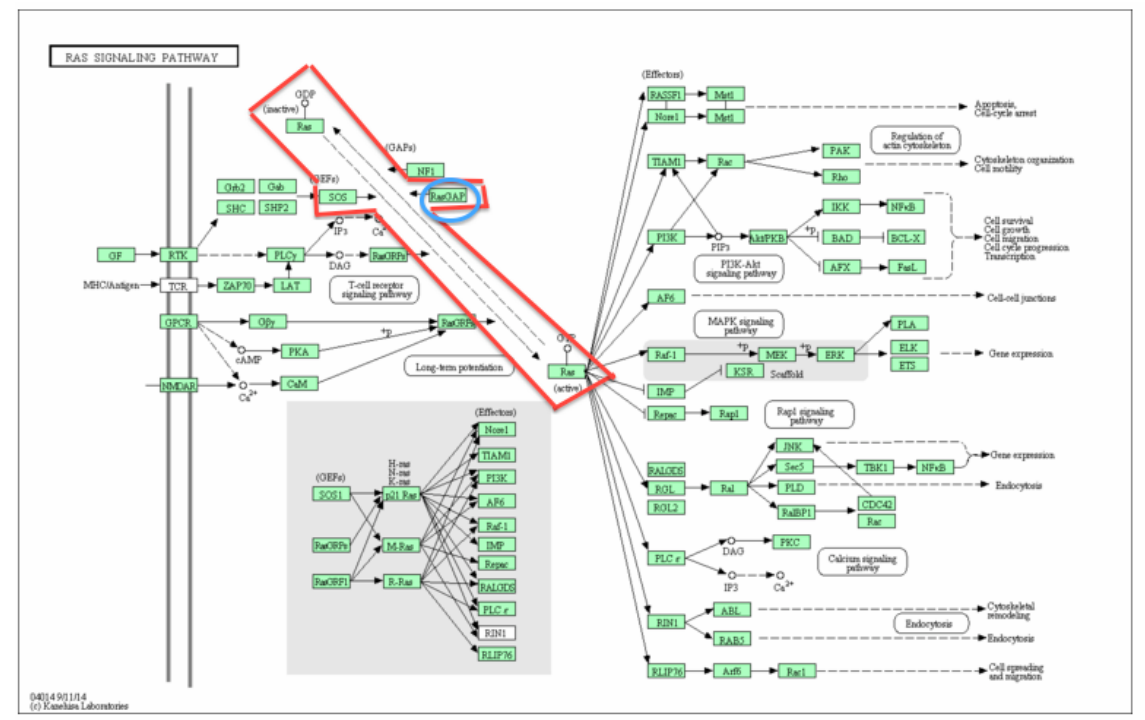

Figura 3.5: expansão do módulo funcional de Ras, de forma a incluir a enzima "RasGAP"(destacada em azul) e a reação química da qual essa enzima participa.

Dessa forma, definimos uma nova hipótese para o módulo funcional de Ras ao acrescentarmos ao conjunto de reações químicas das equações $3.6 \mathrm{a}-3.6 \mathrm{~b}$ a seguinte reação enzimática:

$$
G A P+R a s-G T P \rightleftharpoons{ }_{k_{-3}}^{k_{3}} G A P-R a s-G T P \rightarrow_{3}^{k^{c a t}} G A P+R a s-G D P .
$$


O modelo cinético da nova hipótese para o módulo funcional é obtido através do acréscimo das seguintes equações ao sistema de EDOs mostrado nas equações $3.7 \mathrm{a}-3.7 \mathrm{~d}$ :

$$
\begin{gathered}
\frac{d[G A P]}{d t}=-k_{3}[G A P][R a s-G T P]+k_{-3}[G A P-R a s-G T P]+k_{3}^{c a t}[G A P-R a s-G T P] \\
\frac{d[G A P-R a s-G T P]}{d t}=+k_{3}[G A P][R a s-G T P]-k_{-3}[G A P-R a s-G T P]-k_{3}^{c a t}[G A P-R a s-G T P],
\end{gathered}
$$

além do acréscimo do termo $k_{3}^{c a t}[G A P-R a s-G T P]$ na equação $3.7 \mathrm{~d}$, assim como da inclusão dos termos $-k_{3}[G A P][$ Ras-GTP $]+k_{-3}[G A P-R a s-G T P]$ na equação $3.7 \mathrm{c}$. Por fim, as constantes de velocidade do novo modelo são ajustadas, empregando novamente a metodologia descrita na seção 3.2. Supondo que um bom ajuste seja alcançado em ambos os cenários (figuras 3.6(b) e 3.6(a)), a hipótese atual para o módulo funcional é corroborada.

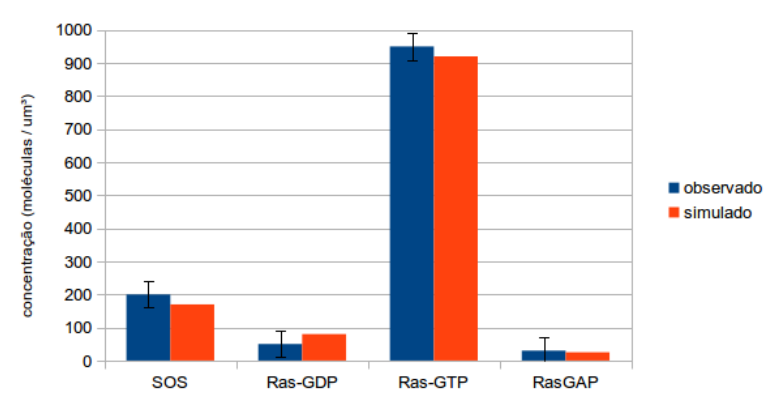

(a)

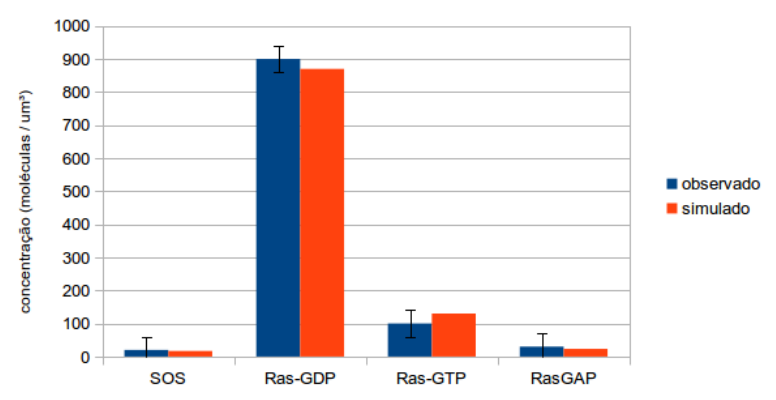

(b)

Figura 3.6: teste da nova hipótese de módulo funcional de Ras reproduz o fenômeno observado: após otimização das constantes de velocidade, 5 minutos de simulação com alta concentração de SOS produz resultados satisfatórios (Figura 3.6(a)); o mesmo ocorre na simulação de 5 minutos com baixa concentração de SOS (Figura 3.6(b)).

Testar de forma manual novas hipóteses para estrutura de módulos funcionais de vias de sinalização molecular pode ser factível para modelos com poucas espécies químicas, tal como o do exemplo deste capítulo. Todavia, o número de hipóteses passíveis de teste cresce exponencialmente em função da inclusão de novas espécies e/ou reações químicas. Portanto, é necessário sistematizar o processo de escolha e teste de novas hipóteses de módulos funcionais de vias de sinalização molecular, assunto que será abordado nos próximos capítulos. 


\section{Capítulo 4}

\section{Métodos de modificação de Grafos de Interação Molecular (GIMs)}

Neste capítulo, introduziremos uma estrutura de dados para representar recortes de via de sinalização molecular. Chamaremos tal estrutura de dados de Grafo de Interação Molecular (GIM). Começaremos apresentando alguns conceitos de Teoria dos Grafos necessários para formalizar a estrutura de dados e os algoritmos que a utilizam. Em seguida, formalizaremos o conceito de GIM e como mapear um recorte de via de sinalização molecular para essa estrutura (figura 4.1, atividade 1). Na sequência, mostraremos como mapear em GIMs bancos de dados de interatomas, em particular o banco KEGG (figura 4.1, atividade 2). Por fim, apresentaremos um algoritmo para modificar GIMs de recortes de vias (figura 4.1, atividade 3). Para fazermos avaliações iniciais da dinâmica desses algoritmos, consideraremos a medida de otimalidade do GIM de recorte de vias como uma função objetiva genérica a ser otimizada (figura 4.1, retângulo cinza). Observe que esse retângulo representa um encapsulamento das atividades 4,5 e 6 mostradas na figura 1.2; isto é, essas atividades definem um tipo particular de função objetiva para ser utilizada pelo algoritmo de modificação de GIMs de recorte de vias; a utilização desse tipo particular de função objetiva será feita nos trabalhos futuros deste projeto e será descrita em um capítulo a ser escrito.

\subsection{Conceitos de teoria dos grafos}

Neste trabalho, um grafo refere-se sempre a um multigrafo direcionado; isto é, um grafo consiste num conjunto finito e não vazio $V$ de elementos chamados vértices e num multi-conjunto finito $A$ de pares ordenados de elementos distintos de $V$ chamados de arcos. Usualmente, os componentes de um grafo $G$ são representados pelo par ordenado $\left(V_{G}, A_{G}\right)$, onde $V_{G}\left(A_{G}\right)$ é o conjunto de vértices (arcos).

Seja $G$ um grafo. Dois vértices $u$ e $v$ de $G$ são adjacentes se o arco $\langle u, v\rangle$ e/ou $\langle v, u\rangle$ pertence(m) a $A_{G}$. Seja $\left(V_{G} \cup V_{H}, A_{G} \cup A_{H}\right)$ um grafo tal que $\left(V_{G}, A_{G}\right)$ e $\left(V_{H}, A_{H}\right)$ também são grafos. Um vértice $v \in V_{H}$ tem um vizinho em $G$ se existe um vértice $u \in V_{G}$ tal que $\langle u, v\rangle$ e/ou $\langle v, u\rangle$ seja(m) arco(s) de $H$. Sejam $G$ e $H$ grafos. $H$ é um grafo aumentado de $G$ se $V_{H}$ e $A_{H}$ contêm, respectivamente, $V_{G}$ e $A_{G}$.

Seja $G$ um grafo e $n$ um inteiro menor ou igual a $\left|V_{G}\right|$, onde $\left|V_{G}\right|$ define o número total de vértices de $G$. Um caminho é uma sequência de vértices $\left\langle u_{1}, \ldots, u_{n}\right\rangle$, tal que existe(m) o(s) arco(s) $\left\langle u_{i}, u_{i+1}\right\rangle$ e/ou $\left\langle u_{i+1}, u_{i}\right\rangle, 1 \leq i \leq n-1$. $G$ é conexo se existe um caminho para cada par de vértices de $G$ tomados dois a dois.

Definimos grafos como direcionados para distinguir se, para um par de espécies $u, v$, se $u$ afeta $v$ ou vice-versa. Já a propriedade de multigrafo existe para permitir a descrição de casos em que ocorrem mais de uma interação do tipo espécie $u$ afetando $v$. 


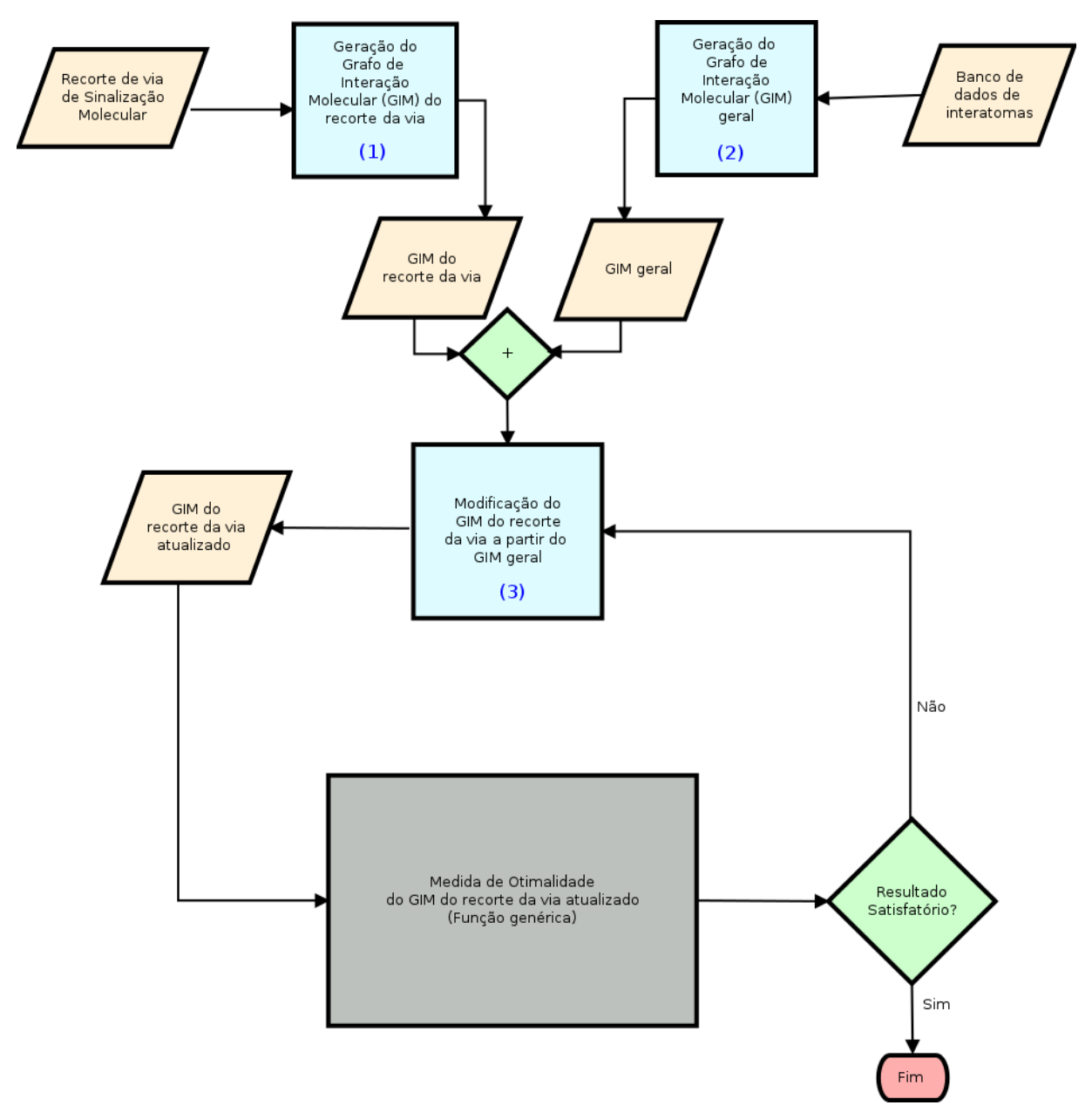

Figura 4.1: Sequência de atividades do processo de modificação de uma via de sinalização. Os retângulos em azul denotam atividades, os quais são unidades de trabalhos realizados no processo; os de cor alaranjado são arquivos de entrada ou de saída das atividades; o retângulo de cor cinza encapsula as atividades 4,5 e 6 . 


\subsection{Geração de GIMs de recortes de via}

Um Grafo de Interação Molecular (GIM) é um grafo (i.e., um multigrafo direcionado) no qual um vértice representa uma espécie química e um arco representa uma interação entre os dois vértices que o compõem. Um exemplo de GIM é dado na figura 4.2.

Dado um recorte de via de sinalização molecular, o mesmo pode ser mapeado para um GIM que representa essa recorte de via. Vamos apresentar um exemplo: considere o recorte de via de sinalização molecular mostrado na figura 3.3; nele vemos três espécies químicas (Ras-GDP, RasGTP e SOS) e três interações entre elas (Ras hidrolizando GTP, Ras trocando GDP por GTP e SOS catalisando o processo de troca de nucleotídeos). O GIM que representa esse recorte de via, mostrado na figura 4.2, guarda informações topológicas desse recorte. A natureza das interações (e.g., catálise, ativação, fosforilação, etc.) são valores de uma função dos arcos; por exemplo, na figura 3.3 a interação entre SOS e Ras-GDP é de ativação. Os tipos de interação entre as espécies químicas são informações relevantes para recuperar um conjunto de reações químicas e serão abordados no próximo capítulo.

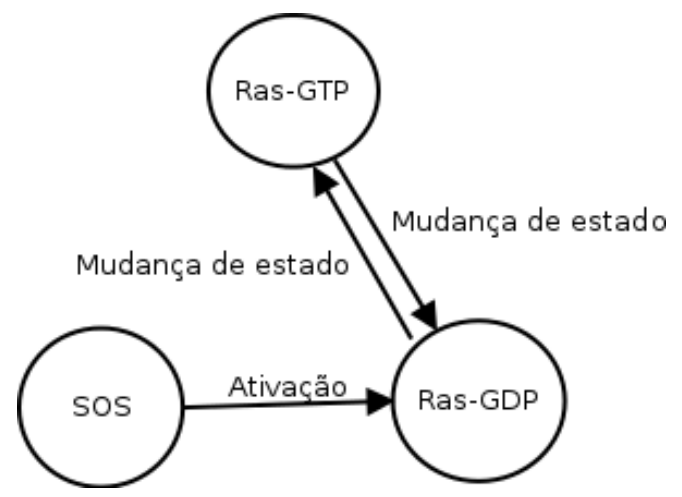

Figura 4.2: Grafo de Interação Molecular (GIM) de um recorte de via molecular de sinalização mostrado na figura 3.3 .

A geração de GIMs de recortes de via, nos moldes aqui apresentada, constitui a atividade 1 exibida na figura 1.2.

\subsection{Geração de GIMs de banco de dados de interatomas (GIM geral)}

Para realizarmos uma modificação de um recorte de via de sinalização molecular, precisamos consultar alguma referência que nos indique quais inclusões (no recorte atual) de novas espécies e/ou interações químicas são possíveis do ponto de vista biológico. Bancos de dados de interatomas são fontes de referência para este fim, uma vez que os mesmos catalogam milhares de espécies químicas e suas respectivas interações, para diversos organismos, tecidos, condições experimentais, etc. Existem bancos de dados montados com ou sem curadoria, bancos que contêm apenas dados verificados experimentalmente, bancos que não especificam a natureza de interação, etc. Dentre as várias opções existentes em domínio público, optamos por utilizar o Kyoto Enclyclopedia of Genes and Genomes (KEGG) [KG00].

O banco KEGG é uma alternativa interessante para iniciar nossos trabalhos devido às seguintes características:

- é um banco que especifica a natureza de interação entre as espécies químicas de uma forma muito clara;

- trata-se de um banco que passa por um processo de curadoria manual, o que torna as interações mais confiáveis; 
- facilidade de manipulação das informações contidas nesse banco.

A seguir, mostraremos como mapear em um GIM geral um banco de dados de interatomas do KEGG.

\subsubsection{Produzindo GIMs a partir de mapas do KEGG}

O banco de dados de interatomas KEGG é estruturado na forma de mapas funcionais, isto é, mapas estáticos que representam espécies químicas, suas interações, a natureza de suas interações, e a interação de espécies químicas com espécies presentes em outros mapas funcionais (como um exemplo deste último, veja na figura 2.1 a espécie química p53 apontando para o mapa funcional "p53 signaling pathway").

Para um dado organismo presente no KEGG, optamos por fazer a união de todos os mapas funcionais de vias de transdução de sinal. A intenção de fazer a união de mapas funcionais é possibilitar a investigação de interações entre espécies químicas que ainda não foram catalogadas como relevantes pelos curadores do KEGG em uma determinada via (i.e., em um dado mapa), as quais podem estar presentes em outra via (i.e., em outro mapa).

Vamos agora ilustrar o processo de geração do GIM geral utilizando mapas funcionais do banco KEGG. Ou seja, definiremos uma maneira de implementar a atividade 2 apresentada na figura 1.2. Cada mapa funcional é mapeado para um GIM desse mapa, nos mesmos moldes que foi mostrado para o GIM de recorte de via exibido na seção anterior. Na sequência, fazemos a união de todos os GIMs de mapas; como um GIM é um multigrafo direcionado, a união desses GIMs admite repetição de arcos mas não a de espécies químicas. O produto dessa união é o GIM geral. Na figura 4.3 resumimos todo o processo aqui descrito.

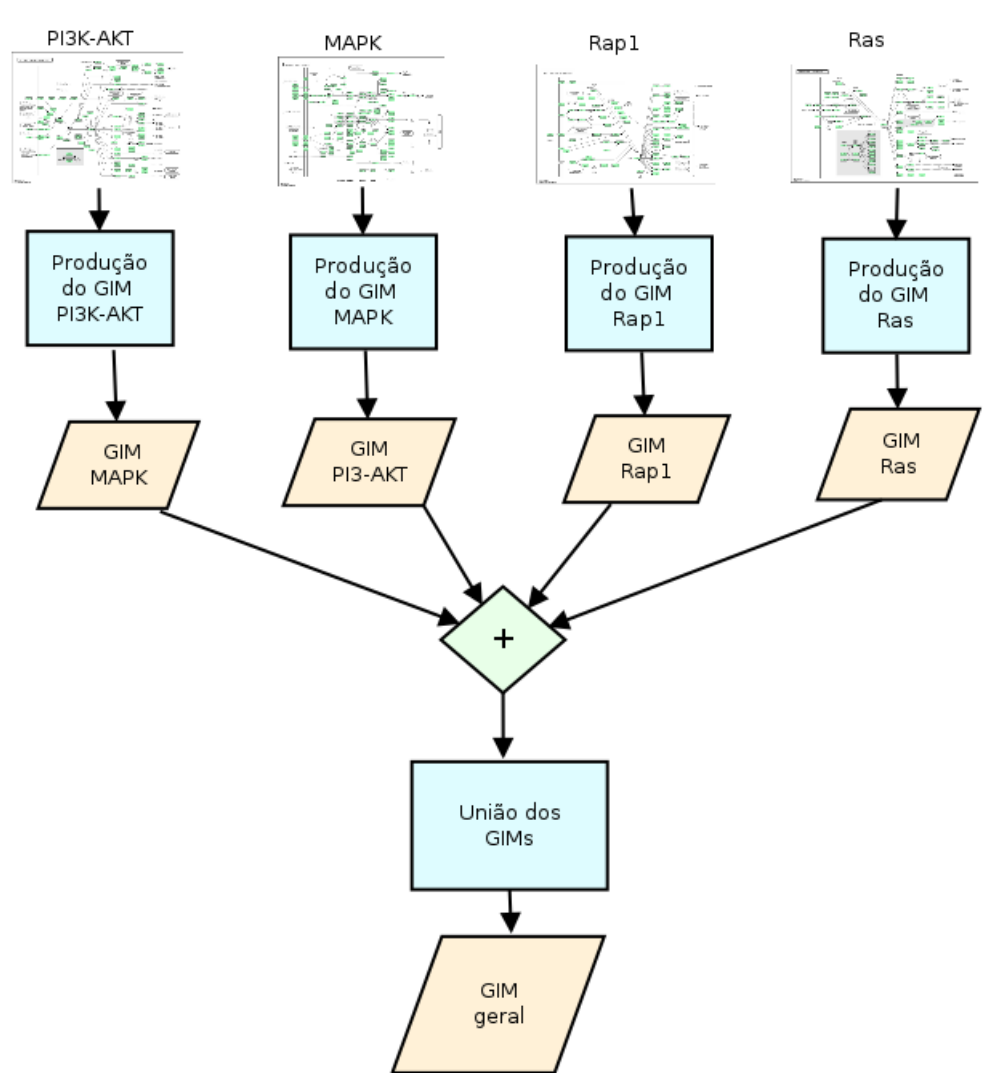

Figura 4.3: exemplo do processo de união de mapas funcionais do banco KEGG. Neste exemplo, quatro mapas funcionais foram convertidos em seus respectivos GIMs, que por sua vez foram unidos em um único GIM geral. 
Um GIM geral pode vir a ser um grafo com uma topologia complexa; na figura 4.4 ilustramos esse fato.

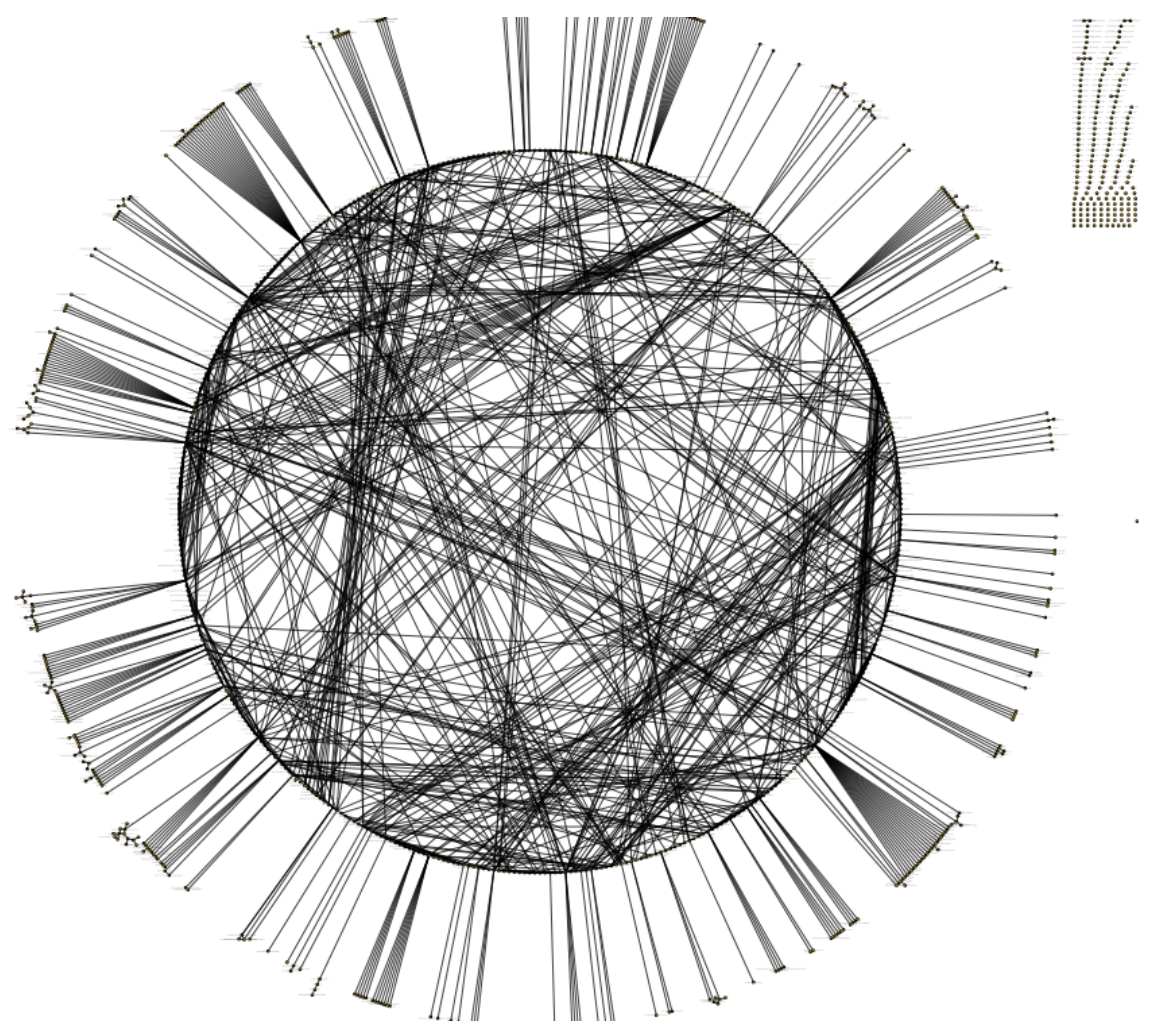

Figura 4.4: topologia do GIM geral produzido a partir da união de todos GIMs dos mapas funcionais de transdução de sinal presentes no KEGG para camundongo (Mus musculus).

A seguir, discutiremos alguns algoritmos de modificação de GIMs de recortes de vias (atividade 3 na figura 4.1), tendo como entrada o GIM do recorte de via obtido como descrito na seção $4.2 \mathrm{e}$ o GIM geral apresentado nesta seção.

\subsection{Algoritmos de modificação de GIMs de recorte de via}

Inicialmente abordaremos o seguinte problema: dado um GIM de recorte de via, queremos aumentá-lo (isto é, adicionar ao mesmo novos vértices e/ou arcos) de forma que o GIM aumentado seja conexo. Existem diversas maneiras de resolver esse problema; quando estabelecemos um critério adequado para avaliar conjuntos de vértices e/ou arcos a serem acrescentados em um GIM, dentro do universo de soluções possíveis, consiste na redução do problema em um problema de otimização. Dessa forma, a função genérica apresentada no retângulo cinza na figura 4.1 é a nossa função objetiva.

Otimização é a busca de uma melhor solução para um dado problema; essa busca consiste em verificar várias soluções e utilizar a informação obtida ao longo do processo para tentar encontrar soluções cada vez melhores. As técnicas de otimização fazem uso de um critério adequado ao problema explorado, denominado função objetiva, que é utilizado para avaliar as soluções produzidas.

Algoritmos podem ser ótimos ou subótimos (heurísticas). Os algoritmos ótimos garantem uma solução ótima, mas podem exigir muito tempo (às vezes inviável do ponto de vista prático) para gerar solução ótima. Já as heurísticas são técnicas que produzem soluções rapidamente, porém não garantem a otimalidade da solução encontrada.

A seguir, apresentaremos um algoritmo para aumentar GIMs de recorte de via, de forma que o GIM aumentado mantenha-se conexo. Dependendo da função objetiva escolhida, esses algoritmos são subótimos (heurísticas) porque baseiam-se em métodos gulosos de seleção sequencial. 


\subsubsection{Heurísticas gulosas}

Nesta seção, apresentaremos uma abordagem que se baseia em seleção sequencial, nos moldes de heurísticas tal como o Sequential Forward Selection (SFS) [WHI71]. Nessa heurística, novos elementos (em nosso caso, vértices e/ou arcos) são incluídos no conjunto original (GIM de recorte de via) segundo algum critério guloso (i.e., um critério que prioriza a melhor escolha a ser feita na iteração corrente, sem se preocupar se o resultado final será ótimo). Nessa abordagem, o critério guloso é adicionar um vértice com um maior número de vizinhos.

\section{Algoritmo de incremento de vértices}

Sejam $G$ e $H$ um par de grafos, $G$ representando o GIM do recorte da via e $H$ o GIM geral. Agora descreveremos um algoritmo para aumentar $G$ utilizando $H$, tendo como critério guloso a adição de vértices com um maior número de vizinhos. Esse algoritmo devolve um grafo conexo $G_{k}$ que é $G$ aumentado. Esse algoritmo recebe $G_{1}:=G$ e $H$ e, numa $k$-ésima iteração, escolhe um vértice $v \in H$ que tenha mais vizinhos em $G_{k}$; então incluímos em $G_{k} v$ e todos os arcos que contenham $v$ e algum vértice em $G_{k}$. O grafo $G_{k}$ atualizado é então avaliado pela função objetiva: caso ele seja adequado dentro do critério adotado, $G_{k}$ é devolvido; caso contrário, uma nova iteração é realizada. O algoritmo itera até ou $G_{k}$ ser adequado dentro do critério adotado ou não existir mais vértices $v \in H$ que tenham um ou mais vizinhos em $G_{k}$. O pseudo-código desse algoritmo é mostrado abaixo, e uma simulação do mesmo utilizando as instâncias 4.5(b) e 4.5(a) é apresentada nas figuras $4.6(\mathrm{a})-4.6(\mathrm{~g})$. Nesta simulação, foram empregados como instâncias grafos simples (i.e., grafos não-direcionados e sem repetição de ligação entre vértices); não obstante, o algoritmo apresentado também funciona para multigrafos direcionados.

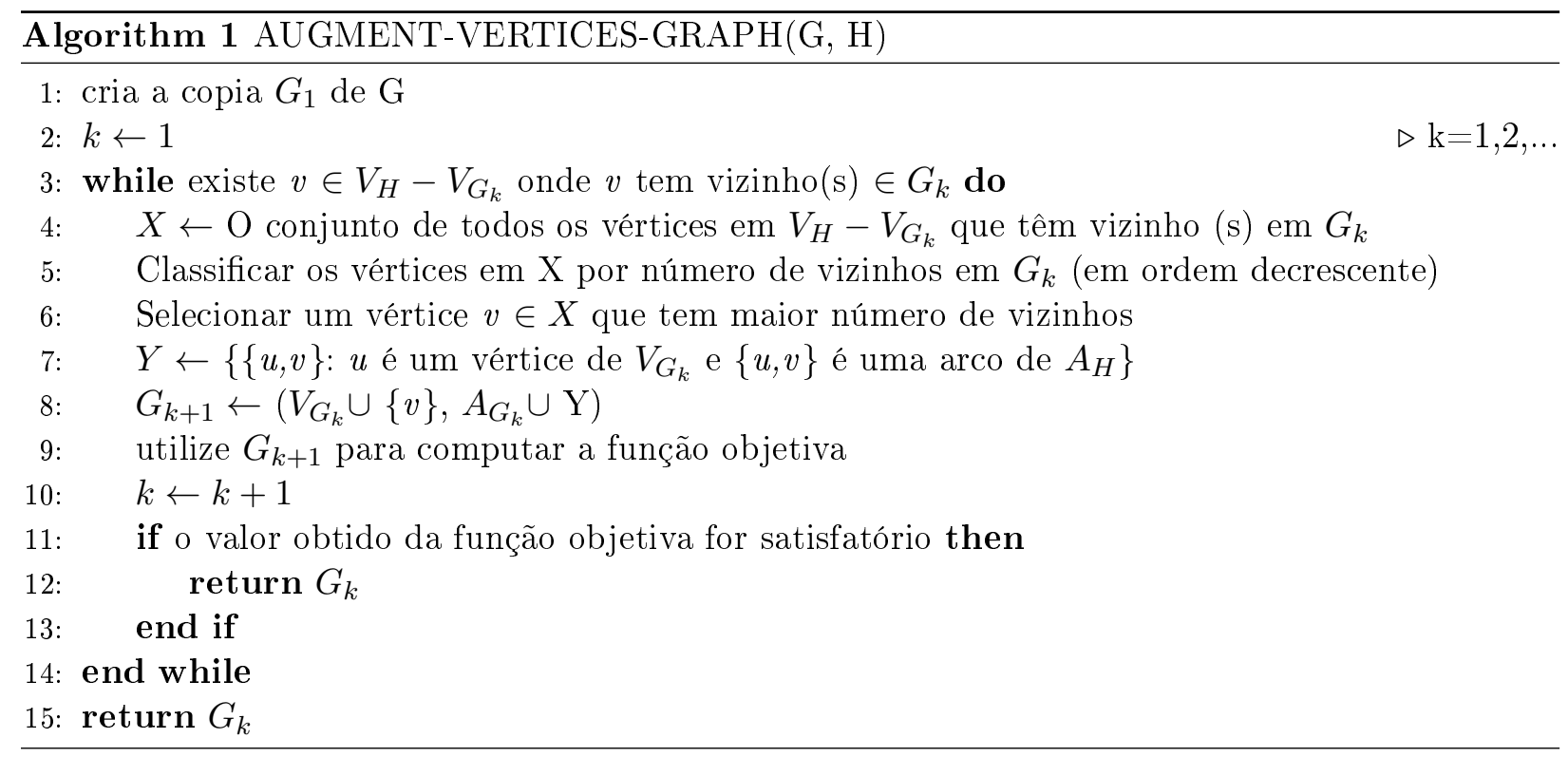

\section{Descrição da simulação do algoritmo 1:}

- Figura 4.6(a): o vértice $\boldsymbol{k}$ (mais conectado ao $G$ ) é adicionado a $G_{1}$ (chamamos aqui de $G_{1}$ a cópia do grafo $G$ ) gerando $G_{2}$.

- Figura 4.6(b): o vértice $\boldsymbol{m}$ é adicionado a $G_{2}$ gerando $G_{3}$.

- Figura 4.6(c): o vértice $\boldsymbol{l}$ é adicionado a $G_{3}$, gerando $G_{4}$.

- Figura 4.6(d): o vértice $\boldsymbol{b}$ é adicionado a $G_{4}$, gerando $G_{5}$.

- Figura 4.6(e): o vértice $\boldsymbol{q}$ é adicionado a $G_{5}$, gerando $G_{6}$. 


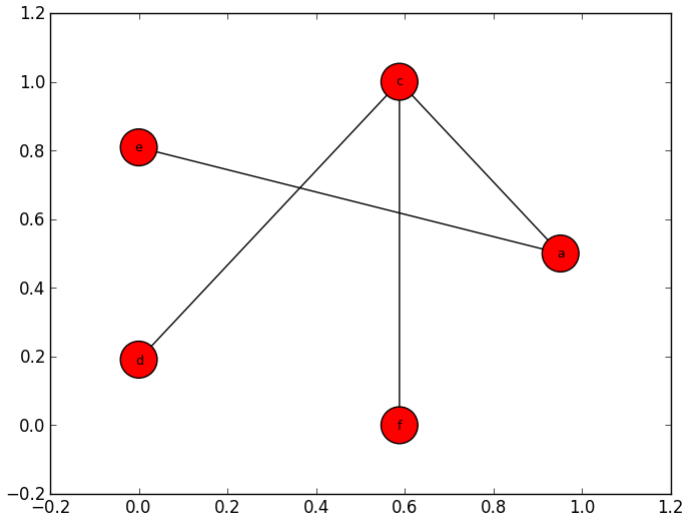

(a)

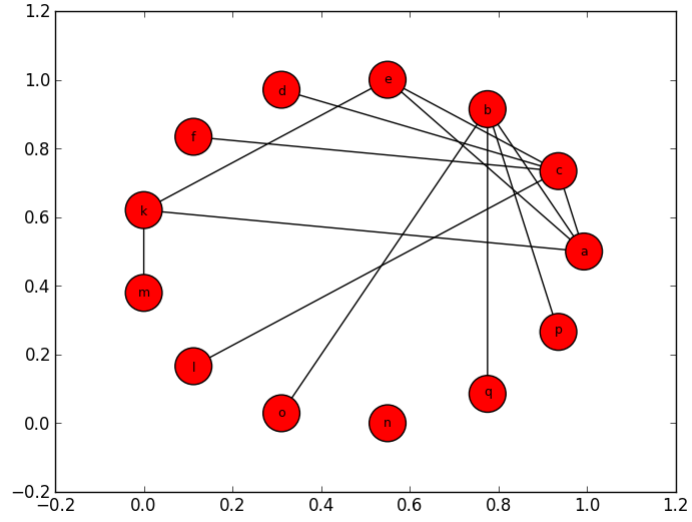

(b)

Figura 4.5: instâncias para a simulação do algoritmo de incremento de vértices. A figura 4.5(a) representa um GIM de recorte de via, enquanto que o grafo da figura 4.5(a) é um GIM geral.

- Figura $4.6(\mathrm{f})$ : o vértice $\boldsymbol{p}$ é adicionado a $G_{6}$, gerando $G_{7}$.

- Figura 4.6(g): o vértice $\boldsymbol{o}$ é adicionado a $G_{7}$, gerando $G_{8}$.

Após produzir $G_{8}$ (figura $4.6(\mathrm{~g})$ ), o processo de incremento de vértices termina, pois não há mais vértice $v$ de $G_{8}$ que seja vizinho de $H$.

\subsection{Comentários}

Neste capítulo, discutimos uma maneira de mapear um recorte de via de sinalização molecular para uma estrutura de grafo (figura 4.1, atividade 1); mostramos o mapeamento de banco de dados de interatomas em GIMs (figura 4.1, atividade 2) e por último apresentamos um algoritmo para modificar GIMs de recortes de vias (figura 4.1, atividade 3). 


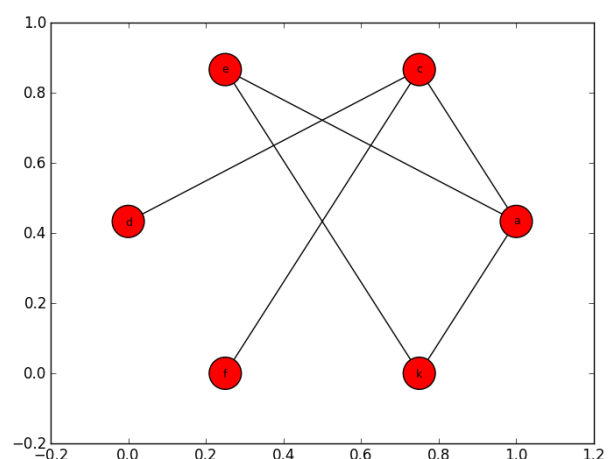

(a)

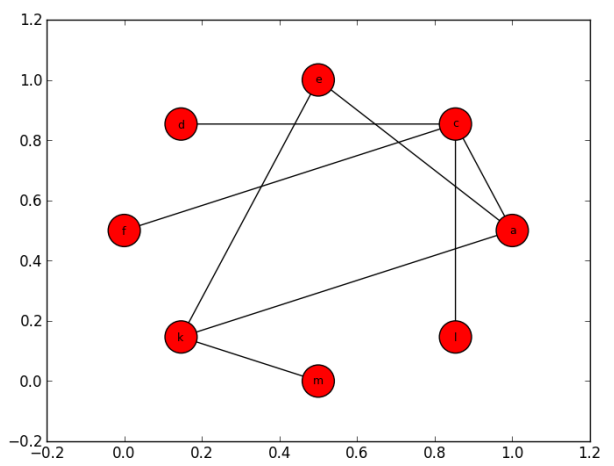

(c)

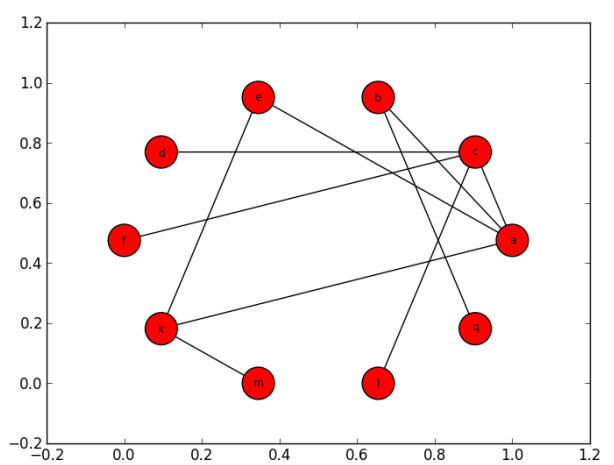

(e)

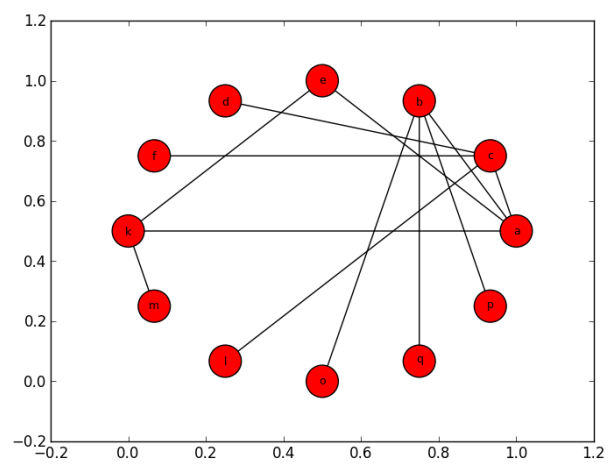

(g)

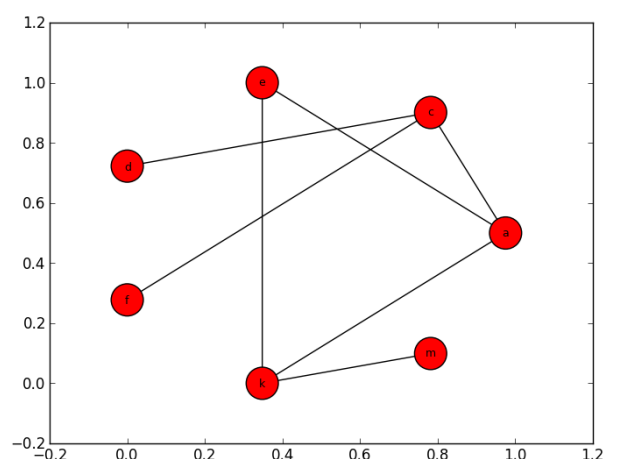

(b)

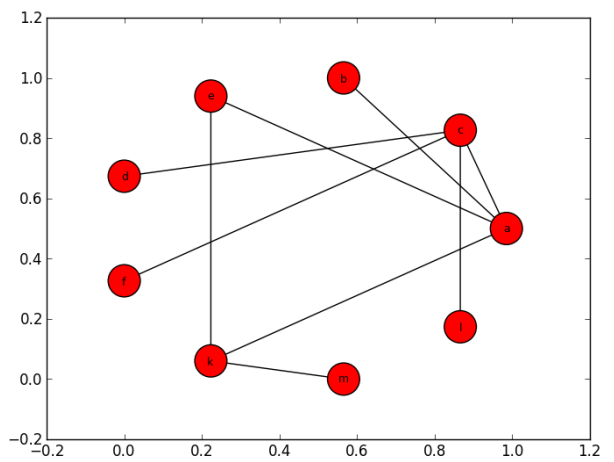

(d)

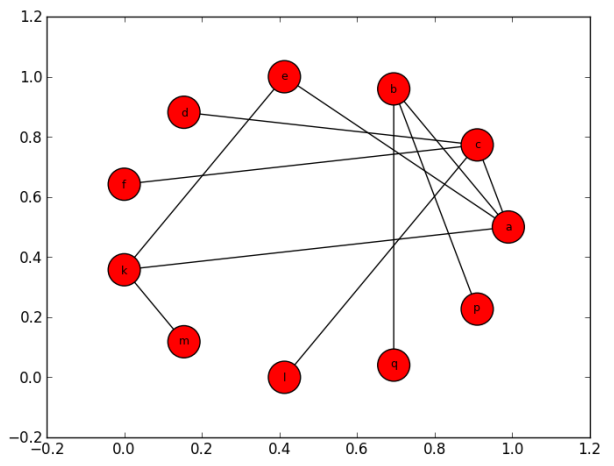

(f)

Figura 4.6: etapas de simulação do processo de incremento de vértices. 


\section{Capítulo 5}

\section{Mapeamento de recorte de vias de sinalização molecular em conjunto de reações químicas}

Conforme discutido em capítulos anteriores, a realização do mapeamento de recorte de vias de sinalização molecular em conjunto de reações químicas (atividade 4 na figura 1.2) é detalhada neste capítulo. Este mapeamento é feito aproveitando as informações armazenadas em um Grafo de Interação Molecular (GIM), a saber:

- espécies químicas, armazenadas nos vértices do GIM;

- existência de interação entre duas espécies químicas, armazenadas nos arcos do GIM;

- direção da interação (i.e., qual espécie química efetua a ação), armazenada no sentido de cada arco do GIM;

- natureza da interação, que é uma função dos arcos do GIM.

Para ilustrar este processo de mapeamento, consideremos o GIM exibido anteriormente na figura 4.2; um possível mapeamento desse grafo em um conjunto de reações químicas é:

$$
\begin{aligned}
\text { Ras-GTP } & \rightarrow^{k_{1}} \text { Ras-GDP } \\
\text { Ras-GDP } & \rightarrow{ }^{k_{2}} \text { Ras-GTP } \\
\text { SOS }+ \text { Ras-GDP } & \rightleftharpoons{ }_{k_{-3}}^{k_{3}} \text { SOS-Ras-GDP } \rightarrow_{3}^{\text {cat }} \text { SOS }+ \text { Ras-GTP },
\end{aligned}
$$

no qual a mudança de estado de Ras-GTP para Ras-GDP é dada pela equação 5.1a, a mudança de estado inversa é descrita na equação 5.1 b, e a ativação de Ras por SOS é formulada como uma reação enzimática apresentada na equação 5.1c. Observe que esse conjunto de reações químicas é equivalente ao conjunto mostrado nas equações 3.6a-3.6b.

O grande desafio neste processo é definir regras de mapeamento de uma dada natureza de interação em uma reação química. Tomemos o exemplo acima: a ativação de SOS em Ras-GDP foi modelada como uma reação enzimática, na qual SOS é a enzima e o Ras-GDP é o substrato; além disso, a ação catalítica de SOS é aceleração na liberação do nucleotídeo por parte do Ras, fazendo com que este último se ligue a um GTP (muito mais abundante na célula que GDP). Todavia, nem todas essas considerações podem ser extraídas do banco KEGG de uma maneira direta. Por outro lado, existem naturezas de interação que podem ser extraídas de forma direta: por exemplo, fosforilações.

Na próxima seção, mostraremos algumas formalizações de regras de mapeamentos que podem ser feitos a partir do banco do KEGG de uma maneira direta. Na sequência, faremos alguns comentários sobre os desafios aqui colocados e possibilidades de abordá-los. 


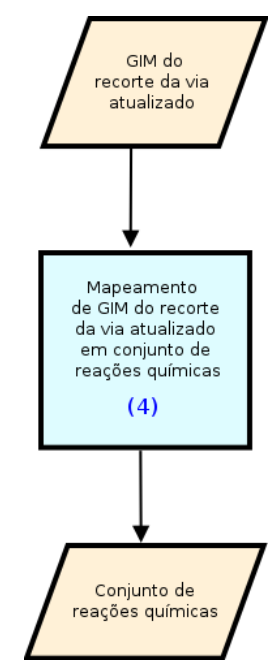

Figura 5.1: diagrama mostrando o fluxo de trabalho do mapeamento de recorte de vias de sinalização molecular em conjunto de reações químicas (atividade 4 na figura 1.2), incluindo suas entrada e saída.

\subsection{Formalização de regras de mapeamentos}

Para formalizar as regras de mapeamento de uma dada natureza de interação em uma reação química, apresentaremos primeiramente as naturezas de interações, que podem ser divididas em tipos e subtipos. Em seguida, ilustraremos as regras de mapeamento para cada natureza de interação, como também seu mapeamento para formato System Biology Markup Language (SBML) (ver apêndice A).

Os quatro tipos de interações encontradas nos arquivos KGML (ver apêndice B) do banco KEGG.

- PPrel: interação proteína-proteína, assim como associação e modificação proteína-proteína;

- ECrel: relação enzima-enzima, indicando duas enzimas catalizando etapas de reações sucessivas;

- GEre: interação de expressão gênica, indicando a relação do fator de transcrição com o produto do gene alvo;

- PCrel: interação proteína-composto químico.

Os subtipos dos tipos "PPrel", "ECrel", "GErel"e "PCrel"são mostrados nas tabelas 5.1, 5.2, 5.3 e 5.4 respectivamente. As informações contidas nos subtipos especificam de forma detalhada a natureza da interação.

Para cada tipo de interação, mostraremos as regras de mapeamento dos subtipos (Trabalhos relacionados que traduzem os mapas funcionais do banco KEGG PATHWAY para outros formatos, principamente para formato SBML, encontramos os trabalhos $\left[\mathrm{MKC}^{+} 09\right]$ e [WDZ11]).

\subsubsection{Interações do tipo PPrel}

\section{- ativação (activation):}

A figura 5.2 mostra a interação de ativação entre os vértices vertex1 e vertexQ, onde o "vertex1 ativa o vertex2". E o mapeamento dessa interação para uma reação é apresentada na equação 5.2 .

$$
\operatorname{vertex}_{1}+\operatorname{vertex}_{2} \underset{k_{-1}}{\stackrel{\mathrm{k}_{1}}{\rightleftharpoons}} \operatorname{vertex}_{1}-\text { vertex }_{2} \stackrel{k_{\text {cat }}}{\longrightarrow} \operatorname{vertex}_{1}+\text { vertex }_{2}-\text { active }
$$


Tabela 5.1: PPrel: nomes dos subtipos e explicação sobre cada subtipo.

PPrel subtipos

\begin{tabular}{ll}
\hline Nome & Explicação \\
\hline composto (compound) & intermédio de duas proteínas que interagem \\
\hline ativação (activation) & $\begin{array}{l}\text { efeito positivo que pode ser associado com } \\
\text { informação molecular seguinte }\end{array}$ \\
\hline inibição (inhibition) & efeito negativo que pode ser associado com \\
& informação molecular seguinte \\
\hline efeito indireto (indirect effect) & efeito indireto sem detalhes moleculares \\
\hline mudança de estado (state change) & transição de estado \\
\hline associação (binding/association) & relação ou interação de associação \\
\hline dissociação (dissociation) & relação ou interação de dissociação \\
\hline fosforilação (phosphorylation) & evento molecular \\
\hline desfosforilação (dephosphorylation) & evento molecular \\
\hline ubiquitinação (ubiquitination) & evento molecular \\
\hline metilação (methylation) & evento molecular \\
\hline
\end{tabular}

Tabela 5.2: ECrel: nomes dos subtipos e explicação sobre cada subtipo.

ECrel subtipos

\begin{tabular}{ll}
\hline Nome & Explicação \\
\hline composto (compound) & compartilhado em duas reações sucessivas \\
\hline
\end{tabular}

Tabela 5.3: GErel: nomes dos subtipos e explicação sobre cada subtipo.

GErel subtipos

\begin{tabular}{ll}
\hline Nome & Explicação \\
\hline expressão (expression) & interação via associação com DNA \\
\hline repressão (repression) & interação via associação com DNA \\
\hline efeito indireto $($ indirect effect) & efeito indireto sem detalhes moleculares \\
\hline
\end{tabular}

Tabela 5.4: PCrel: nomes dos subtipos e explicação sobre cada subtipo.

\begin{tabular}{ll} 
& PCrel subtipos \\
\hline Nome & Explicação \\
\hline ativação (activation) & efeito positivo que pode ser associado com \\
& informação molecular seguinte \\
\hline inibição (inhibition) & efeito negativo que pode ser associado com \\
& informação molecular seguinte \\
\hline efeito indireto (indirect effect) & efeito indireto sem detalhes moleculares \\
\hline associação (binding/association) & relação ou interação de associação \\
\hline fosforilação (phosphorylation) & evento molecular \\
\hline desfosforilação (dephosphorylation) & evento molecular \\
\hline
\end{tabular}

Onde "vertex1" representa a enzima $(\mathrm{E})$, "vertex2" representa o substrato $(\mathrm{S})$, "vertex1vertex2" representa o complexo enzima-substrato (ES) e "vertex2-active" representa o produto $(\mathrm{P})$. O mapeamento dessa reação para o formato SBML é apresentado na apêndice $\mathrm{A}$ (Listing A.2).

O complexo "vertex1-vertex2" é representado por "vertex1_and_vertex2" e o produto "vertex2active" é representado por "vertex2_active" no formato SBML. 


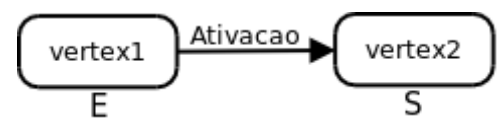

Figura 5.2: PPrel Ativação.

\section{- inibição (inhibition):}

A figura 5.3 mostra a interação de inibição entre os vértices vertex1 e vertex2, onde o "vertex1 inibe o vertex2". E o mapeamento dessa interação para uma reação é apresentada pela equação 5.3 .

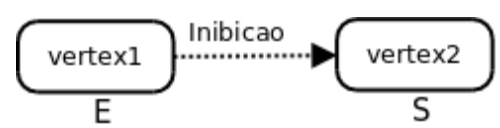

Figura 5.3: PPrel Inibição.

$$
\operatorname{vertex}_{1}+\operatorname{vertex}_{2} \underset{k_{-1}}{\stackrel{\mathrm{k}_{1}}{\rightleftharpoons}} \operatorname{vertex}_{1}-\text { vertex }_{2} \stackrel{k_{c a t}}{\longrightarrow} \operatorname{vertex}_{1}+\text { vertex }_{2} \text {-inactive }
$$

Onde "vertex1" representa a enzima (E), "vertex2" representa o substrato (S), "vertex1vertex2" representa o complexo enzima-substrato (ES) e "vertex2-inactive" representa o produto $(\mathrm{P})$. O mapeamento dessa reação para o formato SBML é semelhante que da "ativação", exceto pela seguinte diferença: o produto "vertex2-inactive" é representado por "vertex2_inactive".

\section{- associação (binding/association):}

A figura 5.4 mostra a interação de associação entre os vértices vertex1 e vertex2, onde o "vertex1 associa com o vertex2". E o mapeamento dessa interação para uma reação é apresentada pela equação 5.4 .

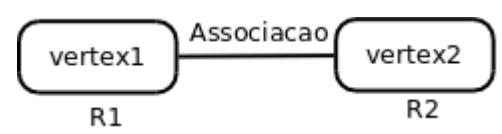

Figura 5.4: PPrel Associação.

$$
\text { vertex }_{1}+\text { vertex }_{2} \underset{k_{-1}}{\stackrel{\mathrm{k}_{1}}{\rightleftharpoons}} \text { vertex }_{1}-\text { vertex }_{2}
$$

Onde "vertex1" representa a proteína (reagente 1 - R1), "vertex2" representa outra proteína (reagente 2 - R2), "vertex1-vertex2" representa o complexo formado pelas duas proteínas. O mapeamento dessa reação para o formato SBML é semelhante que da "ativação", exceto pela diferença: neste subtipo de interação (associação) não temos a reação do tipo $E S \rightarrow E+P$.

\section{- fosforilação (phosphorylation):}

A figura 5.5 mostra a interação de fosforilação entre os vértices vertex1 e vertexQ, onde o "vertex1 fosforila o vertex2". E o mapeamento dessa interação para uma reação é apresentada pela equação 5.5 . 


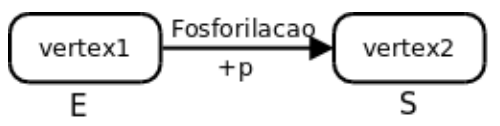

Figura 5.5: PPrel Fosforilação.

$$
\operatorname{vertex}_{1}+\text { vertex }_{2} \underset{k_{-1}}{\stackrel{\mathrm{k}_{1}}{\rightleftharpoons}} \operatorname{vertex}_{1}-\text { vertex }_{2} \stackrel{k_{\text {cat }}}{\longrightarrow} \operatorname{vertex}_{1}+\left(\operatorname{vertex}_{2}+\mathrm{Pi}\right)
$$

Onde "vertex1" representa a enzima (E), "vertex2" representa o substrato (S), "vertex1vertex2" representa o complexo enzima-substrato (ES) e "vertex2 $+P i$ " representa o produto (P). O mapeamento dessa reação para o formato SBML é semelhante que da "ativação", exceto pela seguinte diferença: o produto "vertex2 $+P i$ " é representado por "vertex2_add_P $i$ ".

\section{- desfosforilação (dephosphorylation):}

A figura 5.6 mostra a interação de desfosforilação entre os vértices vertex1 e vertexQ, onde o "vertex1 desfosforila o vertex2". E o mapeamento dessa interação para uma reação é apresentada pela equação 5.6.

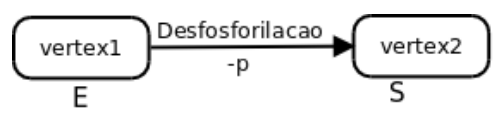

Figura 5.6: PPrel Desfosforilação.

$$
\operatorname{vertex}_{1}+\operatorname{vertex}_{2} \underset{k_{-1}}{\stackrel{\mathrm{k}_{1}}{\rightleftharpoons}} \operatorname{vertex}_{1}-\operatorname{vertex}_{2} \stackrel{k_{c a t}}{\longrightarrow} \operatorname{vertex}_{1}+\left(\operatorname{vertex}_{2}-\mathrm{Pi}\right)
$$

Onde "vertex1" representa a enzima (E), "vertex2" representa o substrato (S), "vertex1vertex2" representa o complexo enzima-substrato (ES) e "vertex2 - P $i$ " representa o produto (P). O mapeamento dessa reação para o formato SBML é semelhante que da "ativação", exceto pela seguinte diferença: o produto "vertex2 - $P i$ " é representado por "vertex2_sub_Pi".

\section{- ubiquitinação (ubiquitination):}

A figura 5.7 mostra a interação de ubiquitinação entre os vértices vertex1 e vertex2, onde o "vertex1 provoca ubiquitinação ao vertex2". E o mapeamento dessa interação para uma reação é apresentada pela equação 5.7 .

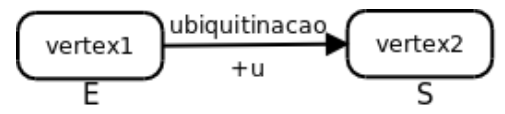

Figura 5.7: PPrel Ubiquitinação.

$$
\operatorname{vertex}_{1}+\operatorname{vertex}_{2} \underset{k_{-1}}{\stackrel{\mathrm{k}_{1}}{\rightleftharpoons}} \operatorname{vertex}_{1}-\operatorname{vertex}_{2} \stackrel{k_{c a t}}{\longrightarrow} \operatorname{vertex}_{1}+\left(\operatorname{vertex}_{2}+\mathrm{u}\right)
$$

Onde "vertex1" representa a enzima (E), "vertex2" representa o substrato (S), "vertex1vertex2" representa o complexo enzima-substrato (ES) e "vertex2 + u" representa o produto 
(P). O mapeamento dessa reação para o formato SBML é semelhante que da "ativação", exceto pela seguinte diferença: o produto "vertex2 $+u$ " é representado por "vertex2_add_u".

\section{- metilação (methylation):}

A figura 5.8 mostra a interação de metilação entre os vértices vertex1 e vertexQ, onde o "vertex1 provoca metilação ao vertex2". E o mapeamento dessa interação para uma reação é apresentada pela equação 5.8 .

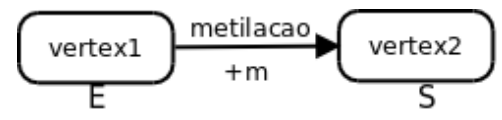

Figura 5.8: PPrel Metilação.

$$
\operatorname{vertex}_{1}+\operatorname{vertex}_{2} \underset{k_{-1}}{\stackrel{\mathrm{k}_{1}}{\rightleftharpoons}} \operatorname{vertex}_{1}-\text { vertex }_{2} \stackrel{k_{\text {cat }}}{\longrightarrow} \operatorname{vertex}_{1}+\left(\operatorname{vertex}_{2}+\mathrm{m}\right)
$$

Onde "vertex1" representa a enzima (E), "vertex2" representa o substrato (S), "vertex1vertex2" representa o complexo enzima-substrato (ES) e "vertex $2+m$ " representa o produto (P). O mapeamento dessa reação para o formato SBML é semelhante que da "ativação", exceto pela seguinte diferença: o produto "vertex2 $+m$ " é representado por "vertex2_add_ $m$ ".

\subsubsection{Interações do tipo PCrel}

\section{- ativação (activation):}

A figura 5.9 mostra a interação de ativação entre os vértices vertex1 e vertex2, onde o "vertex1 ativa o vertex2". E o mapeamento dessa interação para uma reação é apresentada pela equação 5.9 .

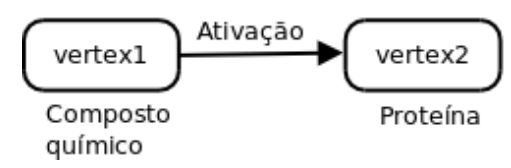

Figura 5.9: PCrel Ativação.

$$
\operatorname{vertex}_{1}+\text { vertex }_{2} \underset{k_{-1}}{\stackrel{\mathrm{k}_{1}}{\rightleftharpoons}} \text { vertex }_{2}-\text { active }
$$

Onde "vertex1" representa o composto químico, "vertex2" representa a proteína, "vertex2active" representa o complexo na forma ativo (proteína). O mapeamento dessa reação para o formato SBML é semelhante que da "ativação"do tipo "PPrel", exceto pelas diferenças: o complexo "vertex2-active"é representado como "vertex2_active"; neste subtipo de interação (ativação) não temos a reação do tipo $E S \rightarrow E+P$.

\section{- inibição (inibition):}

A figura 5.10 mostra a interação de inibição entre os vértices vertex1 e vertex2, onde o "vertex1 inibe o vertex2". E o mapeamento dessa interação para uma reação é apresentada pela equação 5.10. 


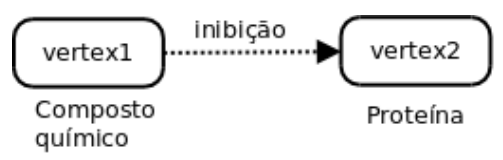

Figura 5.10: PCrel Inibição.

$$
\operatorname{vertex}_{1}+\text { vertex }_{2} \underset{k_{-1}}{\stackrel{\mathrm{k}_{1}}{\rightleftharpoons}} \text { vertex }_{2} \text {-inactive }
$$

Onde "vertex1" representa o composto químico, "vertex2" representa a proteína, "vertex2inactive" representa o complexo na forma inativo (proteína). O mapeamento dessa reação para o formato SBML é semelhante que da "ativação"do tipo "PPrel", exceto pelas diferenças: o complexo "vertex2-inactive"é representado como "vertex2_inactive"; neste subtipo de interação (ativação) não temos a reação do tipo $E S \rightarrow E+P$.

\section{- fosforilação (phosphorylation):}

A figura 5.11 mostra a interação de fosforilação entre os vértices vertex1 e vertexQ, onde o "vertex1 fosforila vertex2". E o mapeamento dessa interação para uma reação é apresentada pela equação 5.11 .

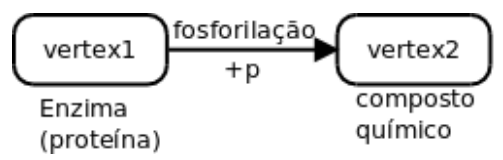

Figura 5.11: PCrel Fosforilação.

$$
\operatorname{vertex}_{1}+\operatorname{vertex}_{2} \underset{k_{-1}}{\stackrel{\mathrm{k}_{1}}{\rightleftharpoons}} \operatorname{vertex}_{1}-\operatorname{vertex}_{2} \stackrel{k_{\text {cat }}}{\longrightarrow} \operatorname{vertex}_{1}+\left(\operatorname{vertex}_{2}+\mathrm{Pi}\right)
$$

Onde "vertex1" representa a enzima (proteína), "vertex2" representa o composto químico, "vertex1-vertex2" representa o complexo e "vertex2 + P $i$ " representa o produto $(\mathrm{P})$. O mapeamento dessa reação para o formato SBML é semelhante que da "ativação"do tipo "PPrel", exceto pela seguinte diferença: o produto "vertex $2+P i$ " é representado por "vertex2_add_Pi".

\section{- desfosforilação (dephosphorylation):}

A figura 5.12 mostra a interação de desfosforilação entre os vértices vertex1 e vertexQ, onde o "vertex1 desfosforila vertex2". E o mapeamento dessa interação para uma reação é apresentada pela equação 5.12 .

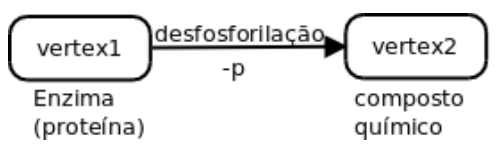

Figura 5.12: PCrel Desfosforilação

$$
\operatorname{vertex}_{1}+\operatorname{vertex}_{2} \underset{k_{-1}}{\stackrel{\mathrm{k}_{1}}{\rightleftharpoons}} \operatorname{vertex}_{1}-\text { vertex }_{2} \stackrel{k_{\text {cat }}}{\longrightarrow} \operatorname{vertex}_{1}+\left(\operatorname{vertex}_{2}-\mathrm{Pi}\right)
$$


Onde "vertex1" representa a enzima (proteína), "vertex2" representa o composto químico, "vertex1-vertex2" representa o complexo e "vertex2 - Pi" representa o produto(P). O mapeamento dessa reação para o formato SBML é semelhante que da "ativação"do tipo "PPrel", exceto pela seguinte diferença: o produto "vertex2 - $P i$ " é representado por "vertex2_sub_P $i$ ".

\subsection{Comentários}

Foi mostrada neste capítulo a formalização das regras de mapeamento de uma dada natureza de interação em uma reação química. Todavia, Existem naturezas de interações que ainda não conseguimos mapear até neste momento. Como interações de efeito indireto (indirect effect) dos três tipos de interação molecular ("PPrel", "PCrel"e "GErel"); assim como as interações mostradas abaixo.

- Tipo "PPrel": composto (compound), mudança de estado (state change) e dissociação (dissociation).

- Tipo "GErel": expressão (expression) e repressão (repression).

- Tipo "ECrel": composto (compound). 


\section{Capítulo 6}

\section{Experimentos}

Neste capítulo, apresentaremos os testes experimentais com a metodologia proposta nos capítulos anteriores. Para realizar tais testes, desenhamos e implementamos um componente integrado ao arcabouço SigNetSim. Esse componente, chamado Hyp Test, utiliza o banco de dados de interatomas KEGG para testar hipóteses para módulos funcionais de forma incremental, isto é, adicionando ao modelo novas espécies e reações químicas.

Para realizar os testes propriamente ditos com o componente implementado, utilizamos modelos da literatura para realizar testes de recuperação da estrutura a partir de subgrafos do modelo original; tal procedimento será explicado com mais detalhes ao longo deste capítulo.

Iniciaremos este capítulo descrevendo brevemente o componente Hyp Test para o SigNetSim. Em seguida, descreveremos os testes feitos com um modelo da literatura e seus respectivos resultados. Por fim, faremos uma análise desses resultados.

\subsection{O componente HypTest do arcabouço SigNetSim}

O componente (Hyp Test), desenvolvido para realizar os testes experimentais deste trabalho, foi implementado integrado ao arcabouço SigNetSim. Tal integração foi feita através do embalamento (wrapping) do arcabouço propriamente dito, através de chamadas de sistema.

Hyp Test foi desenvolvido de acordo com os métodos discutidos nos capítulos 4 e 5 , utilizando a linguagem de programação Python ${ }^{1}$. A programação foi feita seguindo o paradigma de orientação a objetos. Os diagramas de classe e de relações entre as classes do componente desenvolvido são apresentados no apêndice C.

Os testes experimentais apresentados a seguir foram desenvolvidos utilizando a servidora de 64 núcleos do Laboratório Especial de Toxinologia Aplicada (LETA) do Instituto Butantan. O modelo da servidora é DELL PowerEdge R815, com 256 gigabytes (GB) de memória RAM e 12 terabytes (TB) de disco. O sistema operacional da servidora é Linux Ubuntu server 14.04 LTS.

\subsection{Recuperação de estrutura de modelo a partir da escolha de recortes aleatórios}

Os testes experimentais foram sistematizados da seguinte maneira: inicialmente escolhemos um modelo para servir como estudo de caso. Uma vez escolhido esse modelo, utilizamo-o para produzir vários recortes menores. Esse processo consiste em sortear algumas espécies do modelo que, conjuntamente com as reações químicas que descrevem as interações entre elas, definem um subgrafo do grafo do modelo original. Após isso, fizemos o crescimento do subgrafo (subgrafo do recorte) utilizando o GIM geral, cuja construção descrevemos no capítulo 4, para consultar candidatos a ser incorporados. Para fazermos o ajuste de curva, isto é, para calcular a função custo, utilizamos o

\footnotetext{
${ }^{1}$ docs.python.org
} 
arcabouço SigNetSim. A cada iteração do componente HypTest, as cinéticas simuladas do modelo original são utilizadas como referência para a otimização dos parâmetros do recorte atual; o valor da função custo é equivalente ao valor devolvido por esse processo de otimização. O critério de parada desse crescimento foi a definição do número de iterações (i.e., número de espécies acrescentadas ao subgrafo); fizemos isso para viabilizar os testes do ponto de vista de consumo de tempo computacional; portanto, quando atingimos o número de iterações pré-estabelecido, obtivemos uma tentativa de recuperação da estrutura do modelo.

Apresentaremos agora o modelo que escolhemos como estudo de caso do componente desenvolvido.

\subsubsection{Estudo de caso: um modelo de EGFR e IGF1R em câncer de pulmão}

Para realizar os testes experimentais, escolhemos o modelo desenvolvido por Bioconi e colegas $\left[\mathrm{BBL}^{+} 12\right]$. Esse modelo descreve a cinética de ativação das vias de MAP quinases (MAPKs) e de PI3K/Akt por insulina e fator de crescimento nos receptores IGF1R e EGFR, respectivamente. Esse modelo foi escolhido para realização dos testes experimentais pois sua estrutura, descrita através de uma lista de reações químicas, é coberta pelos mapeamentos apresentados no capítulo 5 .

A descrição do modelo em SBML encontra-se disponível no repositório de modelos BioModels [EBI15], através do seguinte link:

$$
\text { https://www.ebi.ac.uk/biomodels-main/BIOMD0000000427. }
$$

O código desse arquivo SBML encontra se no apêndice A.

Este modelo é um módulo funcional das vias de MAPKs e de PI3K/Akt em câncer de pulmão. Ele contém 13 proteínas e 16 interações entre elas (figura 6.1). Como várias dessas proteínas têm mais de um estado (e.g., inativa ou ativa), o mapeamento do interatoma desse modelo leva a 21 espécies químicas (tabela 6.1) e 22 reações químicas. Todavia, nem toda proteína e nem toda interação deste modelo estão presentes no banco KEGG; dessa forma, o Grafo de Interação Molecular (GIM) geral apresentado no capítulo 4 contém somente as proteínas e as interações assinaladas em azul na figura 6.1.

Sorteamos as proteínas do modelo para compor os pequenos recortes utilizados nos testes do componente. Mostramos nas figuras $6.2(\mathrm{a})-6.2(\mathrm{j})$ os dez diferentes recortes que obtivemos desse modelo, sendo que os dois primeiros recortes contêm 5 proteínas, e os demais, 4 proteínas.

\subsubsection{Aplicação da estratégia de incremento de vértices}

Para tentar recuperar a estrutura do modelo original, utilizamos o algoritmo sequencial SFS para aplicar a estratégia de incremento de vértices apresentada no capítulo 4. Para cada recorte aleatório do modelo original descrito na subseção anterior, aplicamos o SFS utilizando como função custo uma chamada do SigNetSim; cada chamada do arcabouço era feita na servidora descrita no início do capítulo e constituída de uma otimização de ajuste de curva com 30 minutos de duração.

Para cada recorte da figura 6.2, realizamos 25 iterações de incremento do recorte. A cada iteração, são examinadas todas as proteínas que interagem com alguma proteína presente no estado atual do recorte; isso é feito da seguinte maneira:

(i) adicionamos uma proteína candidata ao recorte atual, assim como as interações dessa candidata com as proteínas presentes no recorte; tanto a proteína candidata quanto suas interações são extraídas do GIM geral;

(ii) mapeamos o recorte aumentado;

(iii) é feita a otimização do recorte aumentado no SigNetSim, utilizando o modelo original como referência no processo de ajuste de curva; 
Tabela 6.1: Lista das espécies químicas presentes no modelo de MAPKs e PIЗK/Akt em câncer de pulmão descrito por Bioconi e colegas [BBL+12].

\begin{tabular}{ll} 
Espécies & Nome \\
\hline 1 & EGFR_active \\
\hline 2 & D_SOS \\
\hline 3 & A_SOS \\
\hline 4 & Raf__active \\
\hline 5 & Ras_active \\
\hline 6 & Mek__ \\
\hline 7 & ERK_active \\
\hline 8 & IGFR_active \\
\hline 9 & PI3KCA \\
\hline 10 & PI3KCA_active \\
\hline 11 & AKT_active \\
\hline 13 & AKT \\
\hline 14 & PP2A \\
\hline 15 & Ras \\
\hline 16 & Raf_active \\
\hline 17 & Mek \\
\hline 18 & RasGapActive \\
\hline 20 & RafPP \\
\hline 21 & P90RskInactive \\
\hline
\end{tabular}

(iv) o resultado da otimização para a proteína candidata é guardado.

O processo é repetido para todas as proteínas candidatas, e a que tiver melhor resultado de otimização é adicionada ao recorte. O recorte atual é então atualizado e o processo (i)-(iv) é repetido até que 25 iterações sejam concluídas.

Após rodarmos o componente Hyp Test sobre os 10 recortes apresentados na figura 6.2, obtivemos 10 tentativas de recuperação da estrutura do modelo original; os grafos obtidos são apresentados nas figuras 6.3 e 6.4 .

Também produzimos estatísticas dessas execuções. Nas figuras 6.5(a)-6.5(j), mostramos a evolução do custo computado em função do incremento de proteínas do recorte. Na tabela 6.2, exibimos o tempo total mínimo estimado de execução do componente para produzir resultados para todos os 10 recortes. Vale lembrar que, para cada chamada da função custo (i.e. execução do SigNetSim), o limite de tempo foi definido como 30 minutos. Como o tempo de controle dos algoritmos do componente foi ínfimo em relação ao tempo de execução da função custo, não guardamos o tempo total que as execuções do componente realmente levaram.

Finalmente, na tabela 6.3 mostramos algumas medidas de desempenho dos testes. Nesta tabela, dividimos os recortes em dois grupos: no primeiro grupo, temos recortes aleatórios com 5 proteínas, enquanto que o segundo contém todos os demais recortes, com 4 proteínas cada. Cada recorte aleatório levou a um recorte recuperado, no qual medimos: número de proteínas recuperadas; número de interações entre proteínas recuperadas; distância do recorte recuperado em relação ao modelo original. A medida de distância aqui utilizada é a função "ou exclusivo" $V \oplus V^{\prime}$, na qual $V$ e $V^{\prime}$ são os vértices (proteínas) do modelo original e do recorte recuperado, respectivamente. Dessa forma, a medida de distância foi calculada utilizando a seguinte expressão:

$$
\operatorname{Dist}\left(V, V^{\prime}\right)=V \oplus V^{\prime}=\left(V \cup V^{\prime}\right) \backslash\left(V \cap V^{\prime}\right) .
$$




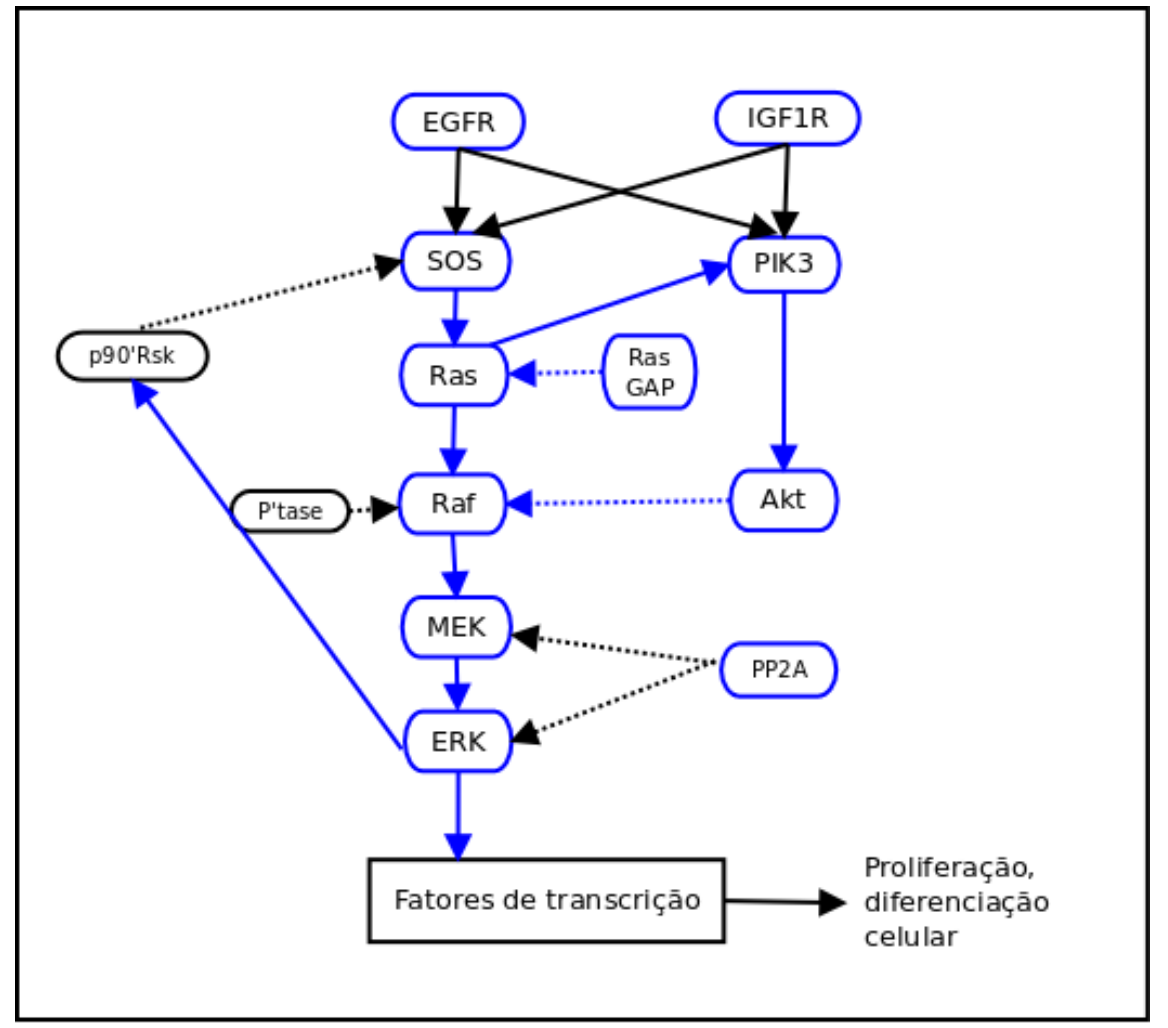

Figura 6.1: representação gráfica do modelo de vias de MAPKs e PIßK/Akt apresentado por Bioconi e colegas $\left[B B L^{+} 12\right]$. Os retângulos representam proteínas e as setas representam interações entre elas; as setas tracejadas e não tracejadas descrevem interações de inibição e ativação, respectivamente. O retângulo maior representa o conjunto de fatores de transcrição à jusante dessas vias, os quais ativam os eventos de transcrição, diferenciação e proliferação celular. Retângulos e setas em azul representam, respectivamente, proteínas e interações presentes no GIM geral.

Na tabela 6.3, verificamos que, para os conjuntos de 5 e 4 proteínas, os melhores recortes recuperados foram o (a) e o (e), respectivamente.

Tabela 6.2: Tempo mínimo necessário para executar os experimentos descritos nesta seção, considerando um total de 15.335 chamadas da função custo, na qual cada chamada leva 30 minutos.

\begin{tabular}{c|c|c|c}
\hline \multicolumn{2}{c}{ Tempo em horas } & \multicolumn{2}{c}{ Tempo em dias } \\
\hline sequencial & paralelo (melhor caso) & sequencial & paralelo (melhor caso) \\
\hline 7667.5 & 119.8 & 319.5 & 4.991 \\
\hline
\end{tabular}

\subsection{Análise dos resultados}

Nesta seção avaliaremos os resultados apresentados ao longo deste capítulo. Faremos uma análise do desempenho da metodologia desenvolvida neste trabalho na recuperação da estrutura do modelo Biaconi e colegas, utilizado como estudo de caso [BBL $\left.{ }^{+} 12\right]$. Para isso, avaliaremos de forma quantitativa a recuperação da estrutura (i.e., recuperação das proteínas e das interações presentes no modelo original) e o desempenho do processo de otimização.

\subsubsection{Recuperação de estrutura do modelo original}

Do ponto de vista de recuperação da estrutura do modelo original, diferentes recortes sorteados levaram a recortes recuperados bem distintos entre si: por exemplo, para o recorte sorteado (e) 
Tabela 6.3: Estatisticas dos testes para 25 iterações do componente. Os recortes 1 e 2 têm 5 proteínas, enquanto que os demais têm 4 proteínas cada. Para cada tamanho, os recortes que mais se aproximaram do modelo original estão indicados em negrito e sublinhado. A distância entre o modelo original e um recorte recuperado foi computada utilizando a função 6.1 .

\begin{tabular}{c|c|c|c}
\hline \hline Recorte & $\begin{array}{c}\text { Proteínas } \\
\text { recuperadas }\end{array}$ & $\begin{array}{c}\text { Interações } \\
\text { recuperadas }\end{array}$ & $\begin{array}{c}\text { Distância } \\
\text { proteínas }\end{array}$ \\
\hline \hline$\underline{\mathbf{a}}$ & 3 & 3 & $\underline{\mathbf{2 7}}$ \\
\hline $\mathrm{b}$ & 2 & 1 & 29 \\
\hline Média & 2.5 & 2 & 28 \\
\hline Desvio & 0.707 & 1.414 & 1.414 \\
\hline \hline $\mathrm{c}$ & 2 & 2 & 30 \\
\hline $\mathrm{d}$ & 0 & 0 & 34 \\
\hline$\underline{\mathbf{e}}$ & 3 & 2 & $\underline{\mathbf{2 8}}$ \\
\hline $\mathrm{f}$ & 0 & 0 & 34 \\
\hline $\mathrm{g}$ & 0 & 0 & 34 \\
\hline $\mathrm{h}$ & 2 & 2 & 30 \\
\hline $\mathrm{i}$ & 1 & 1 & 32 \\
\hline $\mathrm{j}$ & 0 & 0 & 34 \\
\hline Média & 1.0 & 0.875 & 32 \\
\hline Desvio & 1.195 & 0.991 & 2.39 \\
\hline
\end{tabular}

(figura 6.2(e)), três proteínas foram recuperadas (figura 6.3(e)), enquanto que para o recorte sorteado (f) (figura 6.2(f)), nenhuma proteína foi adicionada ao recorte recuperado (figura 6.3(f)). Além disso, verificamos que para recortes sorteados com 5 proteínas tiveram uma recuperação média de proteínas 2,5 vezes superior em relação à recuperação média dos recortes sorteados com quatro proteínas (tabela 6.3).

Também verificamos casos em que a estrutura do modelo original não pode ser recuperada por incompletude do GIM geral (que, por sua vez, foi gerado a partir da união de mapas do KEGG): isso ocorre porque processos tais como interruptores biológicos que dependem da associação entre duas ou mais espécies químicas não são informados nos arquivos KGML que descrevem os interatomas: por exemplo, no recorte recuperado (h) (figura 6.4(h)), os nucleotídeos GTP e GDP foram adicionados como moléculas que interagem com a proteína Ras; todavia, essas interações não descrevem que: i) Ras se associa ou a GDP ou a GTP (um por vez); ii) Ras, quando associado a GDP e GTP está, respectivamente, nas formas inativa e ativa. Portanto, para recuperar corretamente esse interruptor biológico, utilizar somente o GIM geral baseado na união dos mapas do KEGG não é suficiente, precisando acrescentar outras informações a priori.

Por fim, constatamos que, ao iniciarmos com recortes sorteados pequenos, com cerca de um terço das proteínas do modelo original, a distância do melhor recorte recuperado para o modelo original foi 27 (tabela 6.3), valor que consideramos relativamente distante do modelo original. Desconsiderando proteínas do modelo original que não estejam presentes no GIM geral, essa distância tenderia a convergir para zero com o aumento do recorte sorteado, desde que também acompanhado da diminuição do número de iterações do componente Hyp Test; portanto, a metodologia proposta neste trabalho possivelmente seria mais indicada para complementar módulos funcionais já razoavelmente bem delimitados, cuja cinética precise apenas do acréscimo de umas poucas moléculas e/ou interações para ser efetivamente explicada.

\subsubsection{Desempenho do processo de otimização}

Para realizar o processo de otimização de um recorte sorteado e de seus respectivos crescimentos, utilizamos o arcabouço SigNetSim com tempo de otimização limitado a 30 minutos para cada 
crescimento avaliado. Como vimos na tabela 6.2, ao fixarmos o tempo máximo de otimização, conseguimos estimar o tempo global necessário para obter recortes recuperados para todos os dez recortes sorteados, uma vez que o tempo de gerenciamento do componente HypTest é desprezível quando comparado com o tempo gasto pela otimização (dado não mostrado).

Para cada recorte sorteado, acompanhamos a evolução do melhor custo obtido para i vértices adicionados ao recorte; mostramos isso graficamente nas figuras 6.5(a)-6.5(j), que correspondem, respectivamente, ao crescimento dos recortes sorteados (a)-(j) (figuras 6.2(a)-6.2(j)). Observamos que as curvas de evolução descrevem curvas em U. Essa característica da curva em U se deve ao seguinte fato: com o acréscimo de novas moléculas e interações, o valor da curva tende a diminuir, pois cada acréscimo de novas moléculas e interações é uma generalização do modelo anterior ao(s) acréscimo(s), o que aumenta as possibilidade de ajuste de curva, por sua vez favorecendo um menor valor de curva. Por outro lado, acrescentar novas moléculas e interações também aumenta o espaço de busca da otimização: como o tempo de otimização foi o mesmo para recortes de qualquer tamanho, o algoritmo de otimização acaba percorrendo uma menor fatia do espaço de busca, o que favorece um maior valor de curva.

O fenômeno da curva em U tenderia a desaparecer se, ao aumentarmos o espaço de busca, também aumentássemos de forma proporcional o limite de tempo do processo de otimização. Todavia, ao fazermos isso, tornamos o recorte recuperado mais suscetível ao overfitting. Ademais, o crescimento proporcional desse limite de tempo é infactível do ponto de vista de consumo de tempo computacional. Para atacar o primeiro problema, é necessário adotar uma função custo que penalize o acréscimo de novas moléculas e/ou interações; nesse caso, o fenômeno da curva em U continuaria a ocorrer devido à definição da função, e o mesmo poderia ser explorado através de algoritmos que abordam o problema U-curve [Rei12]. Já para o segundo problema, possíveis soluções passam por uma maior paralelização do componente HypTest (e.g., utilizando grades ou Graphics Processing Units - GPUs) ou então pela adoção de modelos híbridos, nos quais a cinética de uma ou mais espécies químicas passaria a ser descrita através de variável discreta ao invés de contínua. 


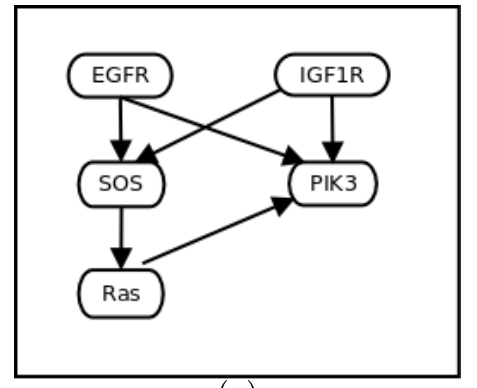

(a)

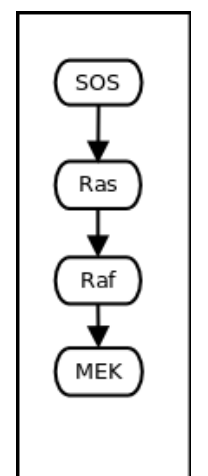

(c)

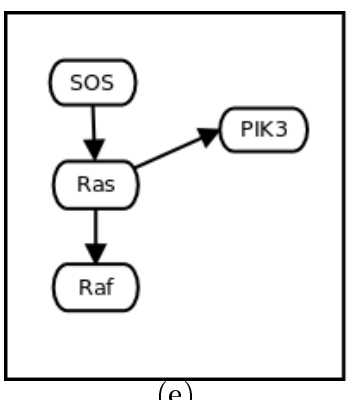

(e)

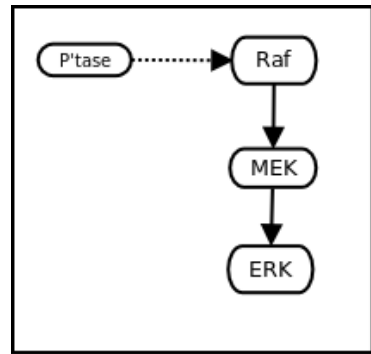

(g)

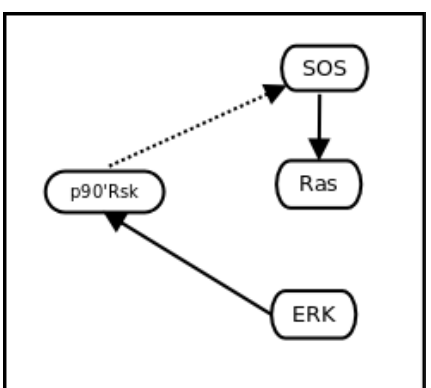

(i)

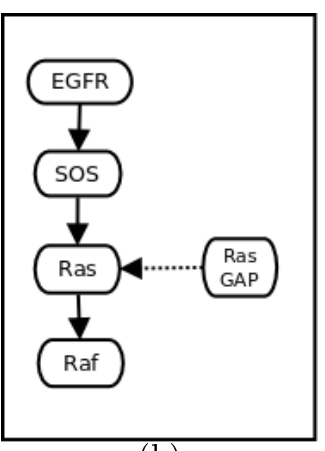

(b)

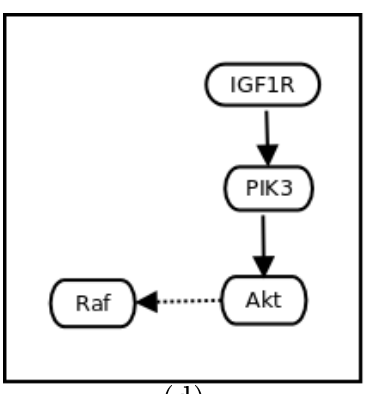

(d)

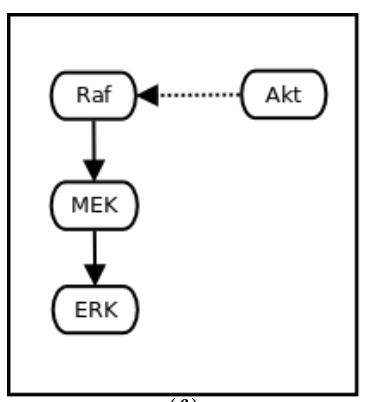

(f)

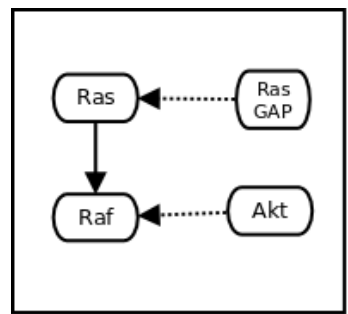

(h)

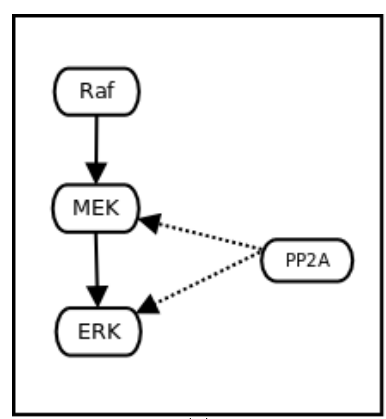

(j)

Figura 6.2: recortes sorteados do modelo de vias de MAPKs e PI3K/Akt apresentado por Bioconi e colegas $\left[B B L^{+} 12\right]$. Os retângulos representam proteinas e as setas representam interações entre elas; as setas tracejadas e não tracejadas descrevem interações de inibição e ativação, respectivamente. 


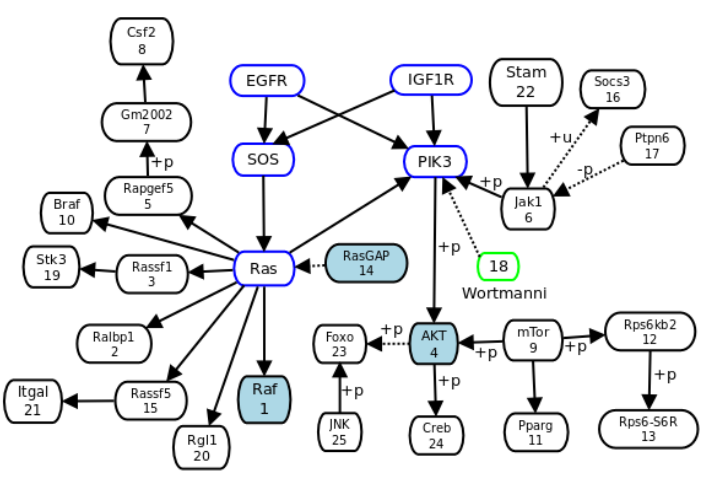

(a)

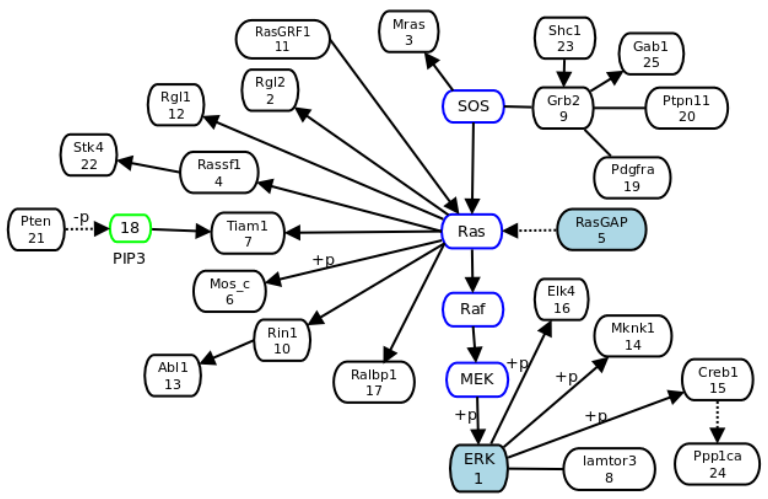

(c)

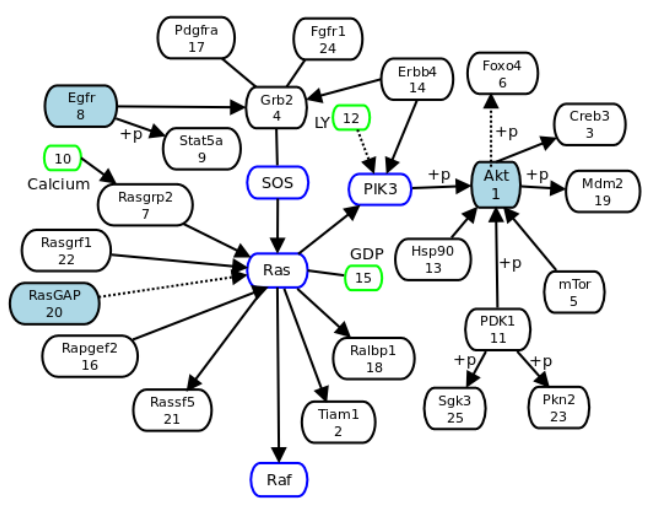

(e)

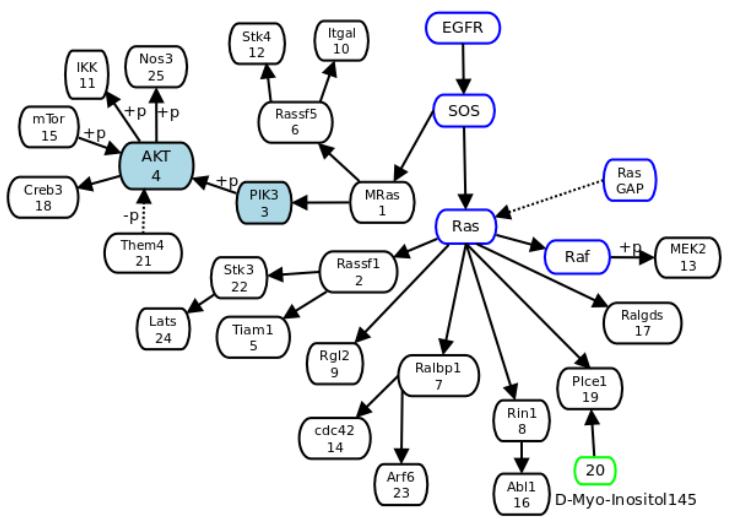

(b)

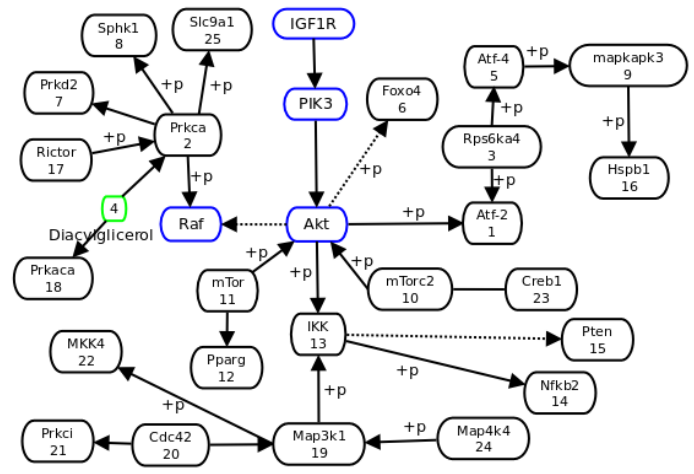

(d)

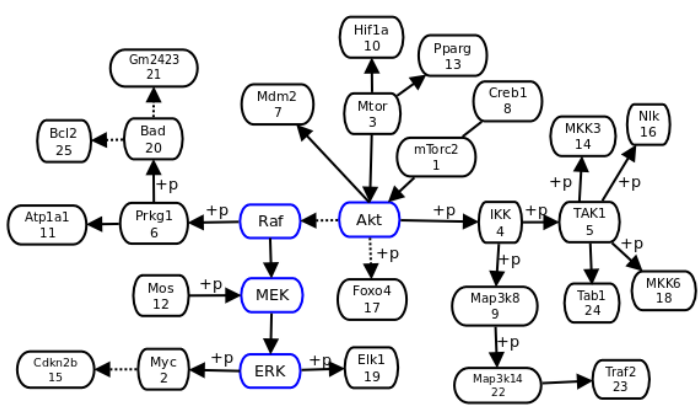

(f)

Figura 6.3: representações gráficas da recuperação da estrutura do modelo após 25 iterações do componente HypTest; os retângulos representam proteinas e compostos, e as setas, as interações entre eles. Os retângulos de borda azul representam as proteinas originais do recorte e os de borda verde representam os compostos quimicos; já os retângulos de preenchimento azul assinalam as proteinas do modelo original que foram recuperadas. Os números dentro dos retângulos representam a sequência em que cada elemento é acrescentado. As setas tracejadas e não tracejadas representam as interações de inibição e de ativação, respectivamente; $+p$ ou $-p$ representam as interações de fosforilação e desfosforilação, respectivamente; enquanto que $+u$ e $+m$ representam as interações de ubiquitinação e metilação, respectivamente. 


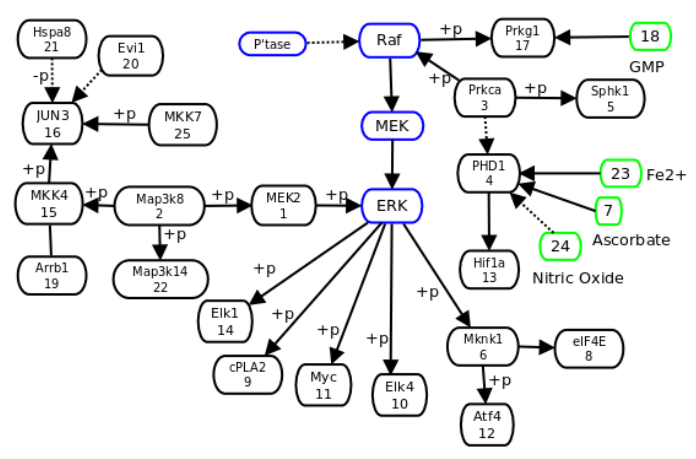

(g)

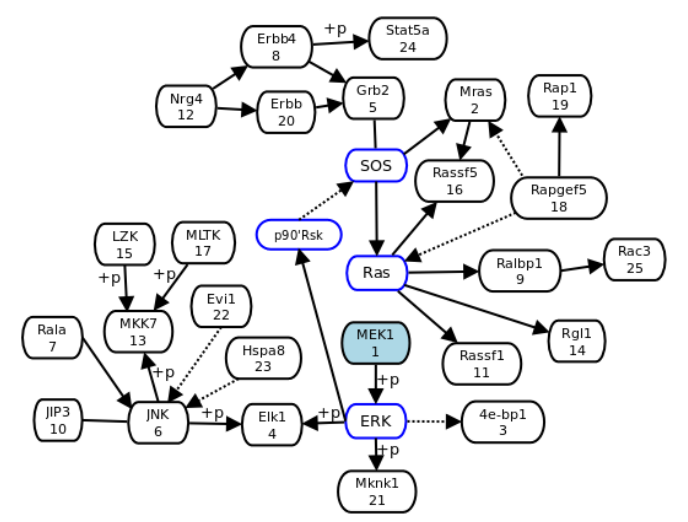

(i)

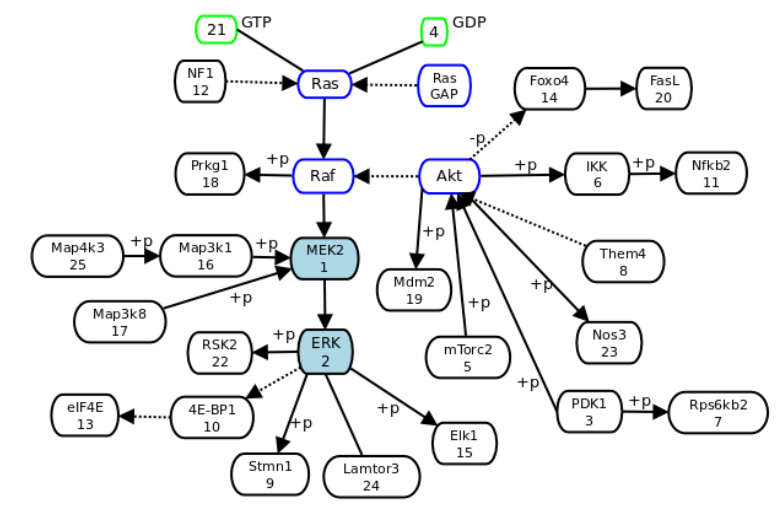

(h)

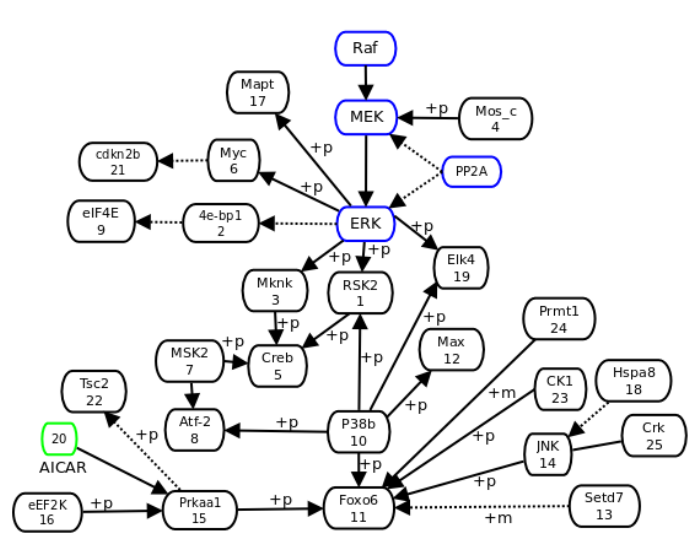

(j)

Figura 6.4: contiuação da figura 6.3. 


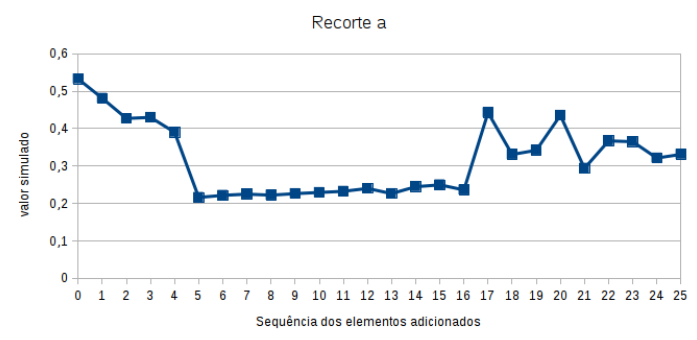

(a)

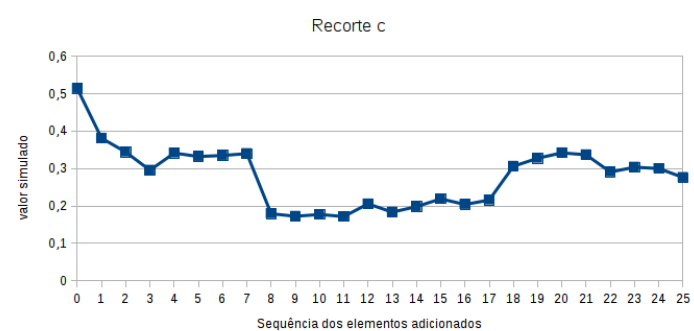

(c)

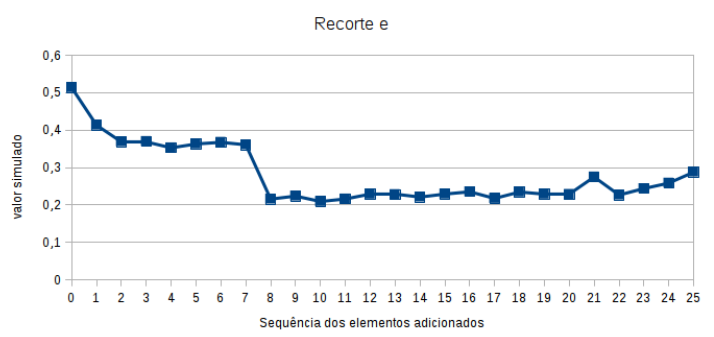

(e)

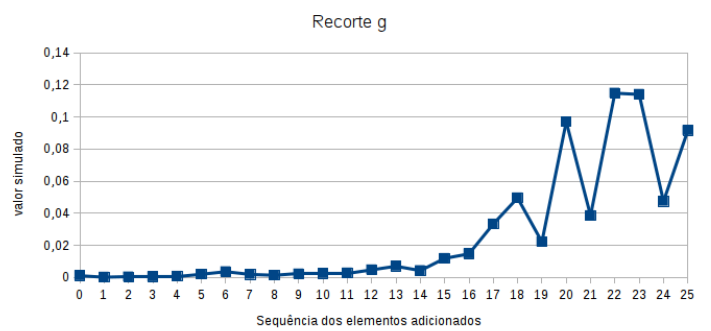

(g)

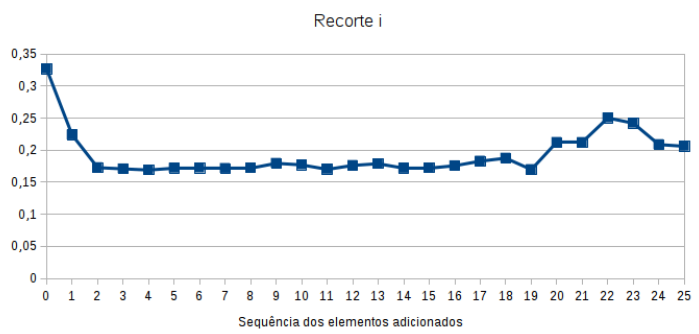

(i)

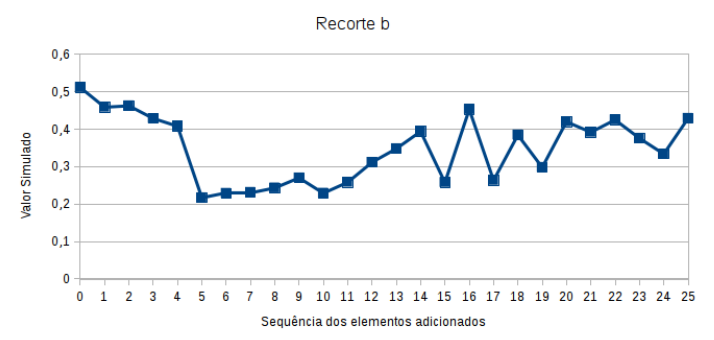

(b)

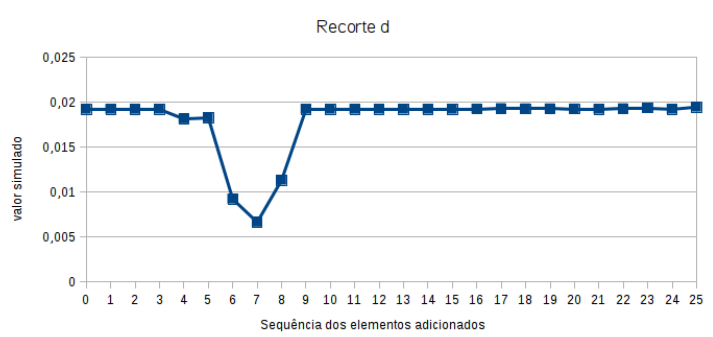

(d)

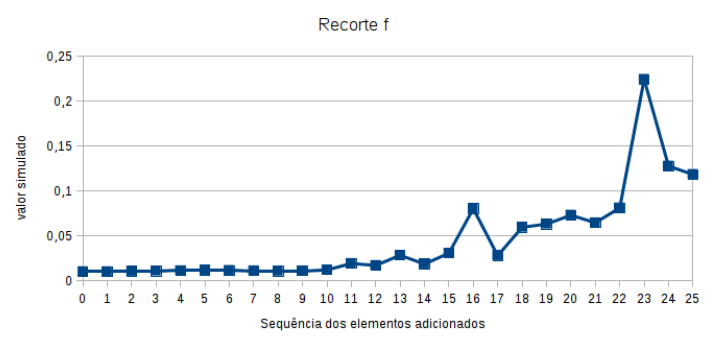

(f)

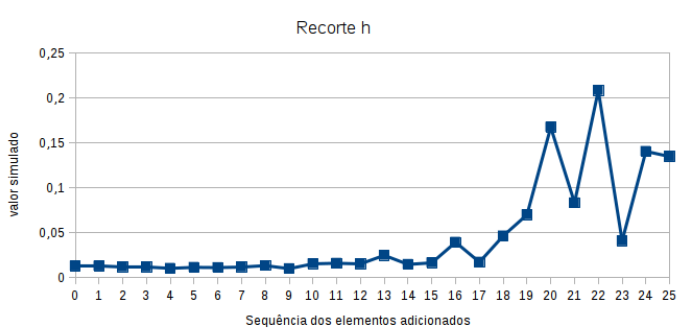

(h)

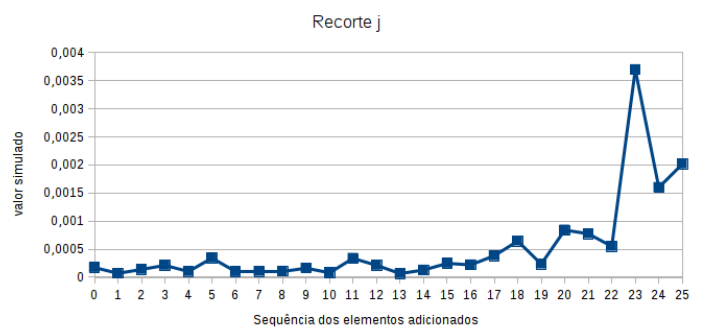

(j)

Figura 6.5: gráficos de evolução do custo computado em função do incremento de proteínas. Os gráficos das figuras 6.5(a)-6.5(j) correspondem, respectivamente, ao incremento dos recortes mostrados nas figuras 6.2(a)-6.2(j). Em cada gráfico, o eixo das abscissas corresponde ao i-ésimo incremento de proteína no recorte, enquanto que o eixo das ordenadas representa o valor obtido na otimização de ajuste de curva. 


\section{Capítulo 7}

\section{Conclusões}

Neste último capítulo apresentaremos as conclusões deste trabalho. Iniciaremos fazendo uma recapitulação do que foi mostrado ao longo desta dissertação. Após isso, apontaremos as principais contribuições deste projeto. Por fim, listaremos algumas alternativas para continuação das atividades nesta linha de pesquisa.

\subsection{Recapitulação do conteúdo deste trabalho}

Em Biologia Molecular Celular, o estudo de vias de sinalização celular é importante para a compreensão de processos celulares. Como o sinal através dessas vias se propaga através da mudança de concentração das espécies químicas envolvidas ao longo do tempo, o estudo da cinética dessas vias tem grande importância científica. Explicamos no capítulo 3 como é feita a modelagem matemática de vias de sinalização, a qual consiste em mapear um conjunto de reações químicas que descreve a cinética da via estudada em um sistema de equações diferenciais ordinárias (EDOs). No final desse mesmo capítulo, mostramos um exemplo do processo de modelagem de um módulo funcional de uma via de sinalização celular.

Para modelar matematicamente e simular computacionalmente a cinética de vias de sinalização celular, o grupo de Biologia Computacional e de Bioinformática do Instituto Butantan desenvolveu o arcabouço SigNetSim [RND $\left.{ }^{+} 14\right]$. As principais características desse arcabouço foram apresentadas no capítulo 3. Todavia, ao longo do processo de modelagem de um módulo funcional utilizando o SigNetSim, diversas estruturas de vias de sinalização precisam ser testadas; tais modificações na estrutura eram feitas manualmente no arcabouço, o que restringia drasticamente o número de hipóteses testáveis.

Assim, nesta dissertação abordamos um método para testar diferentes hipóteses de módulos funcionais de vias de sinalização molecular, baseado no uso de bancos de dados de interatomas para fornecer um conjunto de espécies e de reações químicas candidatas para serem incluídas no módulo funcional tentativo. Implementamos o componente Hyp Test, que é integrado ao arcabouço SigNetSim e atende ao objetivo de testar diferentes hipóteses para um módulo funcional. Fizemos vários testes experimentais para validar o componente desenvolvido, assim como analisamos os resultados obtidos nesses testes.

\subsection{Contribuições deste trabalho}

As principais contribuições deste trabalho foram:

- Uma metodologia para testar diferentes hipóteses para módulos funcionais de recortes de via de sinalização celular. Essa metodologia foi descrita no capítulo 4; 
- Regras de mapeamento para descrever a cinética de interatomas existentes no banco de dados de interatomas KEGG. Essas regras foram apresentadas no capítulo 5;

- Uma implementação da metodologia e das regras de mapeamento introduzidos nos capítulos 4 e 5. Essa implementação, chamada Hyp Test, foi feita em linguagem de programação Python e constitui um componente integrado ao arcabouço SigNetSim. Detalhes dessa implementação são fornecidos no apêndice $\mathrm{C}$.

- Testes experimentais do componente implementado, utilizando como estudo de caso o modelo de vias de MAPKs e PI3K/Akt de Bioconi e colegas [BBL ${ }^{+}$12]. Os resultados dos testes, assim como uma análise dos mesmos, foram apresentados no capítulo 6.

\subsection{Sugestões para Pesquisas Futuras}

Esta linha de pesquisa tem várias possibilidades de trabalhos futuros; a seguir, listaremos algumas possibilidades tanto para continuação imediata dos trabalhos na metodologia apresentada nesta dissertação quanto para novas abordagens ainda na linha de testes de hipóteses para módulos funcionais de recortes de vias de sinalização celular.

Do ponto de vista de melhoramentos da metodologia apresentada neste trabalho, algumas possibilidades incluem: criar regras de mapeamento para os casos que ainda não conseguimos tratar (e.g., em efeito indireto de uma espécie química A em B); testar não somente incremento de espécies e interações de forma sequencial (i.e., com solução subótima), mas também de forma combinatória (i.e., com solução ótima); adotar tempo de otimização proporcional ao tamanho do espaço de busca e penalização da função custo, o que poderia levar à redução do problema de otimização ao problema U-curve [Rei12]; validar a metodologia para outros modelos e também para recortes sorteados mais próximos do tamanho do modelo original, conforme sugerimos na seção 6.3.1.

Já pensando em novas abordagens nesta mesma linha de pesquisa, possibilidades interessantes são: passar a trabalhar em um ambiente Bayesiano, no qual escolhas de diferentes arquiteturas têm uma verossimilhança associada $\left[\mathrm{XVG}^{+} 10, \mathrm{KTS}_{13}, \mathrm{LKF}^{+} 14\right]$; utilização de critérios topológicos ao testar hipóteses para a arquitetura do modelo cinético [BWHK02, BKS14]. 


\section{Apêndice A}

\section{Systems Biology Markup Language (SBML)}

A linguagem de marcação para sistemas biológicas (Systems Biology Markup Language - SBML ${ }^{1}$ ), é um formato baseado em XML (eXtensible Markup Language) para representar vias de reações bioquímicas. A linguagem SBML, que atualmente encontra-se na versão 4, nível 2, é usada para descrever modelos comuns para pesquisas em muitas áreas da biologia computacional, incluindo vias de sinalização molecular, vias metabólicas, regulação gênica, etc [KM08].

Representações gráficas de processos biológicos são úteis para a apresentação visual para os seres humanos. Todavia, ao nível de software, um formato diferente é necessário para que um modelo possa ser simulado e analisado. Portanto, SBML é um formato amigável à máquina para representar modelos biológicos, em particular de modelos cinéticos [HFS $\left.{ }^{+} 03\right]$.

De forma geral, em SBML, uma reação química pode ser dividida em um número de elementos conceituais: espécies reagentes, espécies produtos, reações, estequiometria, leis de velocidade e parâmetros das leis de velocidade. Para analisar ou simular a cinética de um conjunto de reações, componentes adicionais devem ser explicitados, incluindo compartimentos para as espécies, assim como as unidades sobre as diversas quantidades. Por exemplo, considere a seguinte reação enzimática:

$$
\mathrm{E}+\mathrm{S} \underset{k_{o f f}}{\stackrel{k_{o n}}{\rightleftharpoons}} \mathrm{ES} \stackrel{k_{c a t}}{\longrightarrow} \mathrm{E}+\mathrm{P}
$$

Um exemplo de mapeamento da reação enzimática A.1 é mostrado na listagem A.1.

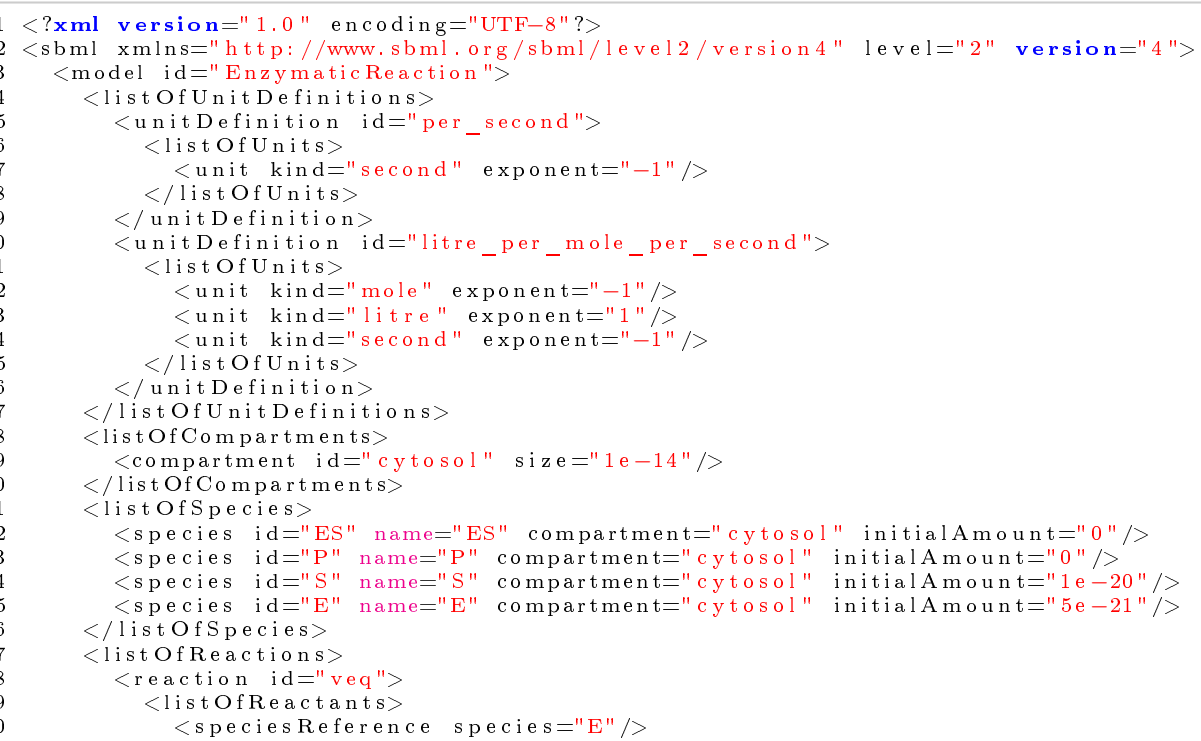

${ }^{1}$ http://sbml.org 


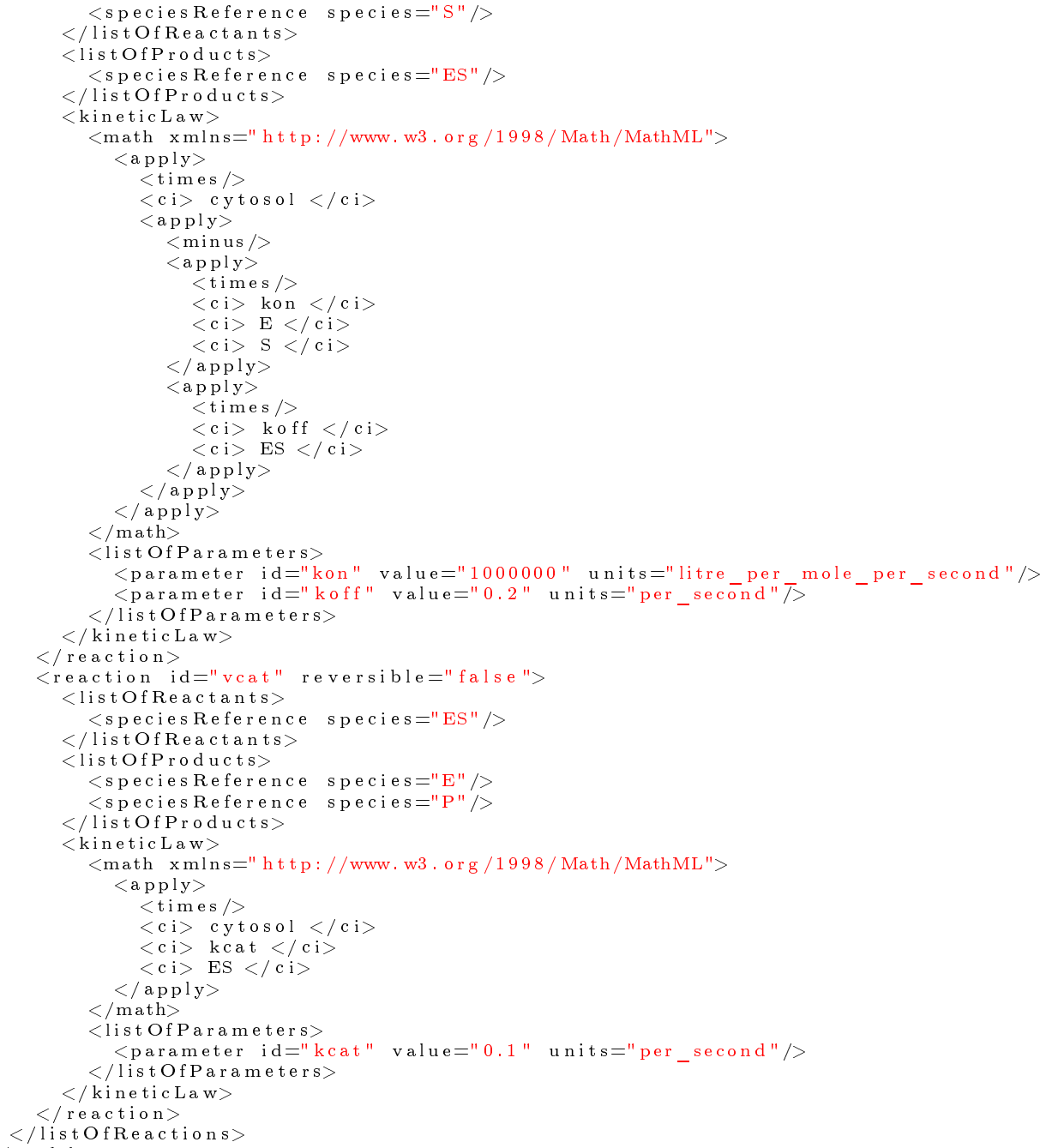

Listing A.1: representação em sbml da reação enzimática A.1

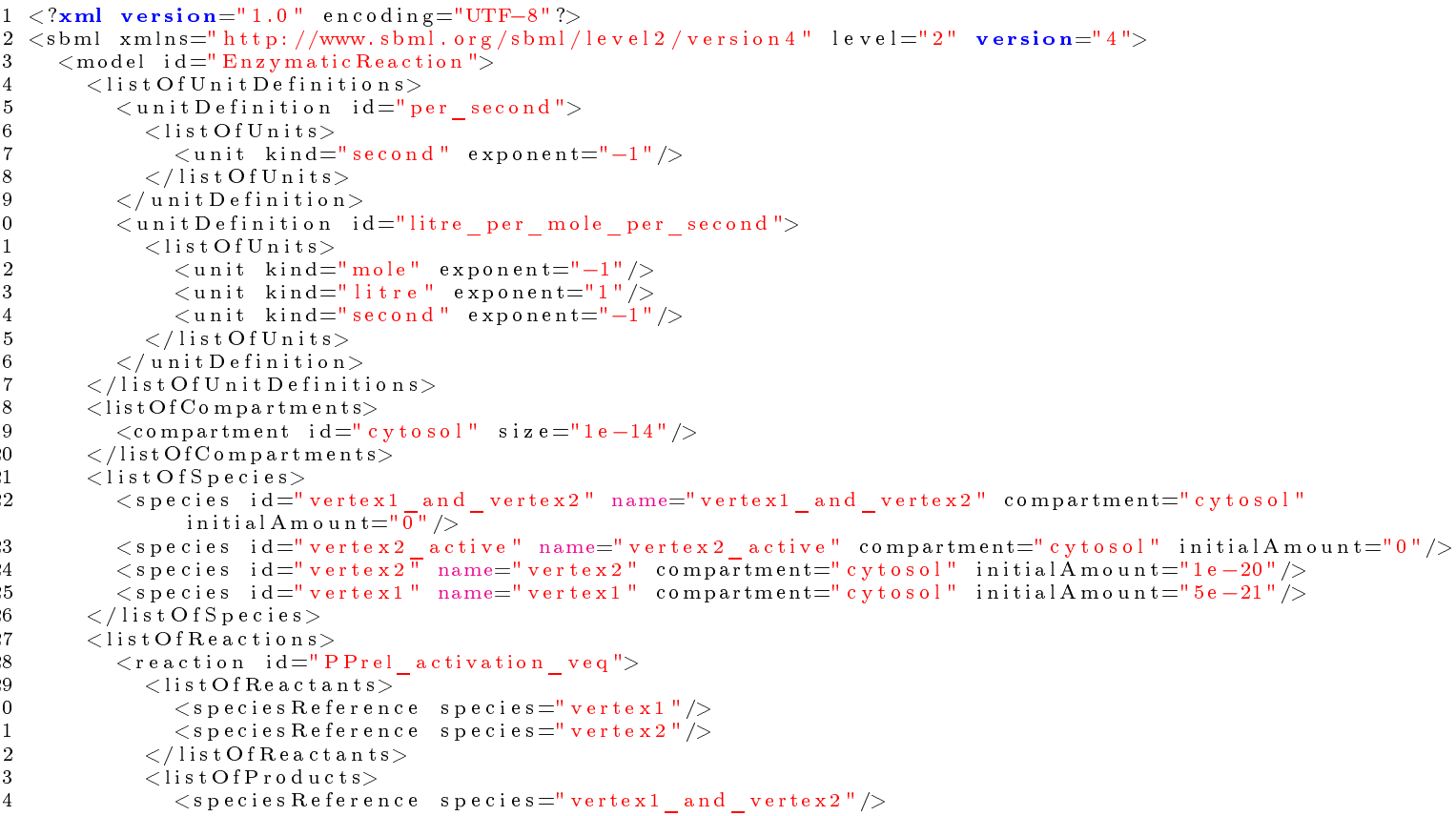




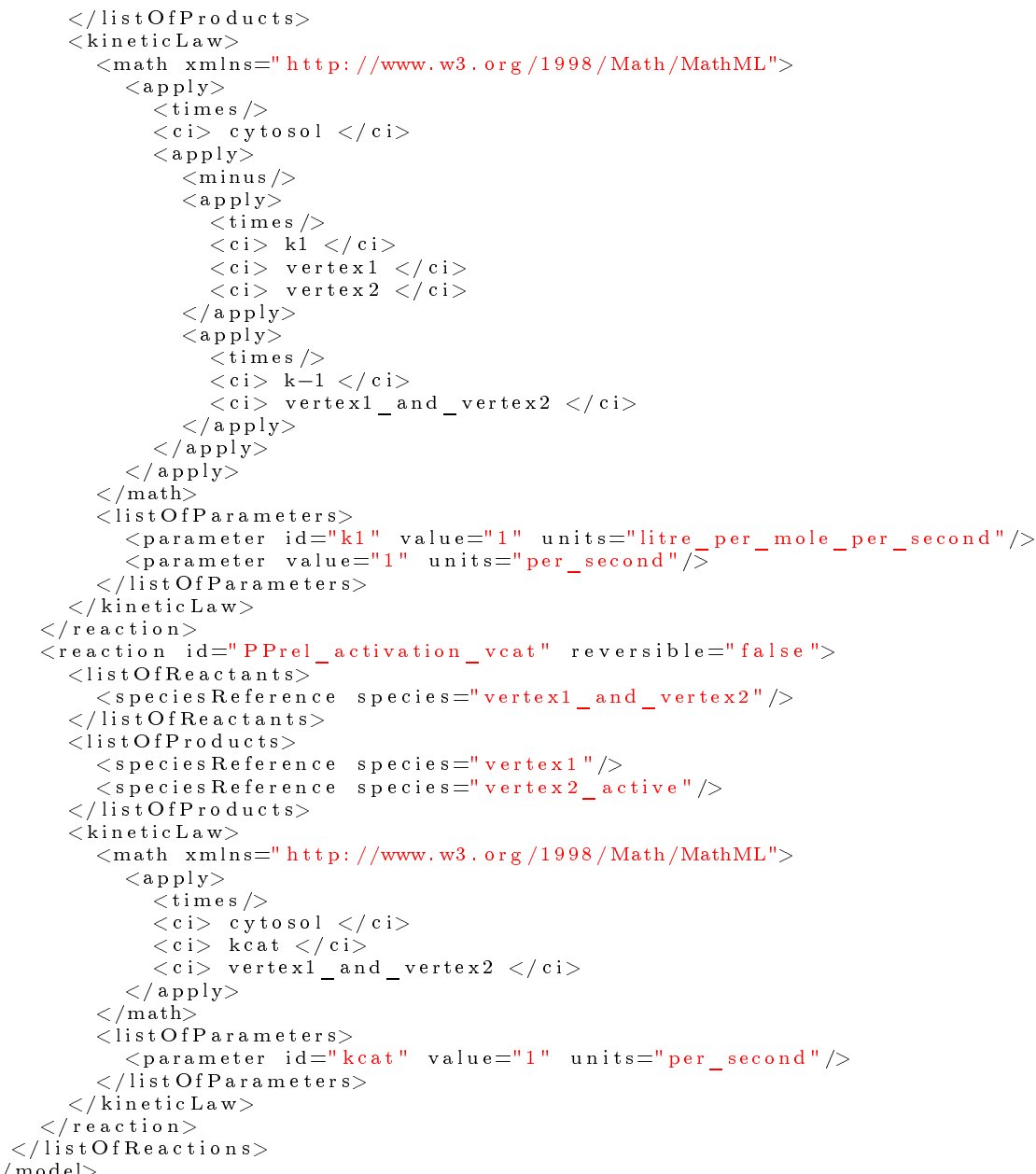

Listing A.2: representação em sbml da reação 5.2

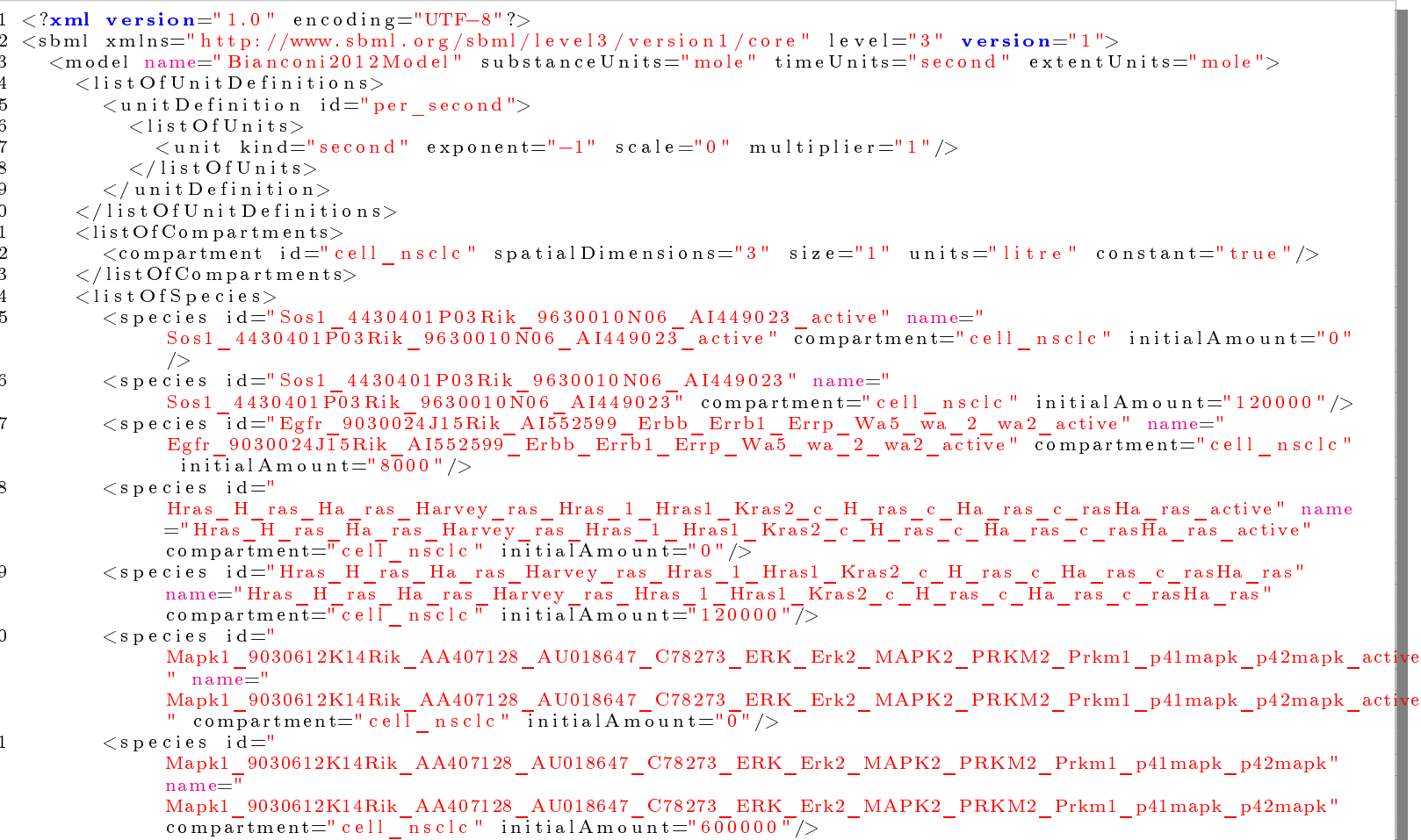


<species id="Map2k1_MAPKK1_MEKK1_Mek1_Prkmk1_active" name="

Map2k1 MAPKK1 -MEKK1 M̄ek1 Prkmk1 active" compartment="cell nsclc" initialAmount="0" <species i $\bar{d}=" P 90 R s \bar{k}$ active" name="P90 Rsk_active" compartment="cell_nsclc" initialAmount="0"/>

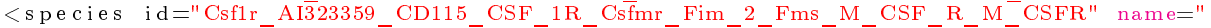

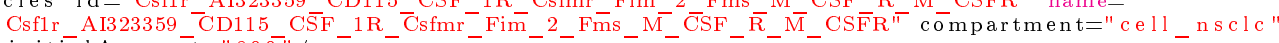
initialAmount=" $80 \overline{\overline{1}} / \mathrm{>}$

<species id="Pik3ca 6330412C24Rik caPI3K p110 p110alpha active" name="

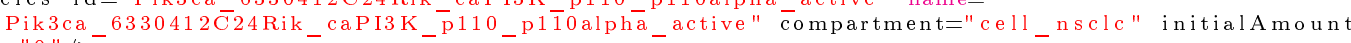

<species id="Pik3ca_6330412C24Rik_caPI3K_p110_p110alpha" name="

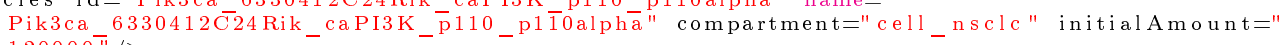
$120000 \pi />$

$<$ species id="Akt1_Akt_PKB_PKB_Akt_PKBalpha_Rac_active" name="

Akt1_Akt_PKB_PKB_Akt_PKBalpha_Rac_active" compartment="cell_nsclc" initial Amount="0"/>

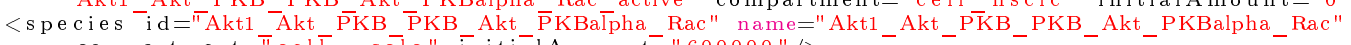
compartment $="$ celi nsclc" initiālAmount="600000"/>

<species id="PP2A" name="PP2A" compartment="cell_nsclc" initialAmount="120000"/>

$<$ species id="

Raf1_6430402F14Rik_AA990557_BB129353_Craf1_D830050J10Rik_Raf_1_c_Raf_v_Raf_active" name="

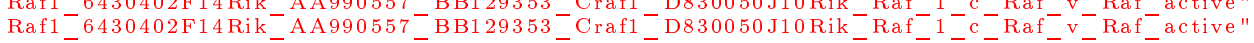
compartment=" cell-nsclc" initialAmount $=" 0 " \bar{T}>$

<species id="Raf1 6430402F14Rik AA990557 BB129353 Craf1 D830050J10Rik Raf 1 c Raf v Raf" name

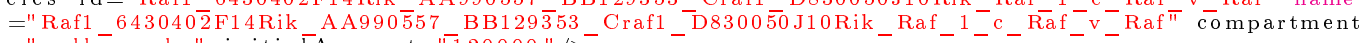
$="$ cell nsclc" initialAmount="120000" $/>$

<species id="Map2k1_MAPKK1_MEKK1_Mek1_Prkmk1" name="Map2k1_MAPKK1_MEKK1_Mek1_Prkmk1" compartment="ce 11 nsclc" initialAmount="600000"/>

$<$ species id="Rasa2_5430433H21Rik_AA517451_AU023900_GAP1m_active" name="

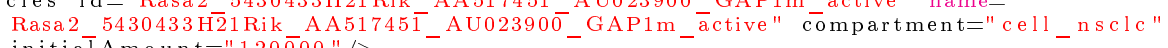
initiā̄Amount=" $120 \overline{0} 00 " />$

$<$ species id="RafPP" name="RafPP" compartment="cell_nsclc" initialAmount="120000"/>

<species id="P90Rsk" name="P90Rsk" compartment="cēll_nsclc" initialAmount="120000"/>

$</ 1$ ist OfSpecies $>$

$<$ ist OfParameters $>$

<parameter id="reaction_1_KM_SOS_E" value="6086070" units="moles_per_second" constant="true"/

$<$ parameter id="reaction_1_k_SOS_E" value="694.731" units="moles_per_second" constant="true"/> $<$ parameter id="reaction_${ }_{2}{ }_{-}{ }_{\mathrm{K}} \overline{\mathrm{M}} \_$Ras $\_$SOS" value="35954.3" units="moles_per_second" constant="true $" />$

$<$ parameter id="reaction_2 ${ }^{2}$ k_Ras_SOS" value="32.344" units="moles_per_second" constant="true"/

<parameter id="reaction 3 gamma EGFR" value="0.02" units="moles per second" constant="true"/> <parameter id="reaction- ${ }_{4}^{-}$KM_ERK_MekActive" value="1007340" units="moles_per_second" constant $=" \operatorname{true} " />$

<parameter id="reaction_4_k_ERK_MekActive" value="9.85367" units="moles_per_second" constant= "true"/>

<parameter id="reaction_5_KM_D_SOS_P90Rsk" value="896896" units="moles_per_second" constant=" true" $/>$

$<$ parameter id="reaction_5_k_D_SOS_P90Rsk" value="161197" units="moles_per_second" constant=" true" $/>$

$<$ parameter id="reaction_6_KM_A_SOS_I" value="100000" units="moles_per_second" constant="true" $>$

<parameter id="reaction 6 k A SOS I" value="500" units="moles per second" constant="true" $>$

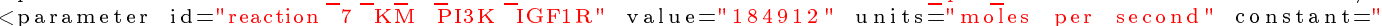
true" $1>$

$<$ parameter id="reaction_7_k_PI3K_IGF1R" value="10.6737" units="moles_per_second" constant=" true" $>$

<parameter id="reaction_8_KM_PI3K_EGF1R" value="184912" units="moles_per_second" constant=" true" $/>$

$<$ parameter id="reaction_8_k_PI3K_EGF1R" value="10.6737" units="moles_per_second" constant=" true" $/>$

$<$ parameter id="reaction_9_KM_AKT_PI3K" value="653951" units="moles_per_second" constant="true

$<$ parameter id="reaction_9 _k_AKT_PI3K" value="0.0566279" units="moles_per_second" constant=" true" $/>$

<parameter id="reaction_10_kd_AKT" value="0.005" units="moles_per_second" constant="true"/>

$<$ parameter id="reaction_11_KM_ERKactive_PP2A" value="3496490" units="moles_per_second" constant="true" $/>$

$<$ parameter id="reaction_11_k_ERKactive_PP2A" value="8.8912" units="moles_per_second" constant $=" \operatorname{true} " />$

$<$ parameter id="reaction_12_KM_PI3K_Ras" value="272056" units="moles_per_second" constant=" true" $>>$

<parameter id="reaction_12_k_PI3K_Ras" value="0.0771067" units="moles_per_second" constant=" true" $/>$

<parameter id="reaction_13_KM_Raf_RasActive" value="62464.6" units="moles_per_second" constant="true" $>$

$<$ parameter id="reaction_13_k_Raf_RasActive" value="0.884096" units="moles_per_second" constant="true"/>

<parameter id="reaction_14_KM_Mek_Raf_active" value="4768350" units="moles_per_second" constant="true" $/>$

<parameter id="reaction_14_k_Mek_Raf_active" value="185.759" units="moles_per_second" constant="true" />

<parameter id="reaction_15_KM_Raf_AKT" value="119355" units="moles_per_second" constant="true $" />$

$<$ parameter id="reaction_15_k_Raf_AKT" value="15.1212" units="moles_per_second" constant="true $">$

<parameter id="reaction_16_KM_RasActiveRasGap" value="1432410" units="moles_per_second" constant="true" $>$

<parameter id="reaction_16_k_RasActiveRasGap" value="1509.36" units="moles_per_second" constant="true" $/>$

<parameter id="reaction_17_KM_MekActivePP2A" value="518753" units="moles_per_second" constant meter id="re

<parameter id="reaction_17_k_MekActivePP2A" value="2.83243" units="moles_per_second" constant $=" \operatorname{true} " />$

<parameter id="reaction_18_gamma_IGFR" value="0.02" units="moles_per_second" constant="true"/

<parameter id="reaction_19_kd_PI3K_a" value="0.005" units="moles_per_second" constant="true"/

$<$ parameter id="reaction_20_KM_RasActive_RafPP" value="1061.71" units="moles_per_second" constant="true" $/>$

<parameter id="reaction_20_k_RasActive_RafPP" value="0.126329" units="moles_per_second" constant="true" $/>$ 
<parameter id="reaction_21_KM_P90Rsk_ERKActive" value="763523" units="moles_per_second"

<parameter id="reaction_21_k_P90Rsk_ERKActive" value="0.0213697" units="moles_per_second" constant="true" $>$

<parameter id="reaction_22_kd_P90Rsk" value="0.005" units="moles_per_second" constant="true"/ $</$ list OfParameters $>$

$</$ list Of Parameters

list OfReactions $>$

reaction id="reaction_1" name="SOS_conformational_activation" reversible="false" $>$

listOfReactants $>$
<speciesReference species="Sos1_4430401P03Rik_9630010N06_AI449023"/>

$</$ list OfReactants $>$

$<$ ist OfProducts $>$

$<$ speciesReference species="Sos1_4430401P03Rik_9630010N06_AI449023_active"/>

$</$ list OfProducts $>$

$<$ ist OfModifiers $>$

$<$ modifierSpeciesReference species="

Egfr_ 9030024.
$</$ ist OfModifiers $>$

$<$ kineticLaw $>$

$<$ math xmlns="http://www.w3.org/1998/Math/MathML">

$<$ apply $>$

$<$ apply $>$ divide $/>$

$<$ divide
$<$ apply $>$

apply $>$
$<$ times

$<\mathrm{times} /\rangle$
$\langle\mathrm{ci}\rangle$ reaction $1 \mathrm{k}$ SOS $\mathrm{E}</ \mathrm{ci}\rangle$

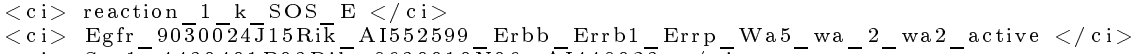

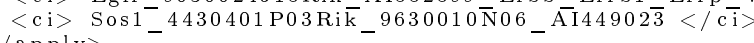

$</$ apply $>$

$<$ apply $>$

$<\mathrm{plus} /\rangle$
$\langle\mathrm{ci}\rangle$ reaction 1 KM SOS $\mathrm{E}\langle/ \mathrm{ci}\rangle$

$<\mathrm{ci}\rangle$ Sos1_4 $4 \overline{4} \overline{0} 401 \overline{\mathrm{P} 03 \mathrm{Rik}}+9630010 \mathrm{~N} 06$ _A I4 $49023</ \mathrm{ci}\rangle$

$</$ apply $>$

$</$ apply $>$

$</$ math $>$

$</$ kineticLaw $>$

$</$ reaction $>$

$<$ reaction id="reaction 2 " name="kRas activation" reversible="false" $>$

$<$ list OfReactants $>$

<speciesReference species="

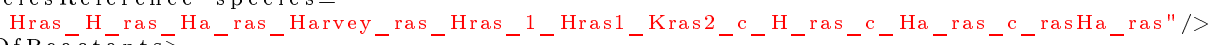

$</ 1$ ist OfReactānts $\overline{ }$

$<$ list OfProducts $>$

$<$ speciesReference species="

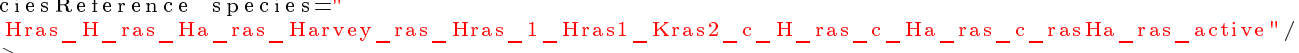

$</$ ist OfProducts $>$

$<$ list OfModifiers $>$

$<$ modifierSpeciesReference species="Sos1_4430401P03Rik_9630010N06_AI449023_active"/> $</$ list OfModifiers $>$

$<$ kinetic Law $>$

<math xmlns="http://www.w3.org/1998/Math/MathML">

$<$ apply $>$

$<$ divide $/>$

$<$ divide $>>$

$<$ times $>$

$<\mathrm{times} /\rangle$
$\langle\mathrm{c} i\rangle$ reaction $2 \mathrm{k}$ Ras $\mathrm{SOS}</ \mathrm{ci}\rangle$

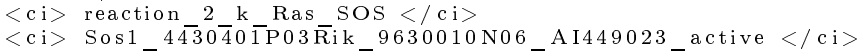

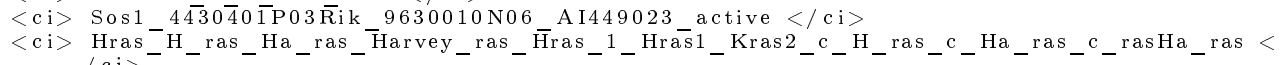
$</$ apply $>$

$<$ apply $>$

$<$ plus $/>$

$\langle\mathrm{c}$ i $\rangle$ reaction 2 KM Ras $\operatorname{SOS}</ \mathrm{ci}\rangle$

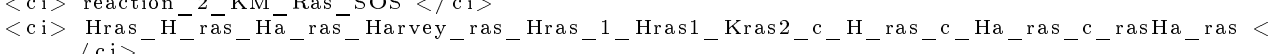
$</$ apply $>$

$</$ apply $>$

$</$ math $>$

$</$ kineticLaw $>$

$</$ reaction $>$

$<$ reaction id="reaction 3 " name="EGFR degradation" reversible="false" $>$

$<$ list OfReactants

<speciesReference species="

Egfr_9030024J15Rik_AI552599_Erbb_Errb1_Errp_Wa5 $-{ }^{2}{ }^{2}{ }^{2}$ _wa2 2 active" $/>$

$</$ ist OfReāctants $>$

$<$ kinetic Law $>$

$<$ math xmlns="http://www.w3.org/1998/Math/MathML">

$<$ apply $>$

$<$ times $/>$

$\langle\mathrm{ci}\rangle$ reaction_3_gamma_EGFR $</ \mathrm{ci}\rangle$

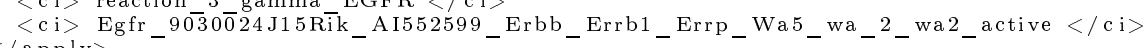
$</$ math $>$

$</$ kinetic Law $>$

$</$ reaction $>$

<reaction id="reaction 4" name="ERK activation by Mek" reversible="false">

$<$ list OfReactants $>$

<speciesReference species="
Mapk1_9030612K14Rik_AA407128_AU018647_C78273_ERK_Erk2_MAPK2_PRKM2_Prkm1_p41mapk_p42mapk "/>

$</ 1$ ist OfReactants $>$

$<$ ist OfProducts $>$

speciesReference species=" Mapk1_9030612K14Rik_AA407128_AU018647_C78273_ERK_Erk2_MAPK2_PRKM2_Prkm1_p41mapk_p42mapk_active $</ 1$ ist OfProducts $>$

$<$ list OfModifiers $>$

$<$ modifierSpeciesReference species="Map2k1_MAPKK1_MEKK1_Mek1_Prkmk1_active" / >

$</$ listOfModifiers $>$ 


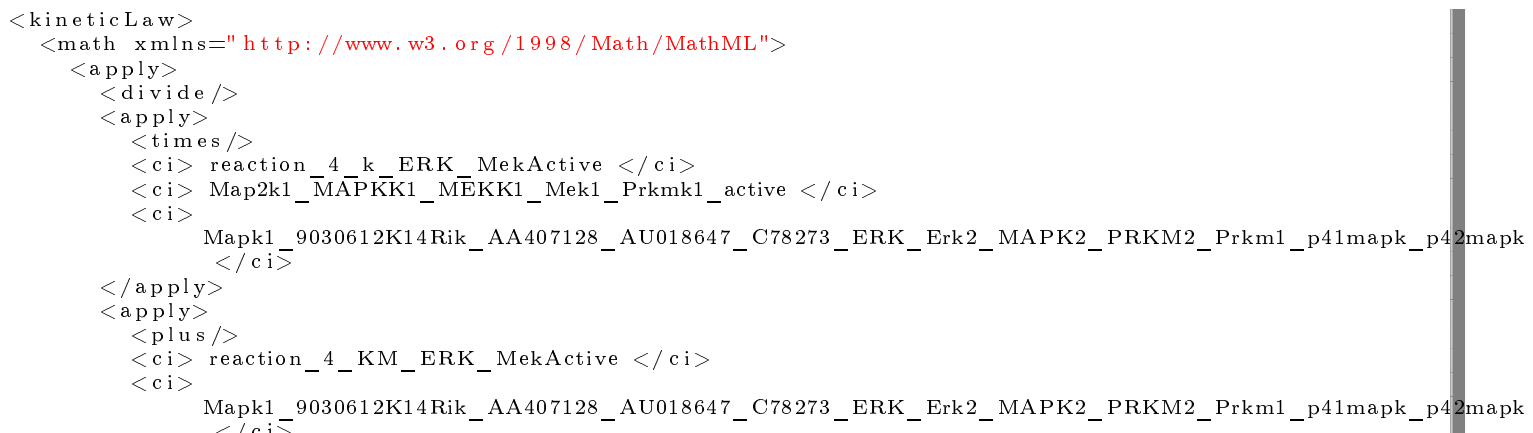


$<$ ci $>$ Pik3ca_6330412C24Rik_caPI3K_p110_p110alpha $</$ ci $>$

$</$ apply $>$

$<$ apply $>$

$<\mathrm{ci}\rangle$ reaction $7 \mathrm{KM}$ PI3K IGF1R $</ \mathrm{ci}>$

$<\mathrm{ci}>$ Pik3ca_-6330412 C24Rik_caPI3K_p110_p110alpha $</$ ci $>$

$</$ apply $>$

$</$ apply

$</$ math $>$

$</$ kinetic Law $>$

$</$ reaction $>$

<reaction id="reaction_8" name="PI3KCA_activation_by_EGF" reversible="false" $>$

$<$ ist OfReactants $>$

<speciesReference species="Pik3ca_6330412C24Rik_caPI3K_p110_p110alpha"/>

$</ 1$ ist OfReactants $>$

$<$ list OfProducts $>$

<speciesReference species="Pik3ca_6330412C24Rik_caPI3K_p110_p110alpha_active"/>

$</$ ist OfProducts $>$

$<$ list OfModifiers $>$

$<$ modifierSpeciesReference species-"

Egfr_9030024J15Rik_AI552599_Erbb_Errb1_Errp_Wa5_wa_2_wa2_active" $/>$

$</$ list OfMōdifiers $>$

$<$ kineticLaw $>$

<math xmlns="http://www.w3.org/1998/Math/MathML">

$<$ apply>

$<$ divide $/>$

$<$ apply $>$

$<$ times $/>$

$\langle\mathrm{ci}\rangle$ reaction 8 k $\mathrm{k}$ PI3K_EGF1R $\langle/ \mathrm{ci}\rangle$

$\langle\mathrm{ci}\rangle$ Egfr_90300 $2 \overline{4 \mathrm{~J}} 15 \mathrm{Ri} \overline{\mathrm{k}}$ AI552599 Erbb_Errb1_Errp_Wa5_wa_2 2 wa2 _active $</ \mathrm{ci}\rangle$

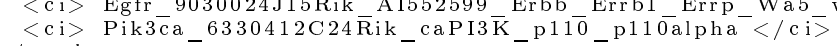

$</$ apply $>$

$<$ apply $>$

$<$ plus $/>$

$\langle\mathrm{ci}\rangle$ reaction $8 \mathrm{KM}$ PI3K EGF1R $</ \mathrm{ci}\rangle$

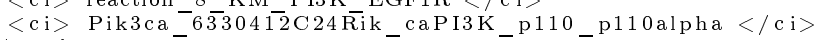

$</$ apply $>$

$</$ apply

$</$ math $>$

$</$ kinetic Law $>$

$</$ reaction $>$

reaction id="reaction_9" name="AKT_activation by_PI3KCA" reversible="false" $>$

list OfReactants $>$
$<$ speciesReference species="Akt1_Akt_PKB_PKB_Akt_PKBalpha_Rac" $/>$

$</$ list OfReactants $>$

$<$ iist OfProducts $>$

$<$ speciesReference species="Akt1_Akt_PKB_PKB_Akt_PKBalpha_Rac_active" $/>$

$</ 1$ ist OfProducts $>$

$<1$ ist OfModifiers $>$

$<$ modifierSpeciesReference species="Pik3ca_6330412C24Rik_caPI3K_p110_p110alpha_active"/> $</$ ist OfModifiers $>$

$<$ kinetic Law $>$

$<$ math xmlns="http://www.w3 org/1998/Math/MathML">

$<$ apply $>$

$<$ divide $>$

$<$ divide $>$

$<$ times $>$

$<\mathrm{times} />$
$\langle\mathrm{ci}\rangle$ reaction $9 \mathrm{k}$ AKT $\mathrm{PI} 3 \mathrm{~K}</ \mathrm{ci}\rangle$

$\langle\mathrm{ci}\rangle$ reaction $\left.{ }^{9}-\mathrm{k}-\mathrm{AKT}-\mathrm{PI} 3 \mathrm{~K}</ \mathrm{ci}\right\rangle$
$\langle\mathrm{ci}\rangle$ Pik3ca-6330 $12 \mathrm{C} 2 \overline{4} \mathrm{Rik}$ caPI3K_p110_p110alpha_active $\langle/ \mathrm{ci}\rangle$

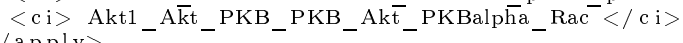

$</$ apply $>$

$<$ apply $>$

$<$ plus $>>$

$\langle\mathrm{ci}\rangle$ reaction $9 \mathrm{KM}$ AKT $\mathrm{PI} 3 \mathrm{~K}</ \mathrm{ci}\rangle$

$<\mathrm{ci}>$ Akt1_Akt_PKB_PKB_Akt_PKBalpha_Rac $</ \mathrm{ci}\rangle$

$</$ apply $>$

$</$ kinetic Law $>$

reaction id="reaction $10 "$ name="AKT deactivation" reversible="false">

$<$ ist OfReactants $>$

$<$ speciesReference species="Akt1_Akt_PKB_PKB_Akt_PKBalpha_Rac_active" $/>$

$</$ ist OfReactants $>$

$<$ list OfProducts>

$<$ speciesReference species="Akt1_Akt_PKB_PKB_Akt_PKBalpha_Rac" $/>$

$</$ list OfProducts $>$

$<$ kineticLaw $>$

$<$ math xmlns="http://www.w3.org/1998/Math/MathML">

$<$ apply $>$

$<$ times $>$

$\langle\mathrm{ci}\rangle$ reaction $\left.10 \_\mathrm{kd} / \mathrm{AKT}</ \mathrm{ci}\right\rangle$

$<$ i $>$ Akt1_Akt_PKB_PKB_Akt_PKBalpha_Rac_active $</$ ci $\rangle$

$</$ kinetic Law $>$

$</$ reaction $>$

<reaction id="reaction 11 " name="ERK deactivation by PP2A" reversible="false">

$<$ list OfReactants $>$

<speciesReference species-"

Mapk1_9030612K14Rik_AA407128_AU018647_C78273_ERK_Erk2_MAPK2_PRKM2_Prkm1_p41mapk_p42mapk_active

$</$ list OfReactants $>$

$<$ listOfProducts> (iesterence Mapk1_9030612K14Rik_AA407128_AU018647_C78273_ERK_Erk2_MAPK2_PRKM2_Prkm1_p41mapk_p42mapk $">>$

$</$ ist OfProducts $>$

$<$ ist OfModifiers $>$

$<$ modifierSpeciesReference species="PP2A" $/>$

$</$ list OfModifiers $>$ 


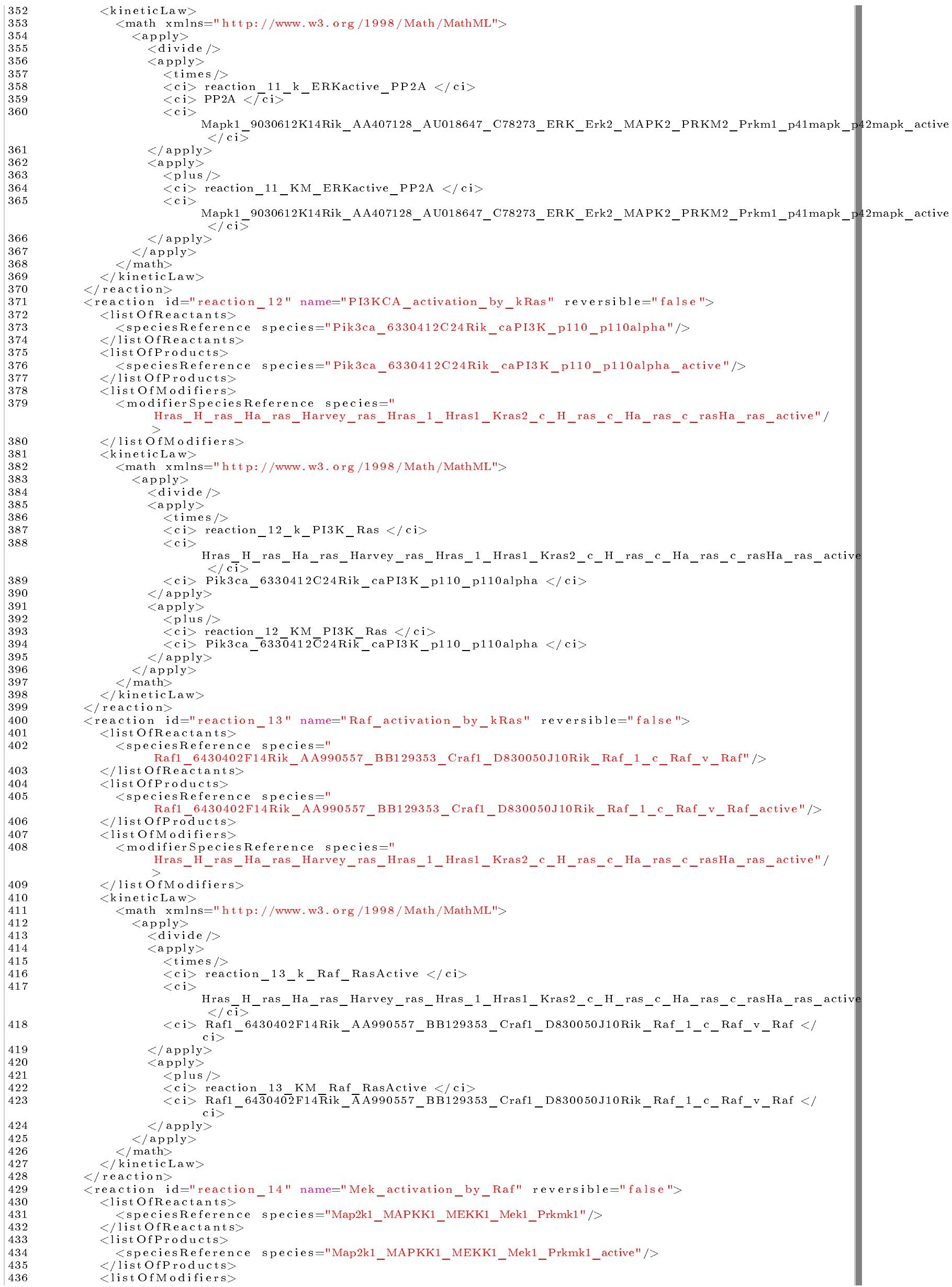


$<$ modifierSpeciesReference species="

Raf1 6430402F14Rik AA990557 BB129353 Craf1_D830050J10Rik Raf_1_c Raf v Raf active"/> $</ 1$ ist OfModifiers $>$

$<$ kinetic Law $>$

$<$ math xmlns="http://www.w3.org/1998/Math/MathML">

$<$ apply>

$<$ divide

$<$ apply $>$

$<$ times $/>$

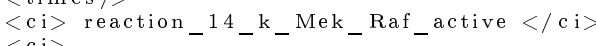

$<\mathrm{ci}\rangle$

Raf1_6430402F14Rik_AA990557_BB129353_Craf1_D830050J10Rik_Raf_1 _c $-{ }^{\text {Raf }}$ - ${ }^{\mathrm{v}}$-Raf_active

$<\mathrm{ci}>$ Map2k1_MAPKK1_MEKK1_Mek1_Prkmk1 $</ \mathrm{c} i \overline{ }$

$</$ apply $>$

$<$ apply $>$

$\langle$ ci $\rangle$ reaction $14 \mathrm{KM}$ Mek Raf active $\langle/ \mathrm{ci}\rangle$

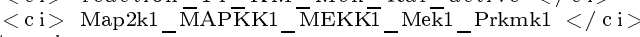

$</$ apply $>$

$<$ math $>$.

$</$ kinetic Law $>$

$</$ reaction $>$

$<$ reaction id="reaction_15" name="Raf_deactivation_by_AKT" reversible="false" $>$

$<$ list OfReactants $>$

<speciesReference species="

$</$ ist $O$ Raf1_6430402

$<$ list OfProducts $>$
$<<$ Prodies

$<$ speciesReference species="

Raf1 643040
$</ 1$ ist OfProducts $>$

$<$ ist OfModifiers $>$

$<$ modifierSpeciesReference species="Akt1_Akt_PKB_PKB_Akt_PKBalpha_Rac_active" $/>$

$</$ ist OfModifiers $>$

$<$ kinetic Law $>$

$<$ math xmlns="http: //www.w3.org/1998/Math/MathML">

$<$ apply $>$

$<$ divide $/>$

$<$ divide
$<$ apply $>$

$<$ times $>$

$\langle\mathrm{ci}\rangle$ reaction $15 \mathrm{k}$ Raf $\mathrm{AKT}</ \mathrm{ci}\rangle$

$<\mathrm{ci}>\mathrm{Akt1}$ A $\overline{\mathrm{Akt}}$ _PKB_PKB_Akt_PKBalpha_Rac_active $</ \mathrm{ci}\rangle$

Raf1_6430402F14Rik_AA990557_BB129353_Craf1 _D830050J10Rik_Raf_1 _c_Raf_v_Raf_active $</$ apply $\overline{\mathbf{i}}>$

$<$ apply $>$

$<$ plus $/>$

$\langle\mathrm{ci}\rangle$ reaction_15_KM_Raf_AKT $</ \mathrm{ci}\rangle$

$\langle\mathrm{ci}\rangle$

Raf1_6430402F14Rik_AA990557_BB129353_Craf1_D830050J10Rik_Raf_1_c_Raf_v_Raf_active

$</$ apply
$</$ apply $>$

$</$ app $>$

$</$ kinetic Law $>$

$</$ reaction $>$

$<$ reaction id="reaction_16" name="Ras_deactivation_by_RasGab" reversible="false" >

$<$ ist OfReactants $>$

<speciesReference species="

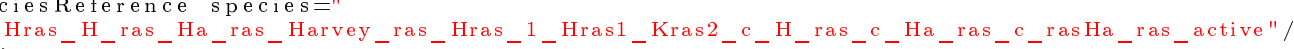

$</$ list OfReactants $>$

$<$ iistOfProducts $>$

$<$ speciesReference species="

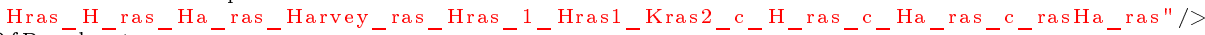

$</ 1$ ist OfProducts $>$

$<$ modifierSpeciesReference species="Rasa2 5430433H21Rik_AA517451 AU023900 GAP1m active"/>

$</$ list OfModifiers $>$

$<$ kinetic Law $>$

$<$ math xmlns="http://www.w3.org/1998/Math/MathML">

$<$ apply $>$

$<$ divide $/>$

$<$ apply $>$

$<$ times $/>$

$<\mathrm{ci}>$ reaction 16 k_RasActiveRasGap $</ \mathrm{ci}>$

$<\mathrm{ci}\rangle$ Rasa2_ $5 \overline{4} \overline{3} 04 \overline{3} 3 \overline{\mathrm{H}} 21 \mathrm{Rik}$ _AA517451_AU023900_GAP1m_active $</ \mathrm{ci}>$

$\langle\mathrm{ci}\rangle$

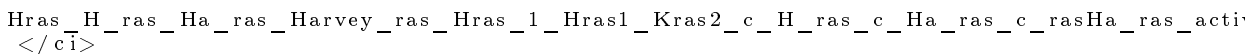

$</$ apply $>$

$<$ plus $>$

$<\mathrm{ci}\rangle$ reaction $16 \quad \mathrm{KM}$ RasActiveRasGap $</ \mathrm{ci}\rangle$

$\langle\mathrm{ci}\rangle$

$</$ apply $>$

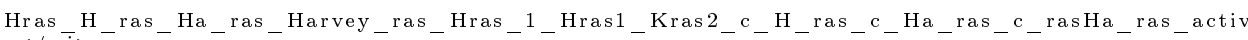

$</$ apply $>$

$</$ math $>$

$</$ kinetic Law $>$

$</$ reaction $>$

<reaction id="reaction_17" name="Mek_deactivation_by_PP2A" reversible="false">

$<$ ist Of Reactants $>$

$<$ speciesReference species="Map2k1_MAPKK1_MEKK1_Mek1_Prkmk1_active" />

$</$ list OfReactants $>$

$<$ ist OfProducts $>$

<speciesReference species="Map2k1_MAPKK1_MEKK1_Mek1_Prkmk1" / 
$</$ ist OfProducts $>$

$<$ modifierSpeciesReference species="PP2A" $/>$

$</$ list OfModifiers $>$

$<$ kinetic Law $>$

$<$ math xmlns="http://www.w3.org/1998/Math/MathML">

$<$ apply $>$

$<$ apply $>$ divide $/>$

$<$ apply $>$

$<$ times $/>$

$<\mathrm{ci}>$ reaction $17{ }_{-}{ }_{-}$MekActivePP2A $</$ci $>$

$<\mathrm{ci}>$ PP2A $</ \mathrm{ci}>$
$<\mathrm{ci}>$ Map2k1_MAPKK1_MEKK1_Mek1_Prkmk1_active $</ \mathrm{ci}>$

$</$ apply $>$

$<$ plus $/>$

$\langle$ ci $\rangle$ reaction $17 \quad \mathrm{KM}$ MekActivePP $2 \mathrm{~A}</ \mathrm{ci}\rangle$

$<$ ci $>$ Map2k1_MAPKK1_MEKK1_Mek1_Prkmk1_active $</$ ci $>$ $</$ apply $>$

$</$ apply $>$

$</$ math $>$

$</$ kinetic Law $>$

$</$ reaction $>$

<reaction id="reaction_18" name="IGFR active degradation" reversible="false ">

$<$ list OfReactants>

$<$ speciesReference species="Csf1r_AI323359_CD115_CSF_1R_Csfmr_Fim_2 $-F m s$ M_CSF_R_M $\_$CSFR" $/>$ $</$ list OfReactants $>$

$<$ kinetic Law $>$

$<$ math xmlns="http://www.w3.org/1998/Math/MathML">

$<$ apply $>$

$<$ times $/>$

$\langle\mathrm{ci}\rangle$ reaction 18 gamma IGFR $</ \mathrm{ci}>$

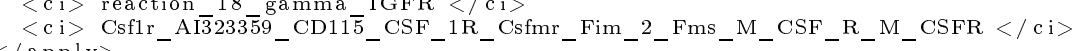

$</$ apply $>$

$</$ kineticLaw $>$

<reaction id="reaction 19 " name="PI3KCA deactivation" reversible="false">

$<$ list OfReactants $>$

<speciesReference species="Pik3ca_6330412C24Rik_caPI3K_p110_p110alpha_active" / >

$</ 1$ ist OfReactants $>$

list OfProducts $>$

<speciesReference species="Pik3ca_6330412C24Rik_caPI3K_p110_p110alpha"/>

$</$ ist OfProducts $>$

$<$ kineticLaw $>$

$<$ math xmlns="http://www.w3.org/1998/Math/MathML">

$<$ apply $>$

$<$ times $>$

$\langle\mathrm{ci}\rangle$ reaction $\left.19{ }_{-} \mathrm{kd}_{-} \mathrm{PI} 3 \mathrm{~K}_{-} \mathrm{a}</ \mathrm{ci}\right\rangle$

$<$ ci $>$ Pik3ca_-6330 $41 \overline{2 \mathrm{C}} 24 \mathrm{Rik}{ }_{-}$caPI3K_p110_p110alpha_active $</ \mathrm{ci}>$

$</$ apply $>$

$</$ inatic

$</$ reaction $>$ Law $>$

reaction

reaction id="reactio

list OfReactants>

<speciesReference species="

Raf1_6430402F14Rik_AA990557_BB129353 _Craf1_D830050J10Rik_Raf_1 $+{ }^{C}+{ }^{2}$ Raf_v_Raf_active" $/>$ $</$ ist OfReactants $>$

$<$ list OfProducts $>$

$<$ speciesReference species="

Raf1 6430402
$</ 1$ ist OfProducts $>$

$<$ list OfModifiers $>$

$<$ modifierSpeciesReference species="RafPP" $/>$

$</ l$ ist OfModifiers $>$

$<$ kinetic Law $>$

$<$ math xmlns="http://www.w3.org/1998/Math/MathML">

$<$ apply $>$

$<$ divide $/>$

$<$ divide

$<$ apply $>$ $<$ imes $>$

$<$ cimes $/>$ reaction_20_k_RasActive_RafPP $</$ ci $>$

$<\mathrm{ci}>\operatorname{RafPP}</ \mathrm{ci}>$

$<\mathrm{ci}>$

Raf1_ 6430402 F14Rik_AA990557_BB129353 _Craf1_D830050J10Rik_Raf _1 _ ${ }^{c}$ - Raf_v - Raf_active $</$ apply $</ \mathrm{c} \overline{\mathbf{i}}>$

$<$ apply $>$

$<$ plus $/>$

$<\mathrm{ci}>$ reaction_20_KM_RasActive_RafPP $</ \mathrm{ci}>$

$<\mathrm{c}$ i $>$

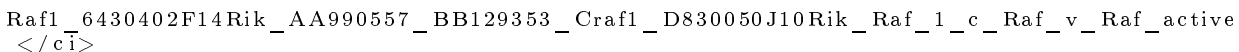
$</$ apply $>$

$</$ apply $>$

$</$ math $>$

$</$ kineticLaw $>$

$</$ reaction

reaction id="reaction 21 " name="P90 activation_by_ERK" reversible="false">

$<$ ist OfReactants $>$

$<$ speciesReference species="P90Rsk" />

$</$ list OfReactants $>$

$<$ list OfProducts $>$

<speciesReference species="P90Rsk_active" $/>$

$</$ iist OfProducts $>$

$<$ list OfModifiers $>$

$<$ modifierspecies Reference species=" Mapk1_9030612K14Rik_AA407128_AU018647_C78273_ERK_Erk2_MAPK2_PRKM2_Prkm1_p41mapk_p42mapk_active

$</ 1$ ist OfModifiers $>$ 


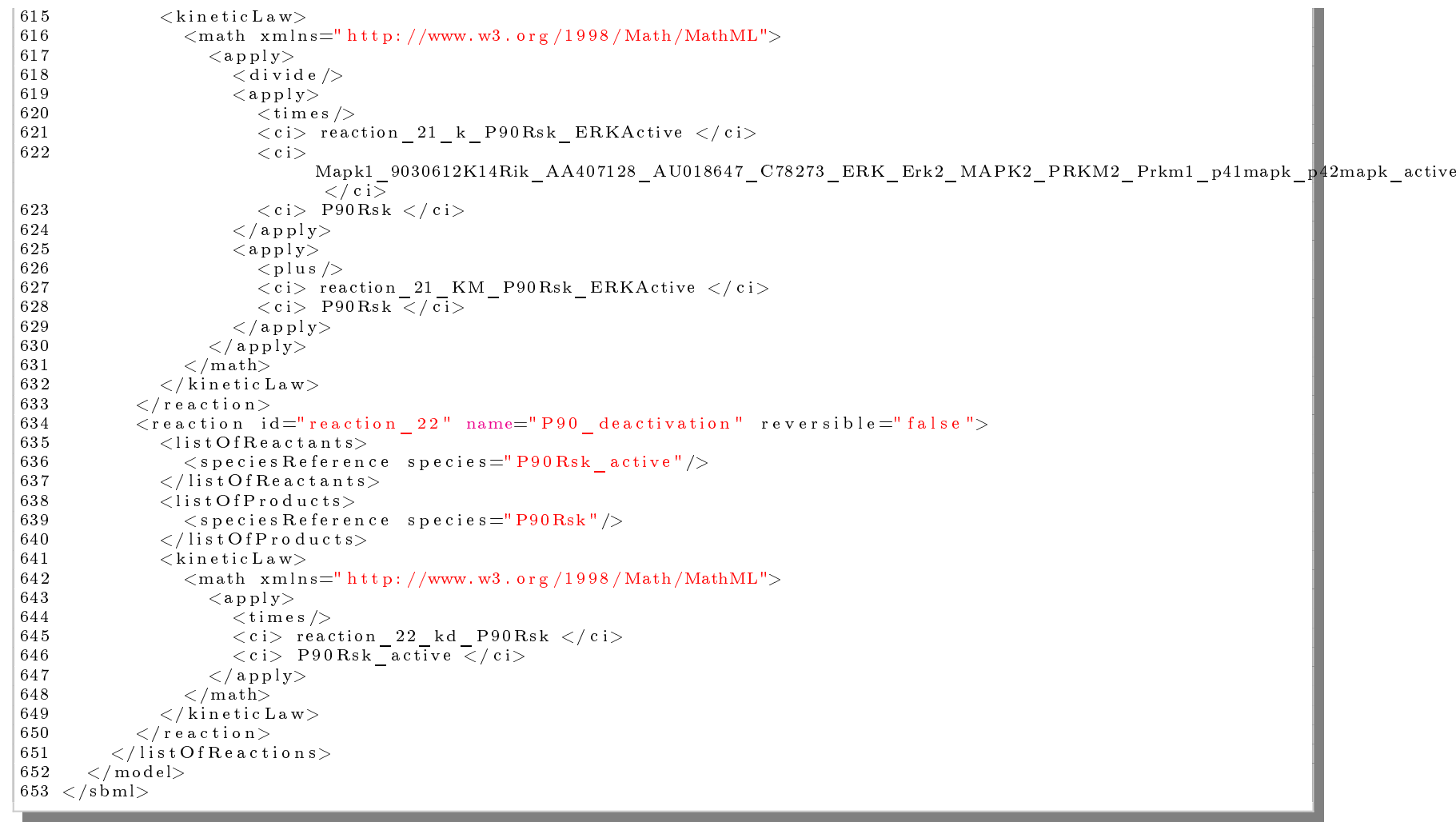

Listing A.3: representação em sbml do modelo Bioconi_2012 
APÊNDICE A 


\section{Apêndice B}

\section{KEGG Markup Language (KGML)}

A linguagem de marcação do KEGG - KEGG Markup Language (KGML) ${ }^{1}$ é um formato para a troca dos objetos gráficos do KEGG. Os documentos KGML são projetados principalmente para representações gráficas das vias de interação molecular. Além disso, os documentos KGML fornecem facilidades de análise computacional e modelagem de vias de proteínas e vias químicas.

Os arquivos KGML contêm informações sobre objetos gráficos e suas relações no KEGG PATHWAY, bem como informações sobre denominações de genes ortólogos (genes originados como resultado de processos de especiação) do KEGG GENES.

Nos arquivos KGML, os elementos pathway e entry especificam objeto grafo e vértice, respectivamente. Enquanto relation e reaction especificam aresta do objeto grafo. Em KEGG PATHWAY, o elemento relation indica padrão de conexão dos retângulos (produtos de genes) e o elemento reaction indica padrão de conexão dos círculos (componentes químicos). O objeto grafo que consiste de elementos entry e relation é chamado de via protéica; e aquele que consiste de elementos entry e reaction é chamado de via química. Assim, as vias de interação molecular do KEGG PATHWAY podem ser distinguidas como:

- Vias metábolicas: podem ser vistas como vias protéicas e vias químicas.

- Vias regulatórias: podem ser vistas como vias protéicas.

A visão geral do KGML é mostrada na figura B.1.

O elemento relation contido nos mapas de regulação codifica informação como "A ativa B". O elemento reaction contido principalmente nos mapas de vias metabólicas, contém informações dos substratos, produtos, como também informações sobre a reversibilidade da reação. Neste trabalho, trabalhamos somente com vias de transdução de sinal, ou seja, vias de regulação, e os arquivos KGML utilizados nesse trabalho se restrigem a aqueles que consistem de elementos entry e relation.

\footnotetext{
${ }^{1}$ http://www.kegg.jp/kegg/xml
} 


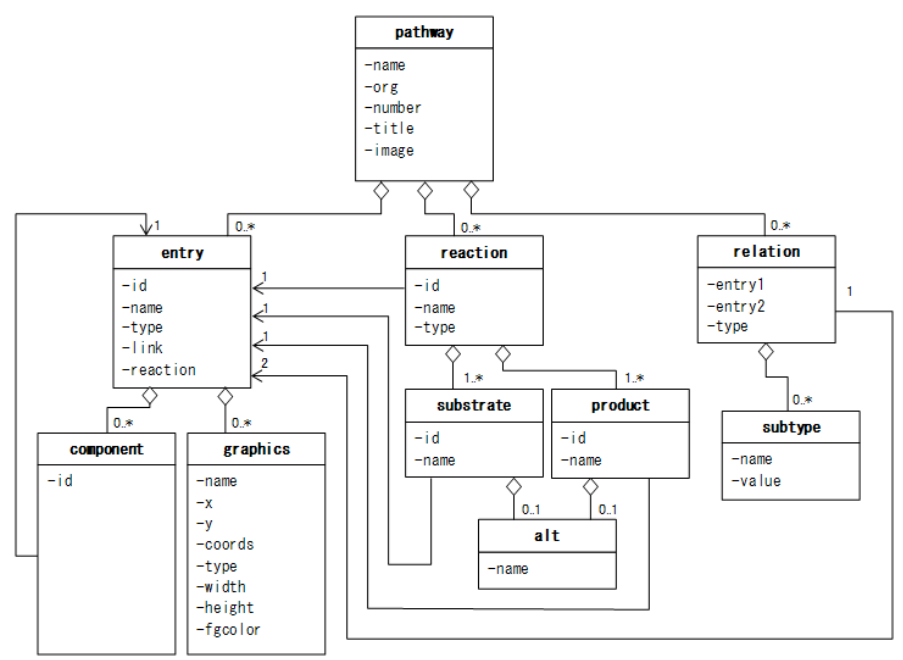

Figura B.1: Visão geral do KGML [KEG14]. O elemento pathway é o elemento raiz, um elemento pathway é especificada para um mapa pathway em KGML. Os elementos entry, relation e reaction especificam as informações do grafo, e os demais elementos especificam informações mais detalhadas sobre os vértices e arestas do grafo. 


\section{Apêndice C}

\section{Um componente para teste de hipóteses utilizando o arcabouço SigNetSim}

Neste apêndice apresentaremos a arquitetura do componente Hyp Test integrado ao arcabouço SigNetSim desenvolvido neste trabalho. O componente Hyp Test foi implementado utilizando a linguagem de programação Python ${ }^{1}$, seguindo o paradigma de orientação a objetos. As bibliotecas externas que o componente Hyp Test utilizam são:

- xml.etree.ElementTree

- libsbml

- multiprocessing

- time

O pacote libsbml foi baixado via o link: http://sbml.org/Software/libSBML/docs/python-api/ libsbml-installation-guide.html.

O componente desenvolvido permite recuperar partes de módulos funcionais dado o módulo funcional modelo e os seus recortes escolhidos. Ele é composto por 25 classes, suporta execução sequencial ou em paralelo. Ambas as formas de execução requerem os parâmetros de entrada como: o caminho do diretório dos arquivos dos recortes a serem testados, o número de iterações de execução para cada recorte e o tempo de otimização para cada chamada da função custo. Os arquivos dos recortes podem estar na forma de arquivos XML ou TXT.

A figura C.1 mostra o diagrama de classes em UML (linguagem de modelagem unificada) do componente Hyp Test e a figura C.2 mostra o diagrama de relações entre as classes do componente.

${ }^{1}$ https://docs.python.org/3/c-api/index.html 


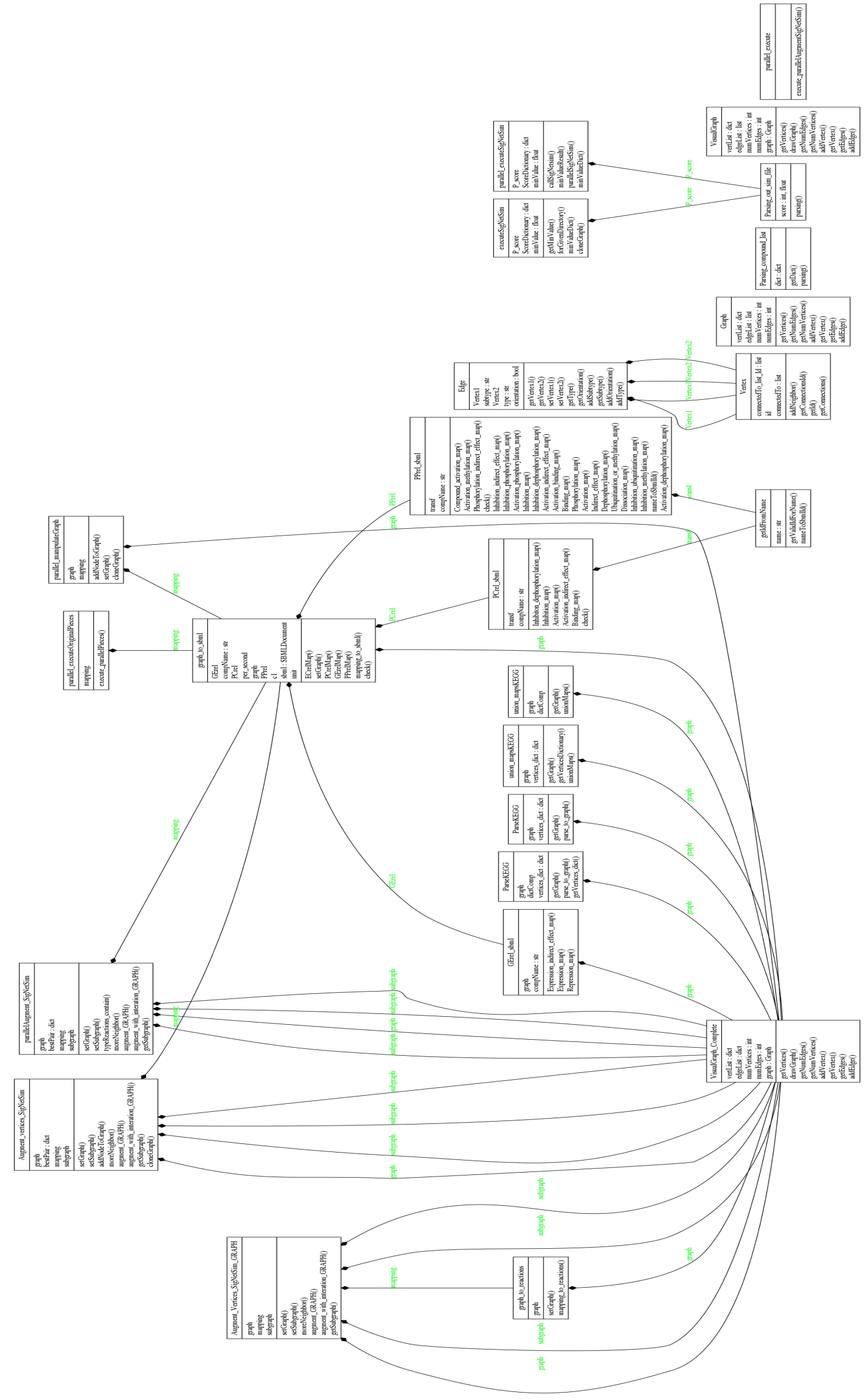

Figura C.1: diagrama de classes em UML do componente HypTest. 


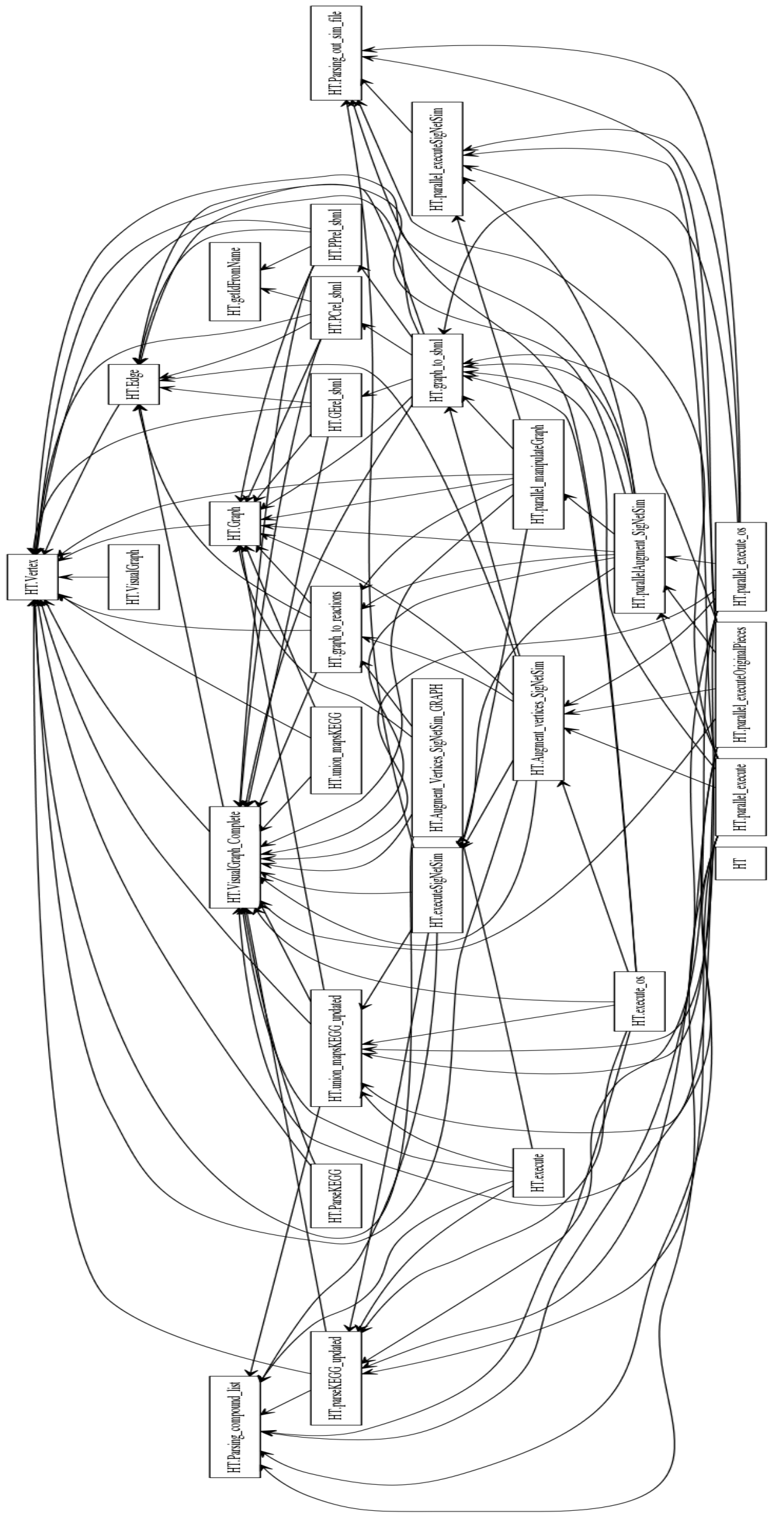

Figura C.2: diagrama de relação entre as classes em UML do componente HypTest. 


\section{Referências Bibliográficas}

$\left[\mathrm{BBL}^{+} 12\right]$ Fortunato Bianconi, Elisa Baldelli, Vienna Ludovini, Lucio Crin, Antonella Flacco e Paolo Valigi. Computational model of EGFR and IGF1R pathways in lung cancer: A Systems Biology approach for Translational Oncology. Biotechnology Advances, 30(1):142 - 153, 2012. xii, xvii, 2, 34, 35, 36, 39, 44

[BKS14] Ann C Babtie, Paul Kirk e Michael PH Stumpf. Topological sensitivity analysis for systems biology. Proceedings of the National Academy of Sciences, 111(52):18507-18512, 2014. 44

[BWHK02] Frank J Bruggeman, Hans V Westerhoff, Jan B Hoek e Boris N Kholodenko. Modular response analysis of cellular regulatory networks. Journal of theoretical biology, 218(4):507-520, 2002. 44

[Dia12] Matheus H.S. Dias. Mecanismos da toxidez de FGF2 em células malignas dependentes de Ras: bloqueio de divisão celular e estresse proteotóxico. Tese de Doutorado, Universidade de São Paulo - USP, 2012. xi, 1

[EBI15] EBI. Biomodels. http://www.ebi.ac.uk/biomodels-main, may 2015. last acess in 20/05/2015. 34

[EI04] Narat J. Eungdamrong e Ravi Iyengar. Modeling Cell Signaling Networks. Biol Cell, 96:355D362, 2004. 1, 6

$\left[\right.$ HFS $^{+}$03] Michael Hucka, Andrew Finney, Herbert M Sauro, Hamid Bolouri, John C Doyle, Hiroaki Kitano, Adam P Arkin, Benjamin J Bornstein, Dennis Bray, Athel Cornish-Bowden et al. The Systems Biology Markup Language (SBML): a medium for representation and exchange of biochemical network models. Bioinformatics, 19(4):524-531, 2003. 45

[IF12] Dagmar Iber e Georgios Fengos. Predictive Models for Cellular Signaling Networks. Em Xuedong Liu e Meredith D. Betterton, editors, Computational Modeling of Signaling Networks, volume 880 of Methods in Molecular Biology, páginas 1-22. Humana Press, 2012. 1

[KEG14] KEGG. KEGG Markup Language. http://www.kegg.jp/kegg/xml/docs, october 2014. last acess in 10/10/2014. xiii, 58

[KG00] Minoru Kanehisa e Susumu Goto. KEGG: Kyoto Encyclopedia of Genes and Genomes. Nucleic acids research, 28:27-30, 2000. 7, 19

[KM08] Douglas B Kell e Pedro Mendes. The markup is the model: reasoning about systems biology models in the Semantic Web era. Journal of theoretical biology, 252(3):538-543, 2008. 45

[KTS13] Paul Kirk, Thomas Thorne e Michael PH Stumpf. Model selection in systems and synthetic biology. Current opinion in biotechnology, 24(4):767-774, 2013. 44 
$\left[\mathrm{LKF}^{+} 14\right]$ Juliane Liepe, Paul Kirk, Sarah Filippi, Tina Toni, Chris P Barnes e Michael PH Stumpf. A framework for parameter estimation and model selection from experimental data in systems biology using approximate bayesian computation. Nature protocols, $9(2): 439-456,2014.44$

[LZ04] Yin Liu e Hongyu Zhao. A computational approach for ordering signal transduction pathway components from genomics and proteomics data. BMC bioinformatics, $5(1): 158,2004.6$

$\left[\mathrm{MKC}^{+} 09\right]$ Konstantinos Moutselos, Ioannis Kanaris, Aristotelis Chatziioannou, Ilias Maglogiannis e Fragiskos N Kolisis. KEGGconverter: a tool for the in-silico modelling of metabolic networks of the KEGG pathways database. BMC bioinformatics, 10(1):324, 2009. 26

[RA14] Marcelo S. Reis e Hugo A. Armelin. Introduction to Modeling of the Kinetics of Signaling Networks., July 2014. 9, 12

[Rei12] Marcelo S. Reis. Minimização de funções decomponíveis em curvas em U definidas sobre cadeias de posets - algoritmos e aplicações. Tese de Doutorado, Instituto de Matemática e Estatística, Universidade de São Paulo, Brasil, 2012. 38, 44

$\left[\mathrm{RND}^{+} 14\right]$ Marcelo S. Reis, Vincent Noel, Matheus H.S. Dias, Layra L. Albuquerque, Fabio Nakano, Junior Barrera e Hugo A. Armelin. SigNetSim: an e-Science framework for mathematical modeling and computational simulation of molecular signaling network kinetics. Manuscript in preparation, 2014. 2, 43

[VV10] Donald Voet e Judith G. Voet. Biochemistry. Wiley; 4th edition (December 14, 2010), December 2010. xi, 6, 7

[WBR $\left.{ }^{+} 13\right]$ Clemens Wrzodek, Finja Büchel, Manuel Ruff, Andreas Dräger e Andreas Zell. Precise generation of systems biology models from KEGG pathways. BMC systems biology, $7(1): 15,2013.7$

[WDZ11] Clemens Wrzodek, Andreas Dräger e Andreas Zell. KEGGtranslator: visualizing and converting the KEGG PATHWAY database to various formats. Bioinformatics, 27(16):2314-2315, 2011. 26

[WHI71] A. W. WHITNEY. A direct method of nonparametric measurement selection. IEEE Transactions on Computers, 20(9):1100-1103, September 1971. 22

[XVG $\left.{ }^{+} 10\right]$ T-R Xu, Vladislav Vyshemirsky, Amelie Gormand et al. Inferring signaling pathway topologies from multiple perturbation measurements of specific biochemical species. Science Signaling, 2010. 44 